\title{
Patterns in the biodiversity of terrestrial environments in the Western Australian wheatbelt
}

\author{
N.L. McKenzie, N. Gibson, G.J. Keighery and J.K. Rolfe \\ Department of Conservation and Land Management, P.O. Box 51, \\ Wanneroo, Western Australia 6946, Australia.
}

\begin{abstract}
Three hundred and four quadrats each of $c a .1$ ha were chosen to represent the geographical extent and diversity of uncleared terrestrial environments in a $205000 \mathrm{~km}^{2}$ area known as the Western Australian agricultural zone. This study area occuples $75 \%$ of south-western Australia, one of the world's 25 bodiversity hotspots under threat. Seventy-four percent of the study area has been cleared for agriculture and $4 \%$ is now salinised. Its subdued landscape comprises isolated remnants of bushland embedded in a mosaic of wheatfields.

Six phylogenetic groups were sampled, and a total of 2071 plant and 807 small ground-dwelling animal species were recorded from the quadrats. An average of 3.1 species per quadrat were recorded from only a single quadrat, but they were not randomly arrayed. The richest assemblages of singletons were around the periphery of the study area, where biogeographical edgeeffects would be expected. A total of 1922 species remained after the singletons were removed from the data set, an average of 71.1 per quadrat $(\mathrm{s} . \mathrm{d} .=22.8)$. They comprised 1335 plants, 472 spiders, 66 reptiles, 21 frogs, 11 mammals and 17 scorpions.
\end{abstract}

Seventeen assemblages were distinguished when the 1922 species were classified according to similarities in their presence or absence at the 304 quadrats. Each assemblage could be characterised in terms of the Australiawide habitat preferences (where known) of its component species. Also, separate quadrat similarity matrices were generated for the four main types of organism sampled (plants, spiders, scorpions and herpetofauna) and for 100 random matrices. These ivere output as linear similarity vectors so that the differences in their biodiversity patterns could be quantified as a single matrix of correlation coefficients.

Analyses revealed that:

1. Geographical patterns in assemblage species composition were correlated with processes operating at both biogeographical and local (ecological) scales: the compositional structure of each assemblage was related to a different set of climatic plus soil and/or landform attributes. Since these attribute-sets were consistent with the assemblages' extrinsic characterisations, they are unlikely to be artefacts of quadrat positioning or study area extent and were treated as realised environmental niches.

2. Broad biogeographical patterns in biodiversity showed strong relationships with temperature and rainfall gradients, especially 'warmest period mean temperature' and 'precipitation seasonality'.

3. The centres of diversity of the 17 assemblages revealed by our analysis were found to cross various biogeographical boundaries currently recognised in the study area, both regional and sub-regional. Because they provide a view of geography from the perspective of a wide range of organisms, these 'centres' provide a tactical framework for managing the effect of salinity on biodiversity.

4. The ecologically different clades (plants, spiders, scorpions and herpetofauna) each had a distinct influence on the biodiversity model; cross-taxon congruence levels were low. If a bio-regionalisation based on only one or two types of organism was used as a framework for conservation activities in the study area it would produce distorted
outcomes.

5. There was an inverse relationship between species richness and soil salinity for the eight assemblages that occur on, or extend onto, landforms affected by rising saline ground-water. Six assemblages are dependent on surface-types low in the landscape, and their uncleared remnants need to be assessed against hydrological models so that priority land parcels can be identified. Collectively, these six assemblages encompass populations of $50.1 \%$ of the 1922 species included in our analysis. The compositional loss associated with secondary salinisation affects all biodiversity components surveyed: plants, vertebrates, spiders and scorpions. 


\section{INTRODUCTION}

The Western Australian Agricultural Zone (herewith referred to as the wheatbelt) comprises isolated remnants of bushland embedded in a mosaic of fields cleared for agriculture. Only $26 \%$ of the wheatbelt remains as uncleared remnants of native vegetation, and between $4 \%$ (McFarlane and George, in press) and 5.5\% (Department of Environment, 2003) of its total land surface is already saline. Clearing has been strongly biased towards the fine-textured, non-salty soils of dissection valley floors and lower slopes, and these are the units that are now most affected by rising ground-water (dryland) salinity.

Dryland salinisation occurs after deep-rooted perennial vegetation is replaced by annual crops with shallow root systems that intercept less of the prevailing rainfall. Aerosol marine salt, stored in the wheatbelt's soil profiles over millenia, is dissolved in the rising watertable and brought to the surface (Commander et al., 1994; Ruprecht and Schofield, 1991). It affects primary ecosystem processes, imposing a high order stress on ecosystems (Whisenant, 1999). Our study was initiated because secondary dryland salinity arising from clearing of agricultural land has caused extensive vegetation death (Keighery, this volume). Halobiont communities found in the wheatbelt reflect the long-term presence of saline environments (e.g. Schofield et al., 1988) but, while recent salinisation might provide such species with a radiation opportunity (e.g. Remigio et al., 2001), it does not imply tolerance to secondary salinisation by the rest of the region's now fragmented biota (e.g. Halse et al., 2003).

In this paper we explore geographical patterns in the composition of communities in non-aquatic environments of the Western Australian wheatbelt (Figure 1). The only previous attempt to define patterns in the biota of the entire study area was by Beard (1981), who mapped vegetation units at a scale of 1:1,000,000 from base maps compiled at $1: 250,000$. Previous data on patterns in the study area's terrestrial biodiversity have been geographically localised (e.g. Kitchener, 1982; Saunders, 1989) or confined to a single phylogenetic group (e.g. Hopper, 1992; Hopper et al., 1997; Main, 2000). Spatial patterns in biodiversity have usually been examined in terms of subjective land-class categorisations based on vegetation structure or soil type, or from the perspective of a narrow range of organisms (e.g. plants or birds). We test the proposition that a more representative view of community patterns can be gained if a variety of ecologically distinct types of organism is sampled (Paine, 1980; Weins, 1985; McKenzie et al., 2000b).

While a number of studies have assessed the effect of increasing soil salinity on wheatbelt vegetation (George et al., 1995; Keighery et al., 2002;
Cramer and Hobbs, 2002), nature conservation planning must also take into account its effect on indigenous animal communities (e.g. Halse et al., 2003), particularly those non-volant species that live at the soil's surface.

Our aims were to:

- investigate the relationships between assemblage composition and measurable attributes of the study area's physical environment (including soil salinity and secondary salinisation) to identify predictors of geographic patterns in species composition across the study area.

- provide an overview of the composition and distribution of species assemblages, as components of communities.

- examine levels of cross-taxon complementarity (sensu Howard et al., 1998) in the study area, as a potential issue in reserve selection (McKenzie et al., 2000a).

We aimed to provide a regional context for conserving the study area's biodiversity by analysing data on four ecologically distinct types of organisms from 304 quadrats. These quadrats were:

- positioned to represent the diversity of the study area's physical environments across its geographical extent (including sites affected by increasing soil salinity).

- defined in terms of a wide array of measured physical attributes that were related to both regional and local scales.

\section{METHODS}

\section{Study Area}

The wheatbelt study area comprises all or part of five biogeographical regions (Figure 1): the entire Avon Wheatbelt bioregion, western two-thirds of the Mallee, southern half of the Geraldton Sandplains, western edge of the Jarrah Forest, and central quarter of the Esperance Plains. In phytogeographic terms, the study area comprises the semi-arid parts of the South-western Botanical Province (Beard, 1980). The inland boundary approximates the $300 \mathrm{~mm}$ isohyet. The western boundary is east of the $600 \mathrm{~mm}$ isohyet. Along the southern coast, the southern boundary approximates the $550 \mathrm{~mm}$ isohyet but avoids nearcoastal environments. It covers $205000 \mathrm{~km}^{2}$ and extends from Esperance to the Hill River. Overall, $74 \%$ of the study area has been cleared for agriculture. Remaining bushland occurs as isolated remnants embedded in a mosaic of canola-, lupinand wheat-fields, and between 4 and $5.5 \%$ of the study area's total surface area is now affected by salinity (Department of Environment, 2003; George and Coleman 2002; McFarlane and George, in press). Its physical environments are detailed by Mulcahy and Hingston (1961), Chin (1986), Myers and 


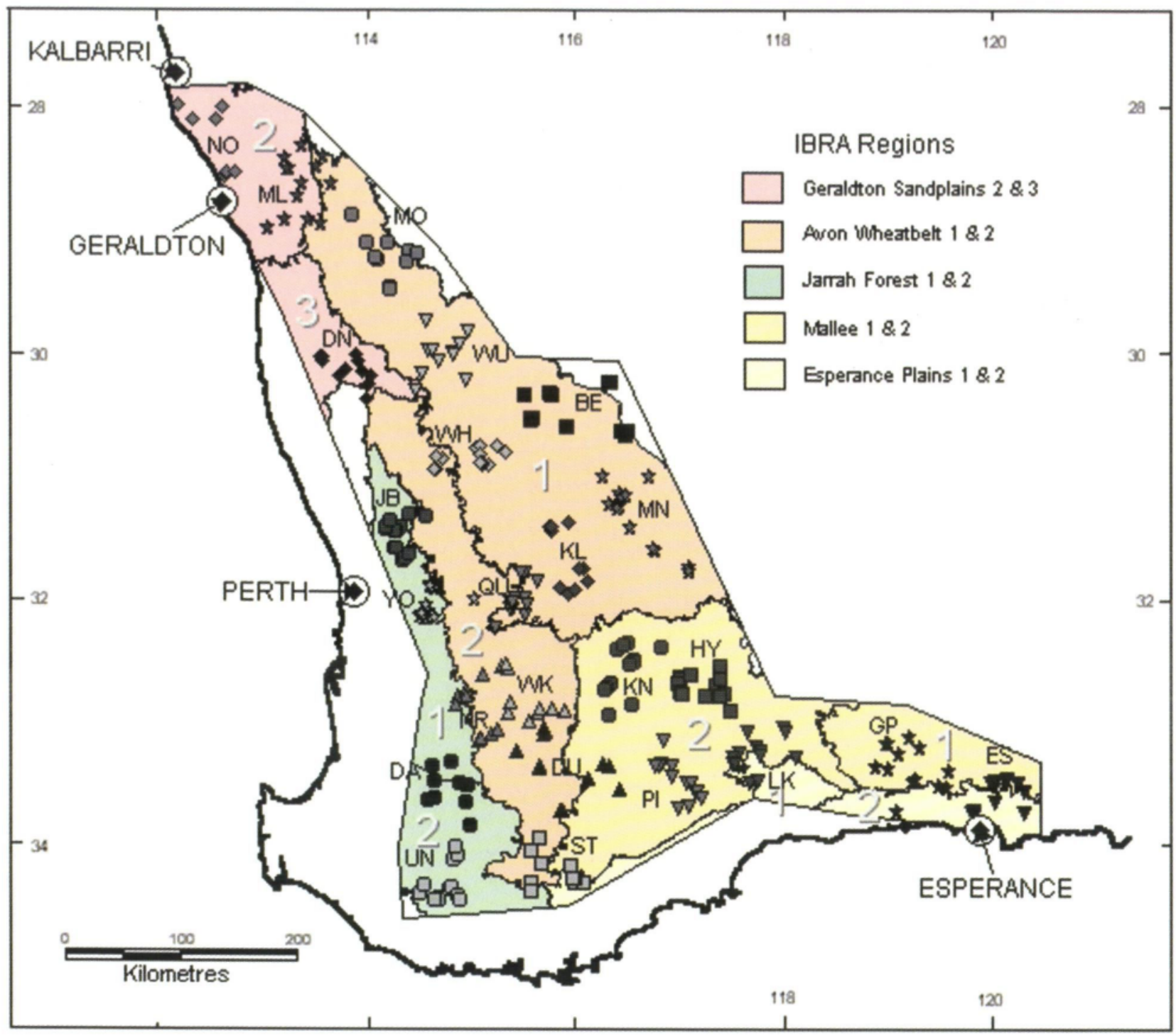

Figure 1 Wheatbelt study area. The relative positions of the 24 survey areas are indicated by their labels (e.g. 'BE', ' $K L^{\prime}$ '), and the positions of the 12 to 13 individual quadrats clustered in each survey area are shown as grey or black symbols (differences indicate survey area membership). Precise quadrat co-ordinates are provided in Appendix 2. The coloured areas indicate bioregions (Environment Australia 2000) modified from Beard (1980). The fine lines across the bioregions are sub-regional boundaries defined from IBRA version 5 (Morgan 2001). Survey area codes from north to south are: NO Northampton, ML Mullewa, MO Morawa, DN Dandaragan, WU Wubin, BE Beacon, WH Wongan Hills, JB Julimar-Bolgart, MN Merredin, KL Kellerberin, QU Quairading, YO York, HY Hyden, KN Kondinin, WK Wickepin, NR Narrogin, DA Darkan, DU Dumbleyung, PI Pingrup, LK Lake King, GP Grass Patch, ES Esperance, UN Unicup and ST Stirling.

Hocking (1998), Bureau of Meteorology (2001), Commander et al. (2002), George and Coleman (2002), Hatton and Ruprecht (2002) and Schoknecht (2002).

Briefly, the bulk of the study area is an undulating plateau of Tertiary duricrust overlying the Archaean granitic and metamorphic rock strata of the Yilgarn Craton. Under a variety of climates, interacting alluvial and aeolian processes have produced a complex landscape mosaic. The plateau is variously eroded into elluvial and colluvial spillway sand deposits, and dissected to expose valley-slope and -floor units characterised by duplex soils derived from the Archaean basement strata. In some areas the valley units are overlain by sands (from alluvial as well as aeolian re-sorting) or reworked as calcareous clays and loams that contain sheet and nodular kankar. Today, the Craton's surface has a semi-arid to sub-humid climate influenced by temperate weather systems (mainly winter rainfall). Its surface hydrology is characterised by low gradients, high potential salt loads and high variability in flows. It is divided into three regions: the Avon Wheatbelt, Mallee and Jarrah Forest bioregions, each of which is divided into two sub-regions (Figure 1). 
The Jarrah Forest bioregion is dominated by the duricrusted plateau of the Yilgarn Craton and has a 'warm mediterranean' climate with an average annual rainfall of between 500 and $600 \mathrm{~mm}$ in the study area. Major land-uses in the north are forestry and conservation, while grazing of improved pastures and dry land agriculture are more prevalent in the south. The Avon Wheatbelt bioregion occupies the northern and eastern-central parts of the Craton and has a semi-arid (dry) 'warm mediterranean' climate. Annual rainfall ranges from $500 \mathrm{~mm}$ in its south-west to $280 \mathrm{~mm}$ on its eastern edge. Land-uses are primarily dryland agriculture and grazing, with smaller areas of crown reserves (mainly conservation estate covering $1.7 \%$ of the region), mining and rural residential. Eighty per cent of the region has been cleared for agriculture and grazing so it has numerous environmental problems, threatened ecological communities and species at risk. Approximately $25 \%$ of the most threatened flora in Western Australia occurs in this region. The Mallee bioregion occupies the southeastern part of Yilgarn Craton. This region is gently undulating, has partially occluded drainage, and a climate that is 'mediterranean' to semi-arid with a mainly winter rainfall of between 250 and $500 \mathrm{~mm}$. Land-uses are similar to those in the Avon Wheatbelt bioregion, although $17 \%$ is conservation reserve.

Two other bioregions sampled during the survey are peripheral to the Yilgarn Craton, and have different geological basements. At its south-eastern end, the study area intersects the Recherche subregion (ESP2) of the Esperance Plains bioregion. This sub-region is within the Albany-Fraser Orogen (Geological Survey of Western Australia, 1999). Its surface has variable relief, comprising Quaternary coastal sandplains and dunes overlying Proterozoic gneiss and granite, as well as Eocene and more recent coastal limestones. Vegetation comprises heaths, coastal dune scrubs, mallees, mallee-heaths and granite heaths. The climate is temperate mediterranean', with $500-600 \mathrm{~mm}$ annual rainfall. Major land-uses include grazing of improved pasture and cultivation (dry-land agriculture). Smaller areas are used for conservation and other Crown reserves. The north-western part of the study area includes two of the Geraldton Sandplains bioregion's three sub-regions. In geological terms, this area comprises the central and northern Perth Basin and the Northampton Complex of the Pinjarra Orogen (Geological Survey of Western Australia, 1999). It has a semi-arid (dry) 'warm mediterranean' climate with an annual average rainfall between $525 \mathrm{~mm}$ (in the south) and $350 \mathrm{~mm}$ (north). The landscape is mainly an undulating lateritic sandplain mantling Permian to Cretaceous strata. Outcrops of Jurassic siltstones and sandstones can be heavily lateralized.
Sandplains are most extensive in the north and south-east where the region overlaps the edges of the Carnarvon Basin and Yilgarn Craton, respectively. Vegetation comprises proteaceous heaths, mallee heaths and woodlands variously dominated by eucalypts, acacias and banksias depending on soil-type. Main land-uses, ordered in terms of their extent, are: cultivation (dry land agriculture), conservation lands, grazing of native pastures, and other Crown lands.

Detailed descriptions of the vegetation in the study area are provided by Beard $(1980,1981,1990)$. Regional and sub-regional boundaries are discussed in Thackway and Cresswell (1995) and Environment Australia (2000), respectively.

\section{Sampling Strategy}

Scale, complexity and patchiness need to be taken into account in sampling the biota of a study area to describe the diversity of its patterns (Braithwaite, 1984; Bowers, 1997). A variety of factors can distort the results, including:

- geographical and seasonal sampling bias (Braithwaite, 1984; Weins, 1985; Rosenzweig and Abramski, 1986).

- historic extinctions and introductions, and storage effects (Burbidge and McKenzie, 1989; Warner and Chesson, 1985).

- limitations in scale (Dale, 1983; Whitmore, 1984, p. 231; Bowers, 1997; MacNally and Quinn, 1997; Huston, 2002).

- inefficient sampling methods (Hobbs et al., 1984; Rolfe and McKenzie, 2000), including the analytical implications of unreliable 'absence' data in the presence-absence matrix (Margules and Austin, 1994).

- the assumption that guilds follow taxonomic boundaries (Adams, 1985; Bowers, 1997; McKenzie and Rolfe, 1986).

- uneven taxonomic resolution (see McKenzie et al. $2000 \mathrm{c}$ ).

- strongly localised patterns of endemism (Solem and McKenzie, 1991).

Aspects of the survey design (details are provided in Gibson et al., this volume; Harvey et al., this volume; Burbidge et al., this volume) offset some of these problems:

- The study area was large enough to encompass significant sections of both the geographical and environmental ranges of the species sampled (Austin and Heyligers, 1989).

- Sampling was carried out during an integrated program; all quadrats were sampled in several seasons.

- The quadrat-size ( $c a .1$ ha for the zoological groups, and enclosing an 0.01 ha plant quadrat) was large enough to encompass the communities of the organisms being sampled considering their mobility, longevity and body- 
size in the context of their density, productivity and standing biomass in the study area. At the same time, the quadrats had to be small enough to allow the assumption that there was a reasonable level of internal homogeneity, and that there was syntopy between all biophysical attributes recorded within each quadrat (McKenzie et al., 1991b).

- Environmental attributes that reflect processes operating at both regional scales and local scales were measured for each quadrat.

- Our quadrats were sampled for perennial and annual vascular plants, frogs and lizards, small ground mammals ( $<25 \mathrm{~g}$ mean adult body weight), ground-dwelling spiders (see Appendix 1), centipedes, and scorpions - clades with established phylogenies at the specieslevel (plants and vertebrates) or for which the survey team had taxonomic expertise (spiders and scorpions). These clades appear to have persisted in the study area's vegetation remnants despite threatening processes other than increased salinity, and members have widely variable mobility, longevity, energy and moisture requirements, nutritional roles, biomass and reproductive strategies.

- Tested sampling methods were applied by experienced field survey ecologists, and species were included in the analysis only if they were reliably captured by the sampling methods (see Rolfe and McKenzie, 2000); thus the problems of unreliable 'absence' data in the presenceabsence matrix were minimised.

- Undescribed species were placed into their taxonomic hierarchy by professional taxonomists familiar with the relevant group in Western Australia (see also Oliver and Beattie, 1996).

Quadrats were positioned throughout the geographical extent of the study area in a stratified random array derived from vegetation, land surface, soil and surface lithology maps (Beard, 1981; Mulcahy and Hingston, 1961; Morgan and Peers, 1973; Baxter and Lipple, 1985; Chin, 1986). The study area was divided into 24 survey areas of similar size so that sampling was evenly dispersed across the study area's areal extent (Figure 1). In each survey area a quadrat was positioned in a typical example of each of the main geomorphological units (on surface lithology) that comprised the landscape's topographic profile (see below).

An additional one to two quadrats were positioned to sample examples of these units that were affected by ground-water salinity. In cases where a unit was particularly extensive within a survey area, two sites were sampled. As well, most quadrats were pseudo-replicated in the other survey areas to allow for the internal heterogeneity of the stratification units (hypothesised scalars) and to minimise any analytical circularity introduced by the stratification (Taylor and Friend, 1984; McKenzie et al., 1989, 1991b; Gaston and Blackburn, 1999). The quadrats chosen were the least disturbed examples we could find to minimise the effect that the uneven probability of disturbance among landform units would have on the survey design, an unavoidable source of variance. For this reason we focussed especially on the $5.6 \%$ of the area that is formally reserved (and managed) for nature conservation. As far as possible, we did not position quadrats in vegetation remnants of less than 100 hectares in area because many of the smaller remnants are managed for purposes other than nature conservation, and have a long history of exploitation. While it was impossible to avoid the historical effects of weed invasions, clearing, feral predators (including the house mouse Mus musculus), changed fire regimes, grazing by feral herbivores including rabbits, and many other changes, we attempted to minimise their influence on our data by positioning the quadrats at least 50 $m$ away from the visible effects of adjacent wheatfield and road edges. Even the sites selected to represent secondarily salt-affected sites were positioned to minimise proximity to wheatfields and avoid evidence of other disturbances such as rubbish disposal, gravel extraction and previous clearing.

Landform units in survey areas on the Yilgarn Craton were numbered from 1 to 12 (see Figure 2), depending on whether they were low in the landscape and part of its dissection profile (fresh water swamps $=1$, valley-sides $=7$ ), or spillway sands on or derived from its top (the ironstone duricrust pavements of the old Tertiary plateau = 12). Unit ' $\mathrm{Bg}$ ' in which spillway sand mantles a clay belonging to the dissected valley profile was assigned to number 8 . Quadrats in survey areas on geological basements other than the Yilgarn Craton (those in the Esperance Plains and Geraldton Sandplains bioregions) were positioned using the relevant 1:250 000 maps of surface lithology (e.g. Morgan and Peers, 1973), and arbitrarily assigned to our 12-class landform catena according to their soil profile (texture and horizon sequence), position in the relevant landscape's profile and soil origin. Thus, a deep, low-level sandsheet would be assigned to the same number as the lowest of the spillway sand units on the Craton (Monkopen =9). This approximation was considered to be acceptable because data taken from the quadrats themselves were used in subsequent analyses.

\section{Field Sampling}

Quadrat locations are listed in Appendix 2, and detailed sampling procedures for the various taxa are provided in Gibson et al. (this volume), 


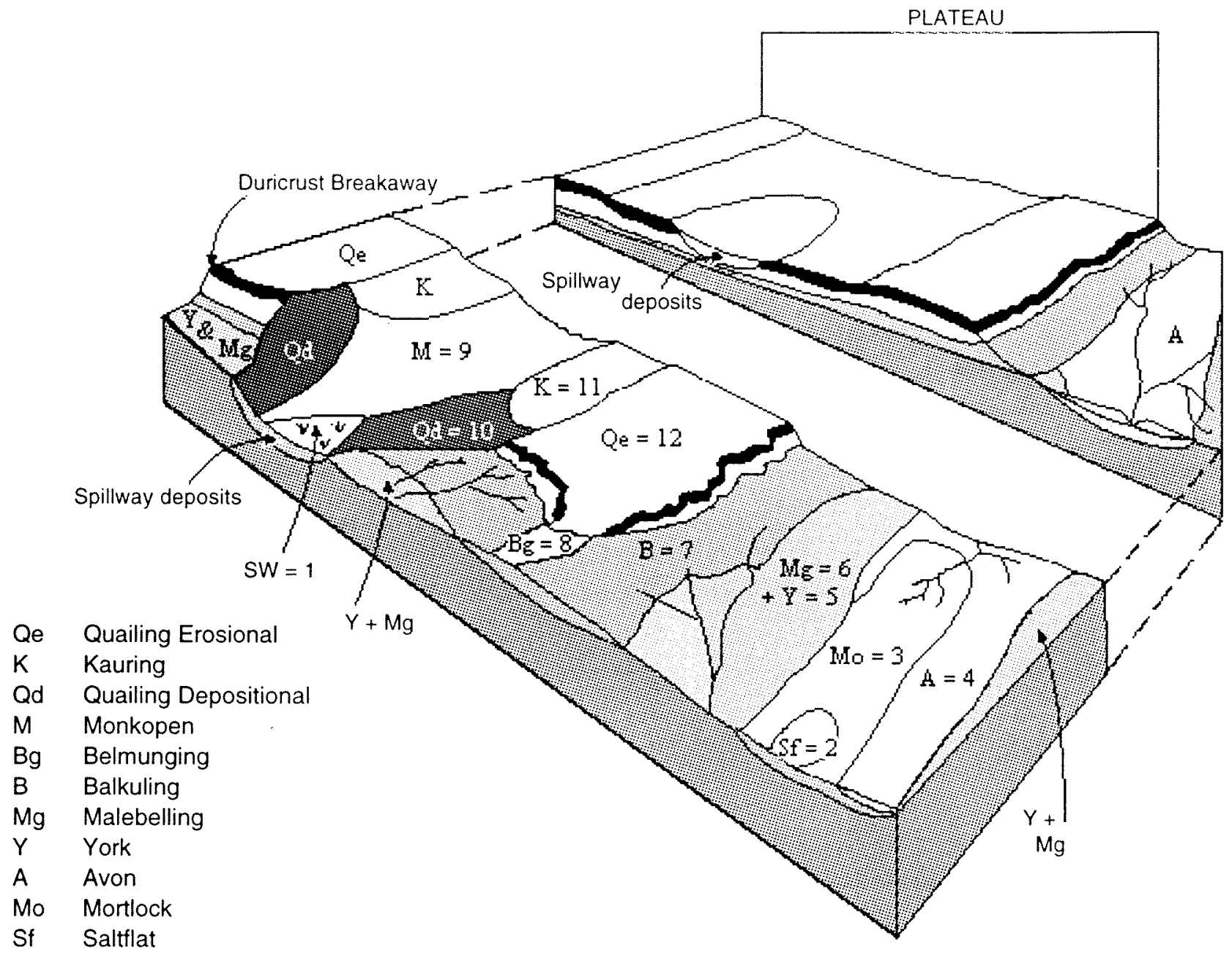

Sw Swamp (fresh)

Figure 2 Wheatbelt landforms, modified from Mulcahy and Hingston (1961). The landscape's plateau profile comprises the duricrusted Tertiary laterite plateau and its derived spillway sands, while the dissection profile comprises finer textured soils derived from bedrock and pallid-zone clays beneath the duricrust.

Burbidge et al. (this volume) and Harvey et al. (this volume). Twelve to 13 quadrats, each a relevé of less than one hectare, were positioned to sample the geomorphic profile of each of the 24 survey areas. Thus, species were sampled from 304 quadrats. During visits over two seasons to each quadrat, all vascular plants were inventoried from a $10 \mathrm{~m} \times 10$ $\mathrm{m}$ area enclosed by a $20 \mathrm{~m} \times 20 \mathrm{~m}$ area that was sampled for overstorey plants (quadrats in Grasspatch and Esperance survey areas were sampled in one season). Reptiles, frogs and mammals were pit-trapped for 8 nights in both Spring and Autumn (3 drift-fences each comprising 5 pit-traps arrayed at regular intervals along a $25 \mathrm{~m}$ flywire fence yielding 240 pit-trap nights per quadrat, 120 in each season). The pits were PVC pipe $125 \mathrm{~mm}$ diameter and $350 \mathrm{~mm}$ deep, had a plastic bottom and included a baffle to hinder escapes. Arachnids were sampled using five, 2-litre, glycol-pits left open for one calendar year at each quadrat (1825 pit trap nights per quadrat).
Sampling was sparse. The study area encompassed 205 million hectares, and less than 304 hectares was actually sampled. Thus, less than $0.0016 \%$ of study area was actually sampled for animals. Furthermore, only $1 \%$ of the area of each terrestrial quadrat was sampled for plants $(0.0000016 \%$ of the study area) except for trees which were sampled from $4 \%$ of each quadrat $(0.000006 \%$ of the study area). Since $74 \%$ of the study area has been cleared for agriculture, the actual figures are significantly larger in relation to the remaining uncleared land.

\section{Physical Attributes of Quadrats}

Eighteen climatic attributes were derived for each quadrat using ANUCLIM (McMahon et al., 1995). These comprised annual and seasonal average and range values for temperature and precipitation (Appendix 3). Soil and geomorphic attributes were also recorded from each quadrat (Appendix 3). The fifteen soil chemical and texture 
values for each quadrat were derived from subsamples collected at a depth of $2-10 \mathrm{~cm}$ (after removal of surface litter) from 20-30 regularly dispersed points, then bulked. These included nitrogen, phosphorus, potassium, pH, electrical conductivity, organic carbon, clay-silt-sand percentages and magnesium. The soil chemical analyses used are described in Wyrwoll it al. (2000). Eight landform and five vegetation attributes were also generated, including latitude, longitude, elevation, landform unit, soil drainage category, slope, salinity risk, salinity class, litter/ log cover, tree cover, shrub cover, herb cover and habitat complexity (modified from Newsome and Catling, 1979). These are defined in Appendix 3. Latitude and longitude values were determined using a hand-held GPS accurate to $\pm 100 \mathrm{~m}$. Significant correlations between these physical attributes were identified using Kendall's rank correlation coefficient (Kendall's tau), and one from each pair of tightly intercorrelated attributes was deleted (if $\tau>0.9$ ). Because 'landform' had already been used to position the quadrats in each survey area, it could not also be used as an attribute in modelling species assemblages. Physical attribute names and codes that are referred to in results and discussion are listed in Table 1.

Because heavy rainfall and/or surface flow events can flush salt from the soil's upper profile, we could not depend on our chemical assay to provide a reliable measure of ground-water salinity. To minimise this problem, electrical conductivity was also measured from a single soil sample taken low in the soil profile (at depths of up to $100 \mathrm{~cm}$, see
Griffin and Stoneman, this volume). In addition, salinity often had discontinuous, uneven or inconsistent effects within quadrats. For instance, distinct patchiness in vegetation-death corresponding to factors such as surface microtopography was observed at some quadrats (see also Cramer and Hobbs, 2002; Dimbock et al., 2002). To ensure robust analyses, these additional data and observations were used to assign quadrats among just four classes of salinity risk (SAL modified from van Gool and Moore, 1999):

- None (1). Salinity will not develop because of any or all of: low water-tables, high soil permeability, elevated position in the landscape and low salt store in the regolith.

- Partial or low (2). Areas with small variation in local relief and geology where rising watertables may not affect all of the site, or where rising water-tables are not currently saline, and the salt store in the regolith is low. May include lower footslopes and sandy rises on valley floors or near incised stream channels.

- High (3). Salinity already present in limited areas of the quadrat, or saline groundwater is already close to the surface with a rising trend.

- Saline land (4). Obviously salt affected areas (entire quadrat is usually salt affected). AIl saltflat quadrats (landform unit 2) are also included in this class and are treated as 'naturally saline' although some of these may have become saline so early in the period of European settlement that they are now indistinguishable from 'naturally' saline sites, and many are now hypersaline in parts.

Table 1 Environmental attribute codes.

\begin{tabular}{|c|c|c|c|}
\hline Code & Attribute & Code & Attribute \\
\hline Pann & Mean annual precipitation ( $\mathrm{mm}$ ) & $\mathrm{C}$ & Organic Carbon $(\%)$ \\
\hline PwetQ & Wettest quarter precipitation ( $\mathrm{mm}$ ) & K & Available $(\mathrm{HCO})$ potassium (ppm) \\
\hline PWmQ & Warmest quarter precipitation ( $\mathrm{mm}$ ) & $\mathrm{exCa}$ & Exchangeable calcium $\left(\mathrm{me}^{*} \%\right)$ \\
\hline Pseas & Precipitation seasonality & $\operatorname{tot} \mathrm{N}$ & Total nitrogen (ppm) \\
\hline Tann & Mean annual temperature ( $\mathrm{C}$ ) & $\mathrm{exMg}$ & Exchangeable magnesium $\left(\mathrm{me}^{\%} \%\right)$ \\
\hline TwetQ & Wettest quarter mean temperature (C) & tot_l & Total phosphorus (ppm) \\
\hline TwmQ & Warmest quarter mean temperature ( $\mathrm{C}$ ) & $P^{-}$ & Available (HCO) phosphorus (ppm) \\
\hline$T_{-} a r$ & Temperature annual range (C) & $\mathrm{exNa}$ & Exchangeable sodium (me $\left.\mathrm{mo}^{\circ}\right)$ \\
\hline isoT & Isothermality & $\mathrm{EC}$ & Electrical conductivity ( $\left.\mathrm{mSm}^{-1}\right)$ \\
\hline mnTicle & $\begin{array}{l}\text { Coldest period ninimum temperature } \\
\text { (C) }\end{array}$ & SAL & $\begin{array}{l}\text { Salinity in } 4 \text { classes (no risk, some risk, high risk, } \\
\text { saline), see Appendix } 3\end{array}$ \\
\hline mxlwml' & $\begin{array}{l}\text { Warmest period maximum temperature } \\
\text { (c) }\end{array}$ & Saltype & $\begin{array}{l}\text { Salinity type in three classes (naturally saline, } \\
\text { salinity affected, not saline) }\end{array}$ \\
\hline L.ongitude & Longitude ( $\mathrm{F})$ & Clay & Percent day \\
\hline Elevation & Altitude above sea-level (m) & Silt & Percent silt \\
\hline licos & $\begin{array}{l}\text { Canopy-cover of tree stratum in } 4 \\
\text { dasses (Muir 1977) }\end{array}$ & Heon & $\begin{array}{l}\text { Canopy-cover of herbaceous stratum in } t \\
\text { classes (Muir 1977) }\end{array}$ \\
\hline Seov & $\begin{array}{l}\text { Canopy-cover of shrub stratum in } 4 \\
\text { classes (Muir 1977) }\end{array}$ & Gistuf & $\begin{array}{l}\text { Ground cover of teaf litfer, rocks } \\
\text { and fallen wood }\end{array}$ \\
\hline 1.F & Landform unit in 12 dasse's (Figure 2) & Drainage & Soil drainage in 6 classes (see Appendix 3). \\
\hline
\end{tabular}




\section{Analytical Strategy}

The analytical approach taken in this paper is based on the assumption that spatial distributions of species reflect an underlying correlation with environmental factors (Austin, 1991; Clarke, 1993).

The input data were the "quadrat-x-species" matrix. We determined and analysed the presence and absence of species in the quadrats, rather than their relative abundance, because limitations in sampling techniques precluded reliable estimates of abundance (Austin, 1984; McKenzie ef al., 1991b).

\section{Cross-taxon Congruence}

We used the analytical procedure detailed in McKenzie et al. (2000b), which was similar to that used by Somerfield and Clarke (1995). Four of the five clades represented in our community matrix were used: herpetofauna, spiders, scorpions and vascular plants, and singleton species were retained in the data sets. The fifth clade, represented by small ground-dwelling mammals, was excluded because our sample of 15 species ( 11 non-singleton species) had an average of only 1.9 species per quadrat, was a fragment of a much more diverse mammalian fauna (see Burbidge et al., this volume), and included the introduced House Mouse which was one of the two most common species in our sample. Thus, our mammal data could not reliably represent this homeothermic clade. Analysis involved six steps:

1. For each sub-set, and for the combined data set, a dissimilarity matrix was derived by using the Czekanowski measure (Czekanowski, 1932) from the ASO module in the computer package PATN (Belbin, 1995) to compare quadrats in terms of their species composition.

2. Each dissimilarity matrix was output as a linear vector (Option 6 in the ASON module of PATN, Belbin, 1995).

3. Using Pearson Product-Moment Correlation, we calculated the correlation between each pair of vectors as a measure of congruence in their (spatial) biodiversity patterns. These correlation coefficients were compiled as a matrix of 'crosstaxon' congruence.

4. Next, the correlation matrix was converted to a dissimilarity matrix (1-coefficient), and Semistrong Hybrid Scaling (SSH in Belbin, 1995) was used to reduce the dimensionality of this matrix, so that the relationships between the sub-set patterns and the combined pattern (the biodiversity model) could be displayed in three dimensions. Three-dimensional separation distances were calculated (as delta values derived from the ordination co-ordinates).

5. A 'minimum spanning tree' (MST in Belbin, 1995) was superimposed to indicate the nearestneighbour linkages in the ordination space.

6. To provide some extrinsic measure of distance (delta values) across the ordination space, 100 random dissimilarity matrices (with the same skewed distribution of linkage distances as the 'combined' matrix) were generated and plotted (one by one) in the same ordination space using the steps listed above. The centroid position of the 100 'random' matrices was displayed in the cross-taxon congruence scatterplot, and the mean and variance of its three-dimensional distance from the 'combined' matrix calculated.

\section{Patterns in Species Composition}

We used cluster analysis (from PATN, Belbin, 1995) to expose patterns of species composition in the data matrices. The clustering techniques selected were described in McKenzie et al. (1991a). Briefly, the association measure "Two-step" (Belbin, 1980) was used to determine the quantitative relationship between each pair of species, and the Czekanowski measure (Czekanowski, 1932) was used to compare the quadrats according to their species similarities. For both measures of association, a modified version of the "unweighted pair group arithmetic averaging" (UPGMA - Sneath and Sokal, 1973; Belbin, 1995) hierarchical clustering strategy was used, with the clustering parameter (Beta) set to -0.1 , to derive classification partition structures (dendrograms). A modification by Hubert and Arabie (1985) of the statistic by Rand (1971) was used to assess the influence of singleton species on classification partition structures (RIND module in PATN, Belbin, 1995).

Analyses were carried out in the following order:

1. Species were classified according to their similarities of occurrence at the 304 quadrats. The structure of the resulting dendrogram was examined extrinsically, in terms of the known habitat associations of component species throughout their ranges in Australia (Anon., 1999; Beard, 1981; Ehmann, 1992; Harvey et al., 2000; How et al., 1988; Jessop, 1981; Keighery et al., 2000; Koch, 1981; Main et al., 2000; McKenzie and Rolfe, 1995; McKenzie et al. 2000c; Paczkowska and Chapman, 2000; Smith \& McKenzie, 2000; Storr et al. 1990, 1999; Strahan, 1995; Tyler et al., 2000; Wilson and Knowles, 1988, as well as reviews in earlier papers in this volume), and adjacent species were amalgamated into assemblages of species with similar habitat preferences. Thus, each assemblage was defined in habitat preference terms, but the process resulted in uneven dendrogram cut-levels. Far more data were available for plants and vertebrates than for arachnids.

2. The species-quadrat matrix of each assemblage was assessed for nestedness (Atmar and Patterson 1993).

3. Quadrats were classified according to 
similarities in species composition (as above), to summarise each assemblage's pattern of occurrence across the study area in the form of a separate dendrogram (its compositional structure). Next, for each assemblage, we superimposed its richness as a histogram on its dendrogram. This process allowed us to assess whether the assemblage's richness pattern conformed with its dendrogram partition structure, ie. whether the pattern of its speciesrichness across the study area was a useful surrogate for its composition.

4. The generalised linear interactive modelling package GLIM (NAG, 1986; Nicholls, 1989) was used to model the relationships between the species richness of each assemblage and a set of attributes related to the physical environment of the quadrats (see Appendix 3). Forward, stepwise regression models were fitted to each of the species-assemblages defined from the classification procedure, with quadrat speciesrichness as the dependent variable. The significance of the parameters in the regression equations was calculated using the Wald statistic.

\section{Geographical Patterns in Biodiversity}

\section{Assemblage Level}

Provided that assemblage richness was good surrogate for assemblage composition, and that most of the scaled deviance in assemblage richness gradients could be explained in terms of climatic and other mapped environmental attributes, then these gradients should, collectively, provide an organism-centred perspective on the internal biogeography of the study area (cf. McKenzie et al. 1989, 1991b, 2000b). There were three steps in mapping the geographical expression of this perspective:

1. We used the interpolation module in the computer package STATISTICA (Statsoft, 2001, p. 599) to contour the species richness of each assemblage across the study area as spatially continuous information. The species richness gradients of the assemblages were related to combinations of climatic and substrate factors (see the GLM equations in 'Results'), and substrates were expressed as local soil-mosaics within regional climatic patterns. Thus, given that survey areas were evenly arrayed across the study area and that an equivalent cross-section of the landscape profile was sampled in each survey area, we could suppress the localised influence of the soil attributes on the contour maps by basing the interpolations on the maximum assemblage-richness value recorded from the 12 to 13 quadrats in each of the 24 survey areas, excluding singletons. This had the additional benefit of reducing the effect of any spatial autocorrelations induced by the contagious distribution of the quadrats across the study area (Figure 1) (Roxburgh and Chesson, 1998). The negative exponential smoothing option was used because the point richness values were at least as high as our sampling program indicated.

2. Any compositional discrepancies in the richness isolines of complex assemblages were assessed by inspecting the relevant two-way table (Appendix 4) to allow for compositional variants, patterns of endemism and allopatry etc.

3. To produce a two-dimensional biogeography from the isoline maps, we classified the 304 quadrats in terms of their relative weighting for each assemblage. For this analysis, the 17 assemblages were weighted equally by using the proportion of an assemblage's maximum speciesrichness recorded at each quadrat as input data. The two-dimensional output could be directly compared with the existing IBRA bioregions and sub-regions (see 'Study Area', above).

\section{Broad Regionalisation}

An assessment of broad biogeographical patterns across the study area was obtained by classifying the 24 survey areas according to the differences in their total species composition. Again, valid analysis at this scale required that (1) the survey areas were evenly arrayed across the study area and covered its geographical extent and variety of landscapes, and (2) a consistent landform model was used to position the individual quadrats so that an equivalent cross-section of the landscape profile's main components was sampled in each survey area. This nested stratification was designed to allow each survey area to be treated as a single landscape-scale releve; by pooling the lists of species from a survey area's 12 to 13 quadrats, we might suppress the influence of substrate on the classification structure, thereby exposing the influence of broad-scale climatic gradients (see Discussion). Briefly, the Czekanowski measure (Czekanowski, 1932) was used to compare the survey areas according to their species similarities, then a modified version of "unweighted pair group arithmetic averaging" (UPGMA - Sneath and Sokal, 1973) hierarchical clustering strategy was used, with the clustering parameter (Beta) set to -0.1 (Belbin, 1995). The structure of the resulting surveyarea dendrogram was used as a summary of overall compositional patterns across the study area. Climatic attributes that most closely conformed to this structure were assessed for statistical significance using Kruskall-Wallis one way analysis of variance by ranks (in the computer package STATISTICA) 


\section{RESULTS}

\section{Species Richness of Quadrats}

A total of 2071 plant and 807 animal species were recorded from the 304 quadrats (Appendix 1), an average of 74.3 species per quadrat (s.d. $=23.2$ ). The animals comprised 107 herpetofauna (21 frogs, 86 reptiles), 16 small ground mammals, 19 scorpions and 665 ground-dwelling spiders (these figures exclude animals for which the sampling methods were unreliable, as detailed in 'Methods').

Relationship between total species richness of quadrats and salinity across the landscape profile is displayed in Figure 3. Quadrats on saline flats were relatively poor in species (average $=35$ species, s.d. $=18, n=16$ ). Ignoring saline flats, we also noted that quadrats with soils of high electrical conductivity $\left(>100 \mathrm{mSm}^{-1}\right)$ were significantly poorer in species than those with less $(47.8 \pm 21.3, \mathrm{n}=18$ versus $78.4 \pm 20.0, n=270$ respectively). If quadrats on soils with $\mathrm{EC}$ values $>100 \mathrm{mSm}^{-1}$ were excluded, Tertiary plateau and its derived 'spillway' sand surfaces (as defined by Mulcahy and Hingston, 1961) were of similar species richness to the generally heavier soil surfaces of valleys dissecting the plateau $(81.0 \pm 17.0, n=120$ versus $75.9 \pm 22.0, n$ $=153$, respectively).

\section{Singleton Species}

An average of 3.1 species per quadrat (s.d. $=2.7$, range $=0-19, \mathrm{n}=304$ ) were excluded from our numerical analyses because they were recorded at only a single quadrat. These 956 singletons comprised $33 \%$ of the entire data set $-36 \%$ of its 2071 plant species, $29 \%$ of 665 spiders, $10 \%$ of 19 scorpions, $0 \%$ of 21 frogs, $23 \%$ of 86 reptiles and $31 \%$ of 16 mammals. The distribution of singletons across the 304 quadrats departs significantly from a random Poisson distribution (Lambda $=3.14$, Chisquare $=70.4, P<0.00001)$; it is best described as 'right-skewed Poisson' so, in assessing singleton richness across the 304 quadrats in terms of environmental variables, we used a Poisson model and logarithmic links for the GLM procedure (NAG 1986). Although only $31 \%$ of the deviance in the data is explained by this model (Table 2), singleton richness was significantly higher:

- on non-saline (-exNa) soils where 'Silt' exceeds $10 \%$, or on sandplains and laterite pavements high in the landscape ('Landform' = 10 to 12), and

- in areas with highest isothermality (southern and south-western margins of the study area: + isoT ${ }^{2}$ ) or in parts of the study area with hottest summers (north-eastern inland: quadratic of TwmQ).

When singleton richness was mapped, highest values tended to be on quadrats around the periphery of the study area. But singleton richness was also related to landform unit (Figure $4, P<$ 0.0001 ), so singleton richness was first averaged for each survey area (see Broad Regionalisation in

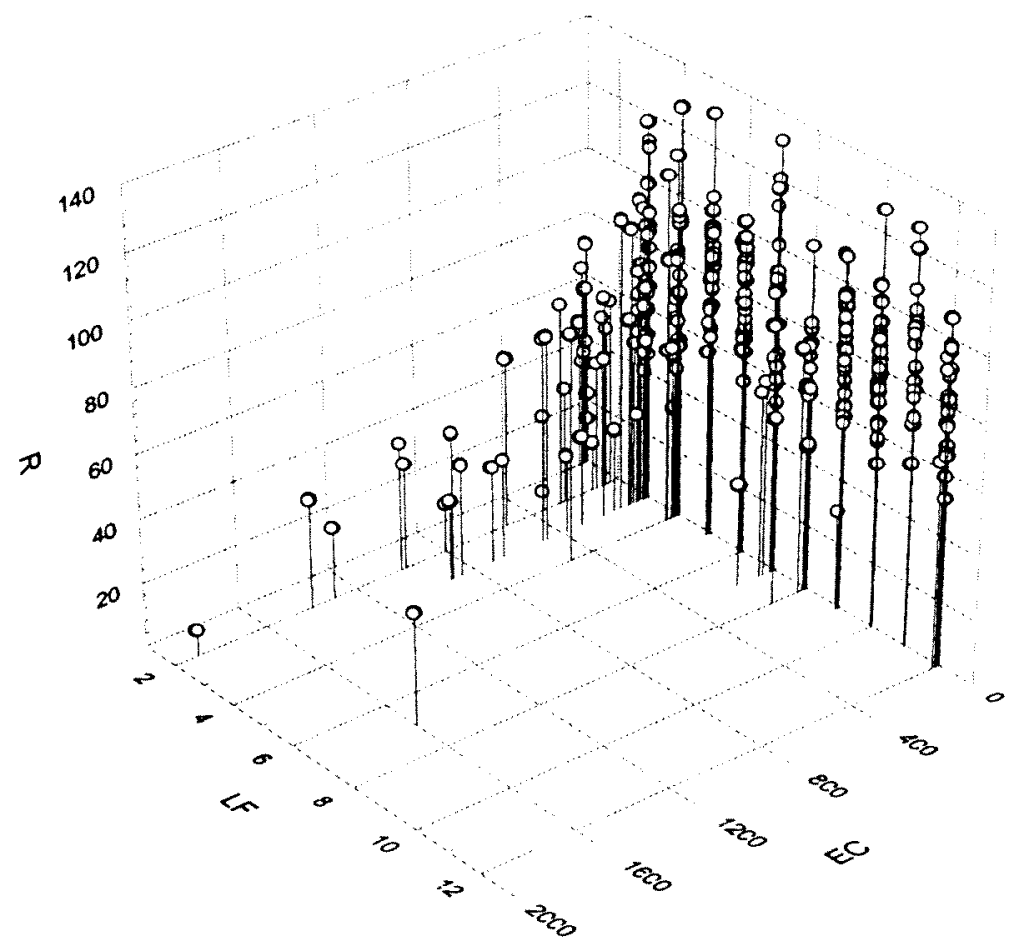

Figure 3 Quadrat species richness (R) plotted against landform unit (LF) and soil electrical conductivity $\left(E C, \mathrm{mSm}^{-1}\right)$. Landform units are numbered from the lowest levels in the landscape profile $(1=$ swamps and $2=$ saltflats $)$ to its top (12= Quailing Erosional) as shown in Figure 2 . 


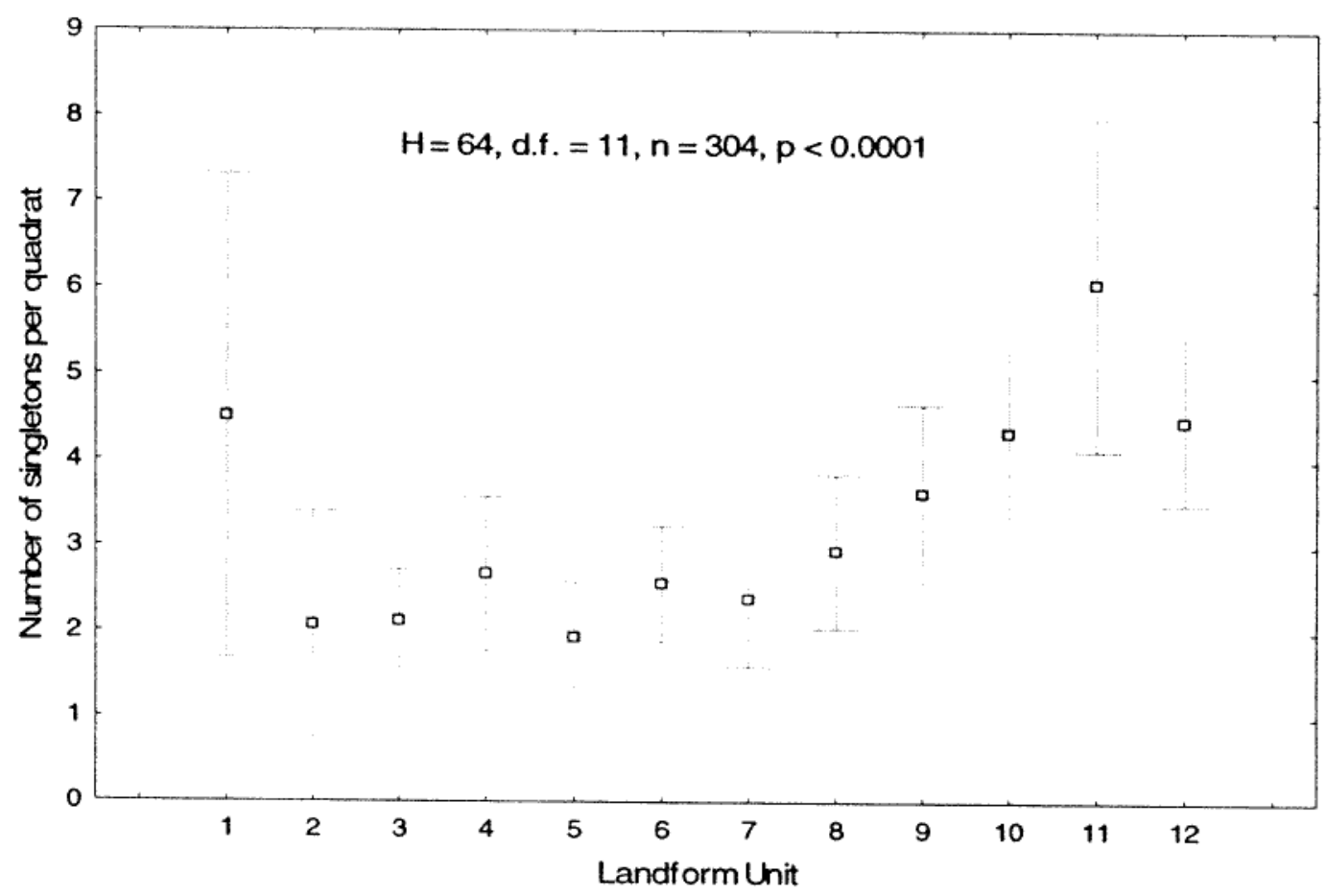

Figure 4 Relationship between landform unit (Figure 2) and number of singleton species at quadrats. Mean and 95\% confidence intervals are shown $(\mathrm{H}=$ Kruskall-Wallis coefficient $)$.

Methods), then assessed against distance to edge of the study area. This revealed a highly significant relationship (Kendall tau $=-0.504, P<0.001, \mathrm{n}=24$ ).

\section{Spatial Patterns in Quadrat Composition}

Using the entire 2878 species, the 304 quadrats were classified in terms of similarities in their species composition. After species that occurred at only one quadrat were removed from the data set, 1922 species remained (an average of 71.1 per quadrat, s.d. $=22.8$ ). These comprised 21 frogs, 66

Table 2 Fitted GLM model relating the richness [as $\mathrm{Ln}(\mathrm{R})]$ of singleton-species to the physical attributes of the 304 quadrats. The scaled deviance of the null model was 654 , whereas that of the fitted model was 450 with 295 degrees of freedom. Thus, it explained only $31 \%$ of the scaled deviance. The model involved five significant terms (three as quadratics), was not sensitive to any quadrat, and was considered to be robust.

\begin{tabular}{rrc}
\hline Parameter & Coefficient & s.e. \\
\hline 1 & 8.484 & 4.446 \\
Silt & -0.201 & 0.057 \\
Silt & 0.031 & 0.007 \\
Landform $_{\text {Landform }}^{2}$ & -0.124 & 0.047 \\
IsoT $^{2}$ & 0.012 & 0.003 \\
TwmQ & 15.45 & 2.411 \\
TwmQ $^{2}$ & -1.042 & 0.361 \\
exNa & 0.024 & 0.008 \\
\hline
\end{tabular}

lizards, 11 small ground mammals, 17 scorpions, 472 ground-dwelling spiders and 1335 plants. Using this reduced matrix, the 304 quadrats were again classified in terms of similarities in their species composition to yield a quadrat dendrogram that summarised geographical patterns of occurrence (Figure 5). Strong patterns are apparent in this dendrogram, separating the old Tertiary plateau and dissection valley components of the landscape profile in different parts of the study area. Within the dissection valley units, the dendrogram structure separated saltflats, secondarily salinised units, freshwater swamp margins and non-saline units.

When the dendrogram partition structures derived from the 2878 species and the 1922-species data sets were compared using the modified RAND statistic (Table 3 ), the differences at the 27 group level were small (ratio of diagonal values to total values $=0.85$; Hubert and Arabie RAND statistic $=$ $0.78)$.

\section{Cross-taxon Congruence}

The results of the sub-set comparison are presented in Table 4 and Figure 6, which maps the position of each of the matrices in a 3-dimensional ordination space defined in terms of the differences between their biodiversity patterns. Three features were noted:

1. The sub-sets were positioned all around the community matrix, so it would shift in 'biodiversity space' if any sub-set was eliminated. 
Table 3 Comparison of quadrat classifications derived from the 1922 species data set (Den-1, see Figure 5) and the 2878 species data set (Den-2).

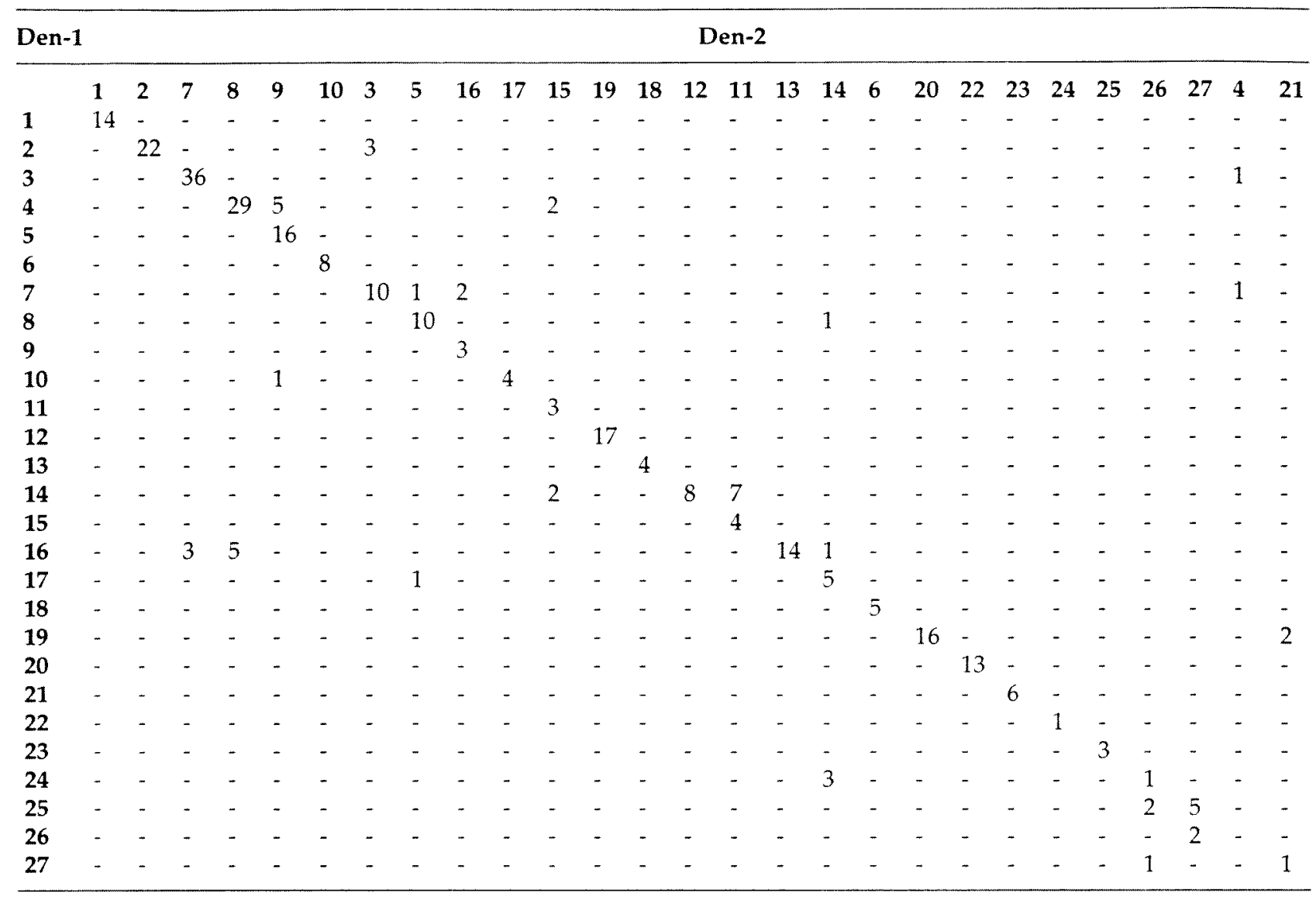

Hubert-Arabie RAND statistic: 0.78

Diagonal/total: $258 / 304=0.85$

2. The 'minimum spanning tree' linkages showed that the sub-sets were closer to the combined (community) matrix than to one another, except for the scorpions which were $9 \%$ closer to the reptile-frog sub-set (delta distance $=1.626$ versus 1.781 ). Given that the scorpion position estimate was the least precise because it was based on only 19 species (compared to 107 reptiles and frogs, 665 spiders and 2071 plants), we concluded that no sub-set provided a surrogate for another sub-set.

3. When 100 randomly-generated matrices were added to the analyses, the cloud of random points was an average delta distance of 1.89 units from the community model, with $99 \%$ of these points between 1.88 and 1.91 units. In comparison, the cluster of taxonomic sub-sets had an average delta radius of 0.90 (48\% of this distance), with individual sub-sets a delta distance of 0.34 (plants), 0.62 (spiders), 0.85 (reptiles and frogs), and 1.78 (scorpions) from the combined matrix. Thus, the four sub-sets were all well-separated from the community model, indicating that they had very different patterns of occurrence; none was a community surrogate.

Table 4 Pearson correlation coefficents between the association matrices derived from each of the 6 data sets (the four taxonomic sub-sets, the combined data, and the centroid of the 100 randomly generated data sets).

\begin{tabular}{llllll}
\hline COMBINED & & & & & \\
PLANTS & 0.88 & & & & \\
REPTILES and FROGS & 0.61 & 0.39 & 0.34 & 0.07 & 0.00 \\
SPIDERS & 0.74 & 0.44 & 0.11 & 0.00 & SCORPIONS \\
SCORPIONS & 0.09 & 0.05 & 0.01 & SPIDERS \\
RANDOM & 0.01 & 0.01 & REP+FROG & & \\
\end{tabular}




\section{Landform}

P9-12

D5-6

D3-7

D3-8

P9-12

P9-12

P9-12

P9-12

P9-12

P9-12

P9-12

P9-12

P9-10

D3-8

D3-4

D3-7

D5-8

P10-12

Ds,salted D3

Salted D3

Salted LF3-8

Df

Df

Df

Df

Df,Ds

Ds
Part of Study Area

north-east

northern half

northern half

south-west

south-west

far south-west corner

north

centre

DN survey area

central south-west

central west

south-east \& centre

far south-east

south-east \& central-south

far south-east

centre

central-south

central-east

all but west edge

central-south

along western edge

DN survey area

south-west

north-east \& south-east

far east \& west in south

GP survey area

far east \& west in south
Group Numbers (inTable 3)

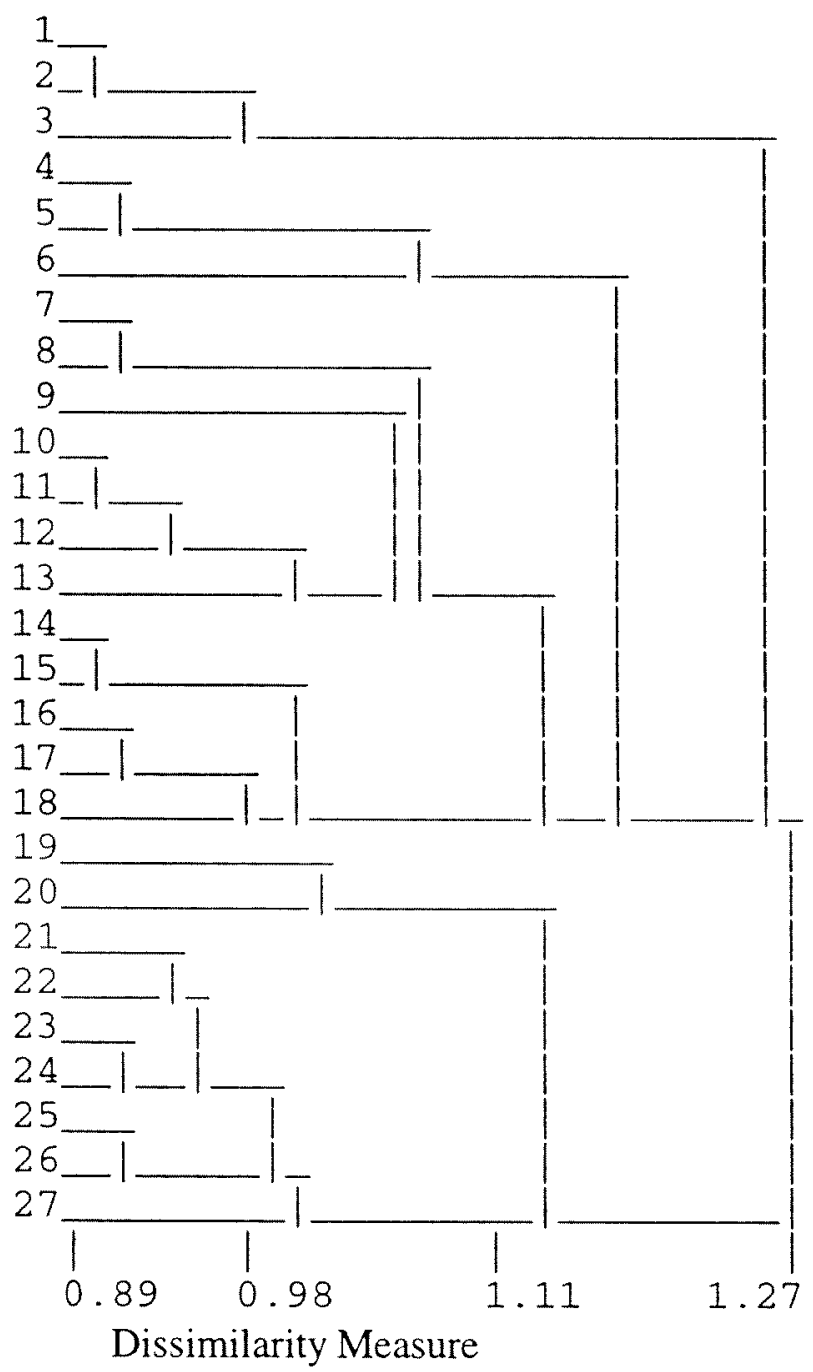

Figure 5 Quadrats classified according to their species composition using the 1922 species data set. Dendrogram structure to the 27-group level is displayed, and related to landform profile. Three landform components are distinguished: old Tertiary plateau and derived spillway sands (P), and dissection valley units (D) including saltflats (Ds) and fresh water swamps (Df). For example, the code 'P9-12' indicates old plateau and spillway units $9,10,11$ and 12 as shown on Figure 2. Survey area codes from Figure 1.

\section{Assemblages}

The 1922 species were classified according to similarity of occurrence at the 304 quadrats. We defined 17 assemblages in terms of the distributional characteristics and habitat preferences of their component species throughout their geographical ranges in Australia, although it should be noted that these data are available for few of the spiders. The uneven nature of the dendrogram cut-level is reflected in the assemblagecodes, that were derived from a lower-level, horizontal cut (at 34-groups) (see Figure 7).

Several distinct step-wise structures dominate both the quadrat- and the species-dendrograms (Figures 5 and 7). Such structures would occur if the assemblages were responding to different gradients in the physical environment or differently to sub-sets of environmental gradients (McKenzie et al.1989, 1991a, 2000b). Thus, the 17 assemblages were treated as independent data sets and analysed separately.

When the 17 assemblages were assessed for twodimensional nestedness in their species composition (Atmar and Patterson 1993), only the two smallest were not significantly nested (Table 5). These two assemblages totalled $1.9 \%$ of the species in the matrix (37 of 1922) and both involved species from habitats we sampled at only a few sites (braided drainage channels and isolated sedimentary hills, respectively).

When the 304 quadrats were classified in terms of an assemblage's species occurrences, the resulting dendrogram summarised its pattern of occurrence across the study area. By superimposing the 


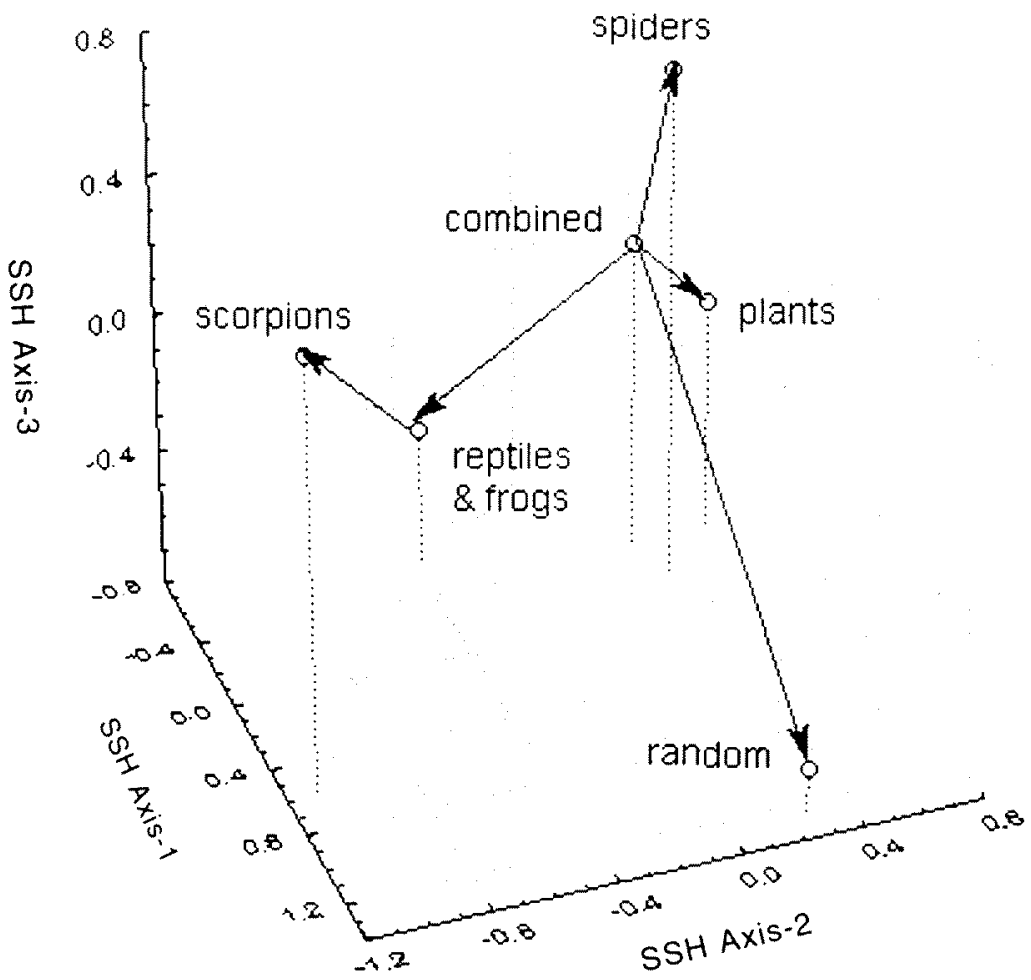

Figure 6 Comparison of the biodiversity patterns derived from four phylogenetic groups sampled, from the combined data set, and from 100 randomly-generated data sets. A matrix of correlation coefficients was compiled from a pairwise comparison of the relevant quadrat similarity matrices. Results are displayed in three-dimensions using Semi-strong Hybrid Scaling (Belbin, 1991, stress =0.08). Minimum Spanning Tree linkages (Belbin, 1995) are superimposed to indicate nearest neighbours in biodiversity space.

Table 5 Nestedness index $\left(\mathrm{T}^{\circ}-\right.$ Atmar and Patterson 1993) for the 17 species assemblages, and probability $(P)$ of encountering an assemblage as nested as the observed species-quadrat array. $R=$ assemblage species richness. $\mathrm{NS}=$ not significant.

\begin{tabular}{rrrr}
\hline Assemblage & $\mathbf{T}^{\circ}$ & $\boldsymbol{P}$ & $\mathbf{R}$ \\
$1 \_2$ & 4.01 & $1.1 \mathrm{e}^{-139}$ & 277 \\
$3 \_5$ & 5.32 & $1.3 \mathrm{e}^{-21}$ & 188 \\
6 & 7.36 & $4.9 \mathrm{e}^{-11}$ & 112 \\
7 & 22.71 & $0.09(\mathrm{NS})$ & 16 \\
$8 \mathrm{a}$ & 21.88 & $9.7 \mathrm{e}^{-219}$ & 138 \\
$8 \mathrm{~b}$ & 34.88 & $1.7 \mathrm{e}^{-73}$ & 39 \\
9 & 14.43 & $9.1 \mathrm{e}^{-72}$ & 101 \\
$10 \_12$ & 5.48 & $4.2 \mathrm{e}^{-32}$ & 134 \\
$13 \_15$ & 6.28 & $1.6 \mathrm{e}^{-43}$ & 110 \\
16 & 5.44 & $2.5 \mathrm{e}^{-23}$ & 130 \\
$17 \_18$ & 9.34 & $1.1 \mathrm{e}^{-12}$ & 60 \\
19 & 12.76 & $2.5 \mathrm{e}^{-7}$ & 46 \\
20 & 21.97 & $0.11\left(\mathrm{NSS}^{3}\right)$ & 21 \\
21 & 14.77 & $9.3 \mathrm{e}^{-5}$ & 38 \\
$22 \_26$ & 3.37 & $4.1 \mathrm{e}^{-\%}$ & 216 \\
$27 \_33$ & 3.30 & $1.6 \mathrm{e}^{-150}$ & 239 \\
34 & 7.93 & $4.1 \mathrm{e}^{-13}$ & 57 \\
\hline
\end{tabular}

assemblage's species richness as a quadrat attribute on the dendrogram (e.g. Figure 8), we could assess whether, and/or how, its richness and composition patterns conformed with each other. Figure 9 displays this relationship for each of the 17 assemblages. The corresponding data matrices, reordered and partitioned according to species similarities within the relevant assemblage, are provided in Appendix 4. As a parallel analysis, the package GLIM was used to model each assemblage's species richness in terms of the physical attributes of the quadrats (Table 6). In all cases, Poisson error models with logarithmic links best fitted the richness gradients.

The assemblage characterisations and the results of these assemblage analyses are compared in the annotated list below.

Assemblage 1_2 (Inland Distributions Centred on Finetextured Soils of Semi-arid and Arid Regions)

This assemblage comprises semi-arid and arid woodland species associated with fine-textured Quaternary soils with low or no salinity of broad 


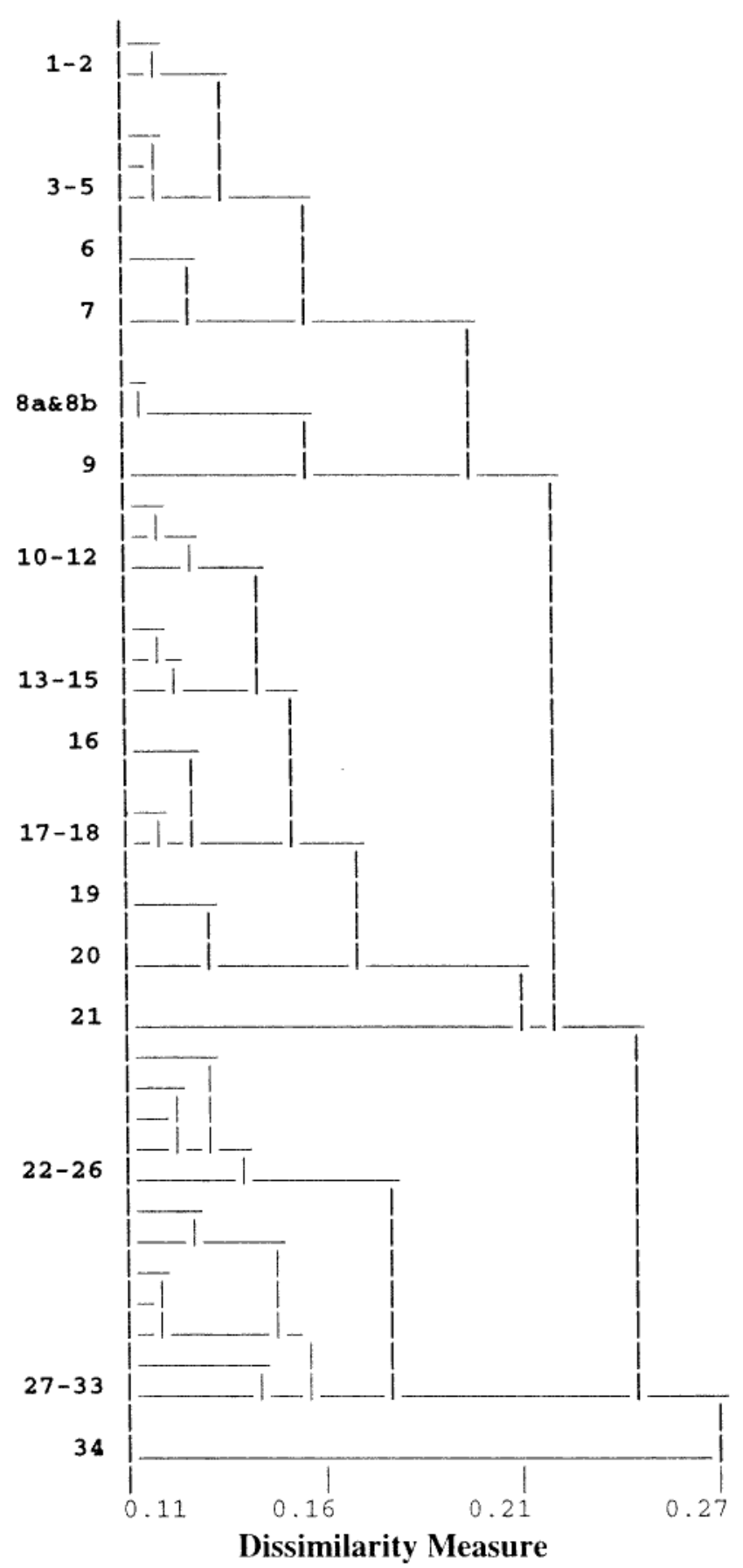

Figure 7 Assemblages derived by classifying species according to similarity of occurrence at the 304 quadrats. Dendrogram structure to the $34-$ group level is displayed.

valley floors in the Coolgardie and southern Yalgoo, eastern Avon Wheatbelt and northern Mallee bioregions, including woodland species on calcareous soils. Examples include the plants Encalyptus salmomophloin, E. longicornts, E. kondininensis, E. viluanensis, E. salubris, Acacia tetragonophlylla, A. merallit, Mclaleaca pauperiflora, Eremophila oppositifolia. Olearia muelleri. Atriplex vesicaria, Evocarpes aphyllas, Santalum acuminatum, the reptiles Diplodactylus maini. Cyclodomorphus branchialis, Ctenophorus scutulatus, C. cristatus, Ctenotus uber, Lerista m. macropisthopsis and the spiders Asadipus phateratus (Lamponidae), Lycosa forresti (Lycosidae). Few species typically associated with highly saline surfaces are included (e.g. Sminthopsis crassicandata). The assemblage's speciesrichness patterns conform with its composition (its dendrogram structure - Figures 8 and 9) and it is highly nested (Table 5), so richness is a reasonable surrogate for composition. The physical attributes significant in the relevant GLM richness model (Table 6) are consistent with the assemblage's characterisation, above. For instance, the relationship between annual rainfall (Pann), species richness and species composition is illustrated in Figure 8. Figure 10 shows that this assemblage occurs low in the landscape $(\mathrm{LF}<8$, with maximum richness on landform units $2,3 \& 4$ ), and displays a negative relationship between species richness and soil electrical conductivity (salinity).

\section{Assemblage 3_5 (Granite Complex Species)}

This assemblage is centred on granites and surrounding (fertile) gritty and loamy soil units in the Avon Wheatbelt bioregion. There are three types of species: (1) sub-sets of localised species centred on granite complexes in a particular part of the study area, including the spiders Storena formosa and Neostorena sp. 4 (both Zodariidae), Opopaen sp. 12 (Oonopidae), Lycidas sp. 18 (Salticidae), Lycosa sp. 16 and Artoria sp. 11 (Lycosidae), (2) widespread Avon Wheatbelt granite outcrop and apron specialists, including the plants Lepidosperma viscidum, L. drummontii, Acacia lasiocalyx, Spartochlon scirpoidea, Borya nitida and the dragon Ctenophorus ornatus, (3) mesic species that use the run-off from granite outcrops as refuges and may occur on the loams surrounding the granite and the duplex soils of slopes and valley floors down-slope of these outcrops (e.g. the frog Crinia psemdinsignifera and the plants Eremophila clarkei, Calycopeplus panciflorus, Rhodanthe chlorocephala subsp. rosen, Gilbertia tenuifolia, Calatenia hirta, Goodenia ocodentalis, Millotia tenuifolia and Wurmber tenella). The assemblage's richness patterns show a general correspondence with its compositional patterns (Figure 9); quadrats on granite complexes are richer in assemblage 3 species than are those on other surface-types because of the specialist and refuging components (such species are rare in quadratclusters 9, 17, 20 and 23-Figure 9). However, richness masks compositional differences caused by local endemism (e.g. clusters 2, 4, 11, 15 and 21 Figure 9). This probably explains why the relevant GLM model accounts for only $35.0 \%$ of the scaled deviance in the null model (Table 6). Nevertheless, the assemblage matrix is highly nested in terms of its composition (Table 5) and the GLM model 
Table 6 Fitted GLM models relating the species richness [as Ln(R)] of each of the 17 assemblages to the environmental attributes of the 304 quadrats (see Methods). Attribute codes are explained in Table 1. All attributes listed in the models are significant at the 0.01 level or better. Attribute ' 1 ' is the intercept. 'd.f.' = degrees of freedom.

Assemblage 1_2

Attribute Coefficient

$1 \quad-36.90$

Clay $\quad 0.268$

$\mathrm{Clav}^{2} \quad-0.015$

tot_P $\quad 0.019$

tot $P^{2} \quad-5.6 \mathrm{e}^{-5}$

MxTwmP 2.351

mxTwmP2 $\quad-0.034$

Pann $\quad-8.3 \mathrm{e}$

HCov $\quad 0.142$

Null model scaled deviance Fitted model scaled deviance d.f.

\section{s.e. Assessment of Model}

4.43

0.024

0.002

0.001

$5.6 \mathrm{e}^{-t^{3}}$

0.269

0.004

$4.4 \mathrm{e}^{-4}$

0.022

4111

1162

295 and southern Yalgoo.
Model explained $71.7 \%$ of the scaled deviance, but was potentially sensitive to quadrat WH02. When the influence of this quadrat was suppressed, the model barely changed so it was considered to be robust (scaled deviance $=1125,<10 \%$ changes to coefficient values, and all attributes were still significant).

Assemblage species richness is maximum on soils with moderate clay (the equation quadratic gives maximum richness on soils with between $9 \%$ and $10 \%$ Clay in the A-horizon) and relatively high phosphorus content (tot_P), and in parts of the study area with high or moderate temperatures in the warmest period (the quadratic of $m \times T w m P$ ) and lowest annual rainfall (-Pann). These climatic conditions are found in inland parts of the study area, the Coolgardie

\section{Assemblage 35}

$\begin{array}{ll}\text { Attribute } & \text { Coefficient } \\ 1 & -28.74 \\ \text { SAL } & \\ \text { mxTwmP } & -0.045 \\ \text { mxTwmP } & 1.535 \\ \text { Pann } & -0.021 \\ \text { Pann } & 0.015 \\ \text { Hcov } & -1.8 \mathrm{e}^{-5} \\ \text { mnTcP } & 0.205 \\ \text { Null } & -0.114\end{array}$

Null model scaled deviance Fitted model scaled deviance 602 d.f.

\section{s.e.

\begin{abstract}
Assessment of Model
It explained $35 \%$ of the scaled deviance, and was considered to be robust because it was not sensitive to any quadrat.

Richness is associated with: (1) the herb stratum (fertile soils have high herb cover - +Hcov), (2) low salinity $\left(-\mathrm{SAL}^{2}\right)$ because granite complexes are on slopes at middle levels in the landscape and their localised, impervious slopes and hollows have a hydrology that is usually independent of surrounding landform units, and (3) their location in central and northern parts of the study area and hence the high summer maximum temperatures (quadratic of $m \times T w m P$ ) and moderate annual precipitation values (quadratic of Pann). The granite basement is scarcely exposed in southern parts of the study area.
\end{abstract}

\begin{tabular}{lll}
\multicolumn{2}{l}{ Assemblage 6} & \\
Attribute & Coefficient & s.e. \\
1 & -14.91 & 3.18 \\
SAL & 1.759 & 0.278 \\
SAL & -0.166 & 0.051 \\
Drainage & -0.322 & 0.044 \\
T_ar & 1.099 & 0.247 \\
T_ar & -0.025 & 0.005 \\
TwetQ & 0.015 & 0.002 \\
exCa & -0.096 & 0.014 \\
Null model scaled deviance & 1823 \\
Fitted model scaled deviance & 488 \\
d.f. & & 296
\end{tabular}

\section{Assemblage 7}

$\begin{array}{ll}\text { Attribute } & \text { Coefficient } \\ 1 & 81.66 \\ \text { SAL } & 5.804 \\ \text { SAL }^{2} & -0.881 \\ \text { TwmQ } & -8.599 \\ \text { TwmQ }^{2} & 0.197\end{array}$

220 Fitted model scaled deviance 77 d.f.

s.e.
23.79
1.270
0.212
1.997
0.041
336
77
299

\section{Assessment of Model \\ It explained $72.5 \%$ of the deviance, and was considered to be robust because it was not sensitive to any quadrat.}

The assemblage is richest on poorly drained soils (-Drainage) in moderate to high salinity categories (quadratic of SAL), and in parts of the study area with an annual temperature range of $\angle 24^{\circ} \mathrm{C}$ (southern) or high mean winter temperature (near the coast in the north).

Assessment of Model
It explained $79 \%$ of the scaled deviance, but was potentially sensitive to quadrats
ML04, ST05, UN11 and YO12. When the influence of these quadrats was
suppressed, coefficient values changed by $<20 \%$, all attributes remained
significant and scaled deviance was 56 , so it was considered to be robust.
The assemblage is richest in areas with high mean summer temperatures
$\left(+\mathrm{Twm} \mathrm{Q}^{2}-\mathrm{TwmQ}\right.$ ) and on soils with a salinity value of 3 (partly or imminently
saline) rather than 4 (obviously salt affected), hence the quadratic relationship
with SAL. These conditions are only present along the inland north-eastern
margin of the study area.


Table 6 (cont.)

\section{Assemblage 8a}

$\begin{array}{lll}\text { Attribute } & \text { Coefficient } & \text { s.e. } \\ \text { I } & -63.16 & 7.56 \\ \text { EC } & -1.40 & 2.50 \\ \text { EC } & 6.30 & 1.90 \\ \text { isot } & 281.7 & 30.2 \\ \text { isot } & -296.0 & 30.2 \\ \text { Pann } & -1.8 e^{\circ} & 1.60 \\ \text { Hoov } & 0.104 & 0.013 \\ \text { Saltyp } & -0.262 & 0.033 \\ \text { Null model scaled deviance } & 2454 \\ \text { Fitted model scaled deviance } & 946 \\ \text { d.f. } & & 296\end{array}$

\author{
Assessment of Model \\ It explained $61.4 \%$ of the deviance, but was potentially sensitive to quadrat DA02. \\ When the influence of this quadrat was suppressed, EC changed from quadratic \\ to linear, but all attributes (except EC) were still significant. The coefficient for \\ EC was halved, but the other coefficients as well as the scaled deviance of the \\ fitted model barely changed, so the model was considered to be robust. \\ "Widespread ard and semi-arid species (-Pann" \& low isoT) that ... farour fine-textured \\ soils (Hcov), except wetlands (-EC, -Saltyp), .. but not into the mesic ... south-awest."
}

\section{Assemblage $8 b$}

$\begin{array}{lll}\text { Attribute } & \text { Coefficient } & \text { s.e. } \\ 1 & 4.357 & 0.359 \\ \text { Drainage } & 0.549 & 0.078 \\ \text { Drainage }^{2} & -0.060 & 0.010 \\ \text { Tann }^{2} & -1.2 \mathrm{e}^{-2} & 6.6 \mathrm{e}^{-4} \\ \text { Pann }^{2} & -1.1 \mathrm{e}^{-7} & 8.1 \mathrm{e}^{-} \\ \text {PwetQ } & 5.1 \mathrm{e}^{-3} & 1.9 \mathrm{e}^{-3} \\ \text { PwetQ } & 2.7 \mathrm{e}^{-3} & 5.1 \mathrm{e}^{-6} \\ \text { EC } & -1.3 \mathrm{e}^{-3} & 2.0 \mathrm{e}^{-4} \\ \text { Null model scaled deviance } & 1212 \\ \text { Fitted model scaled deviance } & 464 \\ \text { d.f. } & & 296\end{array}$

\author{
Assessment of Model \\ It explained $61.7 \%$ of the deviance, and was considered to be robust because it \\ was not sensitive to any quadrat. \\ "Widespread temperate mesic to semi-arid species (-Tann", +PwetQ, +PwetQ2, -Pann") \\ ...that barely penetrate the ard zone ... and ...ocour on all surface-types excopt actlands, \\ saline or otherwise'..." (-EC, soil drainage not 'poor').
}

\section{Assemblage 9}

$\begin{array}{ll}\text { Attribute } & \text { Coefficient } \\ \mathrm{I} & -33.58 \\ \text { tot_N } & -11.23 \\ \text { tot_N } & 14.03 \\ \mathrm{~K} & -5.7 \mathrm{e}^{-3} \\ \mathrm{~K}^{2} & 4.7 \mathrm{e}^{-1} \\ \text { SAL } & -0.486 \\ \text { TwmQ } & 3.508 \\ \text { TwmQ } & -0.083 \\ \text { Pseas } & 0.011\end{array}$

Null model scaled deviance Fitted model scaled deviance d.f.

\begin{tabular}{|c|c|c|}
\hline \multicolumn{3}{|c|}{ Assemblage 10_12 } \\
\hline Attribute & Coefficient & s.e. \\
\hline 1 & -185.80 & 29.36 \\
\hline K & $-1.4 e^{-3}$ & $1.3 e^{-3}$ \\
\hline$K^{2}$ & $1.2 \mathrm{e}$ & $1.3 e^{-6}$ \\
\hline 1soT & 790.3 & 118.6 \\
\hline isot? & -813.3 & 119.4 \\
\hline PwetQ & $-1.6 x^{2}$ & 1.40 \\
\hline Tcov & -0.675 & 0.082 \\
\hline $\log \mathrm{EC}$ & -0.419 & 0.065 \\
\hline \multicolumn{2}{|c|}{ Null model scaled deviance } & 1745 \\
\hline \multirow{2}{*}{\multicolumn{2}{|c|}{$\begin{array}{l}\text { Fitted model scaled deviance } \\
\text { d.f. }\end{array}$}} & 538 \\
\hline & & 296 \\
\hline
\end{tabular}

\section{s.e. Assessment of Model}

3.84 It explained $69.5 \%$ of the deviance, but was potentially sensitive to quadrat UN13. 1.25 When the influence of this quadrat was suppressed, all attributes were still 2.66 significant, scaled deviance was 659 , and changes to coefficient values were < $7.2 \mathrm{e}^{-4} \quad 10 \%$, except $\mathrm{N}^{2}$ which increased by $50 \%$. Given that $\mathrm{N}$ is a quadratic, the model $7.7 \mathrm{e}^{-7}$ was considered to be robust.

0.044

0.343 "Species associated with Tertiary parements and spillway sand shects (-N, -K, -SAL) ... $7.6 e^{3}$ of the westem Malle', southern Avon Whentbelt and/or eastem Jamah Forest bionegions" 0.002 (quadratic of TwmQ has positive affect at low to intermediate values, +Pseas).
29.36 It explained $69.2 \%$ of the deviance, but was potentially sensitive to quadrats $13 e^{-3}$ UNO1 and ML12. After the influence of these quadrats was suppressed, scaled $.3 e^{-6}$ deviance was 525 , all attributes were still significant, and changes to coefficient values were $<10 \%$, so the model was considered to be robust.

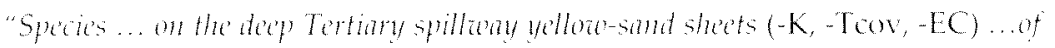

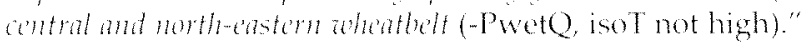


Table 6 (cont.)

Assemblage 13_15

$\begin{array}{ll}\text { Attribute } & \text { Coefficient } \\ 1 & -51.99 \\ \text { tot_N } & -33.95 \\ \text { tot_N } & 42.78 \\ \text { Elevation } & 2 \\ \text { TwmQ } & 9.1 \mathrm{e}^{-} \\ \text {TwmQ } & 5.297 \\ \text { Tcov2 } & -0.126 \\ \text { SAL } & -0.674 \\ \text { S } & -0.977\end{array}$

Null model scaled deviance Fitted model scaled deviance d.f.

\begin{tabular}{lll}
\multicolumn{2}{l}{ Assemblage $\mathbf{1 6}$} & \\
Attribute & Coefficient & s.e. \\
1 & 2.887 & 0.256 \\
Silt & 1.125 & 0.140 \\
Silt $^{2}$ & -0.136 & 0.019 \\
$\mathrm{P}$ & -0.028 & 0.002 \\
$\mathrm{P}^{2}$ & $6.9 \mathrm{e}^{-5}$ & $7.8 \mathrm{e}^{-6}$ \\
Pseas & -0.056 & 0.004 \\
Hcov & -0.576 & 0.060 \\
$\mathrm{C}$ & 0.361 & 0.041 \\
Null model scaled deviance & 1508 \\
Fitted model scaled deviance & 658 \\
d.f. & & 296
\end{tabular}

\section{Assemblage 17_18 \\ Attribute Coefficient s.e.

$\begin{array}{lll}1 & 21.37 & 1.51\end{array}$ \\ exCa $\quad-0.674$ \\ $\begin{array}{ll}\text { exCa } & \\ & 0.029\end{array}$ \\ SAL $\quad-1.376$ \\ TwmQ $\quad-0.724$ \\ Pseas $\quad-0.052$ \\ Hcov $\quad-0.379$ \\ Null model scaled deviance 1015 \\ Fitted model scaled deviance 218 d.f. \\ Assessment of Model \\ 0.073 \\ 0.004 \\ 0.236 \\ 0.073 \\ 0.006 \\ 0.101 \\ 297 \\ It explained $78.8 \%$ of the deviance, but was potentially sensitive to quadrats JB08, DA05, WH08, ML13 and MO11. After the influence of these quadrats was suppressed, scaled deviance was 189 , all attributes were still significant, and changes to coefficient values were $<20 \%$, so the model was considered to be robust. \\ "... grey and white sandsheets and dunefields (-exCa, -SAL, -Hcov) of the Esperance Plains bioregion, southern-western conner and/or eastern Mallee bioregion..." (-TwmQ, -Pseas).}

\section{Assessment of Model}

It explained $56.4 \%$ of the deviance, but was potentially sensitive to quadrat UN05. After the influence of this quadrat was suppressed, the model barely changed so it was considered to be robust (scaled deviance $=641$, all attributes were still significant, and changes to coefficient values were $<10 \%$ ).

"... restricted to the duplex soils and clay surfaces $(+\mathrm{C},+\mathrm{Hcov},+$ silt but - tot_P) ... in the Mallee bioregion and northern margin of the eastern Esperance Plains bioregion.." (Pseas - the Grass Patch, Esperance and Lake King survey areas have the lowest precipitation seasonality in the study area).

\section{Assemblage 19}

$\begin{array}{ll}\text { Attribute } & \text { Coefficient } \\ 1 & -26.42 \\ \text { Silt } & -0.661 \\ \text { exMg } & -2.251 \\ \text { exMg } & 0.141 \\ \text { Pseas } & -0.455 \\ \text { Pseas } & 3.3 \mathrm{e}^{-3} \\ \text { PwetQ }^{-3} & 0.201 \\ \text { PwetQ }^{2} & -4.6 \mathrm{e}^{-4} \\ \text { mxTwmP } & 0.680\end{array}$

Null model scaled deviance Fitted model scaled deviance d.f.

\section{s.e. \\ 3.61 \\ 0.093 \\ 0.357 \\ 0.041 \\ 0.096 \\ $6.1 \mathrm{e}^{-4}$ \\ 0.029 \\ $6.3 \mathrm{e}^{-5}$ \\ 0.116 \\ 848 \\ 174 \\ 295}

\begin{abstract}
Assessment of Model
It explained $79.5 \%$ of the deviance, but was potentially sensitive to 13 quadrats (GP01-4, 8, 11, 12, ES11, LK11, 13, WU10, MN11 and ML10). When the influence of these quadrats was suppressed, the re-fitted model had a scaled deviance of 136 and exMg changed from quadratic to linear, but all attributes (except ex $\mathrm{Mg}^{2}$ ) were still significant and their coefficients barely changed (even exMg changed by $<20 \%$ ) so the model was considered to be robust.

"... semi-arid sand sheets and dunefields (-silt, -exMg) in the Geraldton Sandplains bioregion (moderate PwetQ combined with high mxTwmP and high Pseas)". Within this specification, the compositionally different clusters comprise Northampton and Mullewa quadrats (in the far north of the study area, with the highest Pseas values) versus Dandaragan and western Avon Wheatbelt quadrats (further south, with moderate PwetQ modified by high $\mathrm{mxTwmP}$ ).
\end{abstract}


Table 6 (cont.)

\section{Assemblage 20}

$\begin{array}{lll}\text { Attribute } & \text { Coefficient } & \text { s.e. } \\ 1 & -8.59 & 0.66 \\ \text { Pseas } & 7.0 e^{+} & 8.6 e^{-} \\ \text {Scov } & 1.017 & 0.244 \\ \text { Hoov } & 0.162 & 0.034 \\ \text { Null model scaled deviance } & 379 \\ \text { Fitted model scaled deviance } & 103 \\ \text { d.f. } & & 300\end{array}$

\section{Assessment of Model}

It explained $72.9 \%$ of the deviance, but was potentially sensitive to 9 quadrats (GP12, Pl11, 13, LK06, DU04, UN05, NO08, 09, and YO03), all with zero, one or two species belonging to this assemblage. When their influence was suppressed, the re-fitted model had a scaled deviance of 63 , but all attributes were still significant and their coefficients changed $<20 \%$, so the model was considered to be robust.

"... sondstone surfaces and their derived fine-textured outwosh soils (high Scov and Hcov) in the Geraldton Sondplains bioregion" (high Pseas).

\section{Assemblage 21}

$\begin{array}{ll}\text { Attribute } & \text { Coefficient } \\ 1 & 15.76 \\ \text { K } & -0.049 \\ \text { exCa } & -0.807 \\ \text { T_ar } & -0.685 \\ \text { Gstuf } & 1.361\end{array}$

Null model scaled deviance Fitted model scaled deviance d.t.

\section{s.e. \\ 1.18 \\ 0.007 \\ 0.191 \\ 0.056 \\ 0.281 \\ 683 \\ 52 \\ 299}

\begin{abstract}
Assessment of Model
It explained $92.4 \%$ of the deviance, but was sensitive to 17 quadrats (GP02, PI02, ST02,10,13, UN01,11, DA04, JB02, WH04,11, HY11, KL06, MN11, NO09, 12, and ML04). When their influence was suppressed, the model barely changed so it was considered to be robust (all attributes were still significant and scaled deviance $=26$ ). One coefficient value changed by nearly $30 \%$.

"...chitite and grey samplains ( $\mathrm{K}$, -exCa) ... peripheral to the southern eige of our study ar' $\pi^{\prime \prime}\left(-T_{-}\right.$ar). The two species rich quadrats (ES01, ES11) are the southern-most deep sand quadrats (closest to the coast) and have intermediate level of ground litter and rocks (Gstuf).
\end{abstract}

\section{Assemblage 22_26}

$\begin{array}{lll}\text { Attribute } & \text { Coefficient } & \text { s.e. } \\ 1 & 20.25 & 5.47 \\ \text { SAL } & -0.551 & 0.053 \\ \text { TwmQ } & -2.191 & 0.501 \\ \text { TwmQ } & 0.044 & 0.011 \\ \text { Pann } & 0.032 & 0.002 \\ \text { Pann } & -2.2 \mathrm{e}^{-3} & 1.8 \mathrm{e}^{-6} \\ \text { PwmQ } & -3.5 \mathrm{e}^{-1} & 4.2 \mathrm{e}^{-5} \\ \text { Silt } & -0.206 & 0.022 \\ \text { Null model scaled deviance } & 3520 \\ \text { Fitted model scaled deviance } & 562 \\ \text { d.f. } & & 296\end{array}$

\section{Assessment of Model \\ It explained $84.0 \%$ of the deviance, and was considered to be robust because it was not sensitive to any quadrat. \\ .. centred on the Jarrah Forest bioregion (richer in areas with low PwmQ and low $\mathrm{Tw} \mathrm{mQ}=\mathrm{dry}, \mathrm{cool}$ summers, providing Pann is high) ... large'st group ... species associated with ... lateritic platean ... mantled by sandy loams (low 'silt') ... A thind comprises species ... deep grey sands on slopes and valley floors...}

\section{Assemblage 27_33}

$\begin{array}{lll}\text { Attribute } & \text { Coefficient } & \text { s.e. } \\ 1 & -6.00 & 0.95 \\ \text { EC } & -1.7 \mathrm{e}^{-3} & 2.1 \mathrm{e}^{4} \\ \text { TwmQ } & -4.8 \mathrm{e}^{-3} & 3.9 \mathrm{e}^{4} \\ \text { Pann } & 0.024 & 0.002 \\ \text { Pann } & -1.9 \mathrm{e}^{-3} & 1.5 \mathrm{e}^{-1} \\ \text { PwmQ } & 0.189 & 0.025 \\ \text { PwmQ } & -2.3 \mathrm{e}^{-} & 2.5 \mathrm{e}^{-4} \\ \text { Hoov } & 0.265 & 0.021 \\ \text { Null model scaled deviance } & 3634 \\ \text { Fitted model scaled deviance } & 1121 \\ \text { d.f. } & & 296\end{array}$

\section{Assessment of Model}

It explained $69.2 \%$ of the deviance, and was considered to be robust because it was not sensitive to any quadrat.

"Spectes ... in the eastem larmh Forest and western Azon Whentelt and western Malle" bioregions (richest in areas with medium-high Pann, low TwmQ and medium-low Pw $\mathrm{mQ}=$ a moderate annual rainfall with cool summers and medium-low summer rainfall), with fine fextured clays or fertile grmite lomm..." (high Hoov). 
Table 6 (cont.)

Assemblage 34

\begin{tabular}{|c|c|c|c|}
\hline Attribute & Coefficient & s.e. & Assessment of Model \\
\hline 1 & 4626.0 & 668.0 & It explained $83.4 \%$ of the deviance, but was potentially sensitive to 15 quadrats \\
\hline tot_P & -0.043 & $6.6 \mathrm{e}^{-3}$ & (ES01, GP04, 06, 07, 11, 12, 13, UN05,09, JB11, YO01, DU05, WU10, MN02 and \\
\hline tot_p $P^{2}$ & $6.3 e^{-5}$ & $1.5 e^{-5}$ & MO11). When the influence of these quadrats was suppressed, the re-fitted model \\
\hline Longitude & -77.83 & 11.37 & had a scaled deviance of 147 and tot_P changed from quadratic to linear, but all \\
\hline Longitude ${ }^{2}$ & 0.325 & 0.048 & attributes (except tot_ $\mathrm{P}^{2}$ ) were still significant and their coefficients changed by \\
\hline TwetQ & 5.422 & 1.495 & $<20 \%$ (even tot_P changed by $<15 \%$ ) so the model was considered to be robust. \\
\hline TwetQ ${ }^{2}$ & -0.247 & 0.060 & \\
\hline Scov & 0.547 & 0.179 & "... deep yellowe and white' sands $(+\mathrm{Scov},-$ tot_P), including sands mantling laterite, high \\
\hline Elevation & $9.0 \mathrm{e}^{-3}$ & $2.1 \mathrm{e}^{3}$ & in the landscape (+Elev) in the southern Geraldton Sandplains and northern Suan \\
\hline \multirow{3}{*}{\multicolumn{2}{|c|}{$\begin{array}{l}\text { Null model scaled deviance } \\
\text { Fitted model scaled deviance } \\
\text { d.f. }\end{array}$}} & 1110 & Coastal Plain ..." (richest quadrats have low or moderate TwetQ and \\
\hline & & 184 & low Longitude). \\
\hline & & 295 & \\
\hline
\end{tabular}

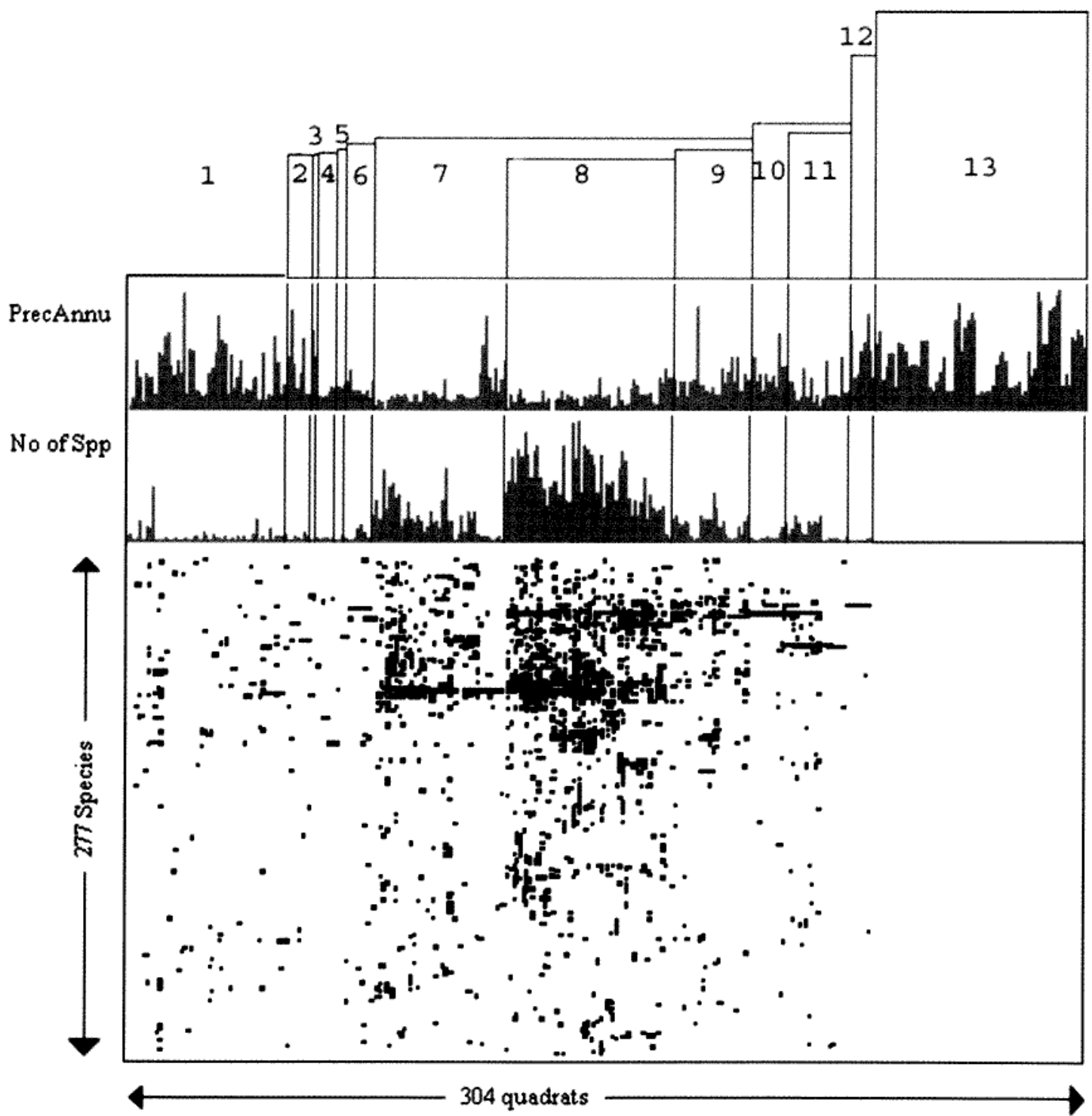

Figure 8 Dendrogram structure derived by classifying the 304 quadrats in terms of species belonging to assemblage 1_2. Quadrat attribute values for assemblage species-richness (No of Spp) and mean annual precipitation (PrecAnnu) are aligned as histograms beneath the dendrogram. A highly compressed version of the reordered data matrix for assemblage 1_2 (from Appendix 4) is aligned beneath the histograms. 

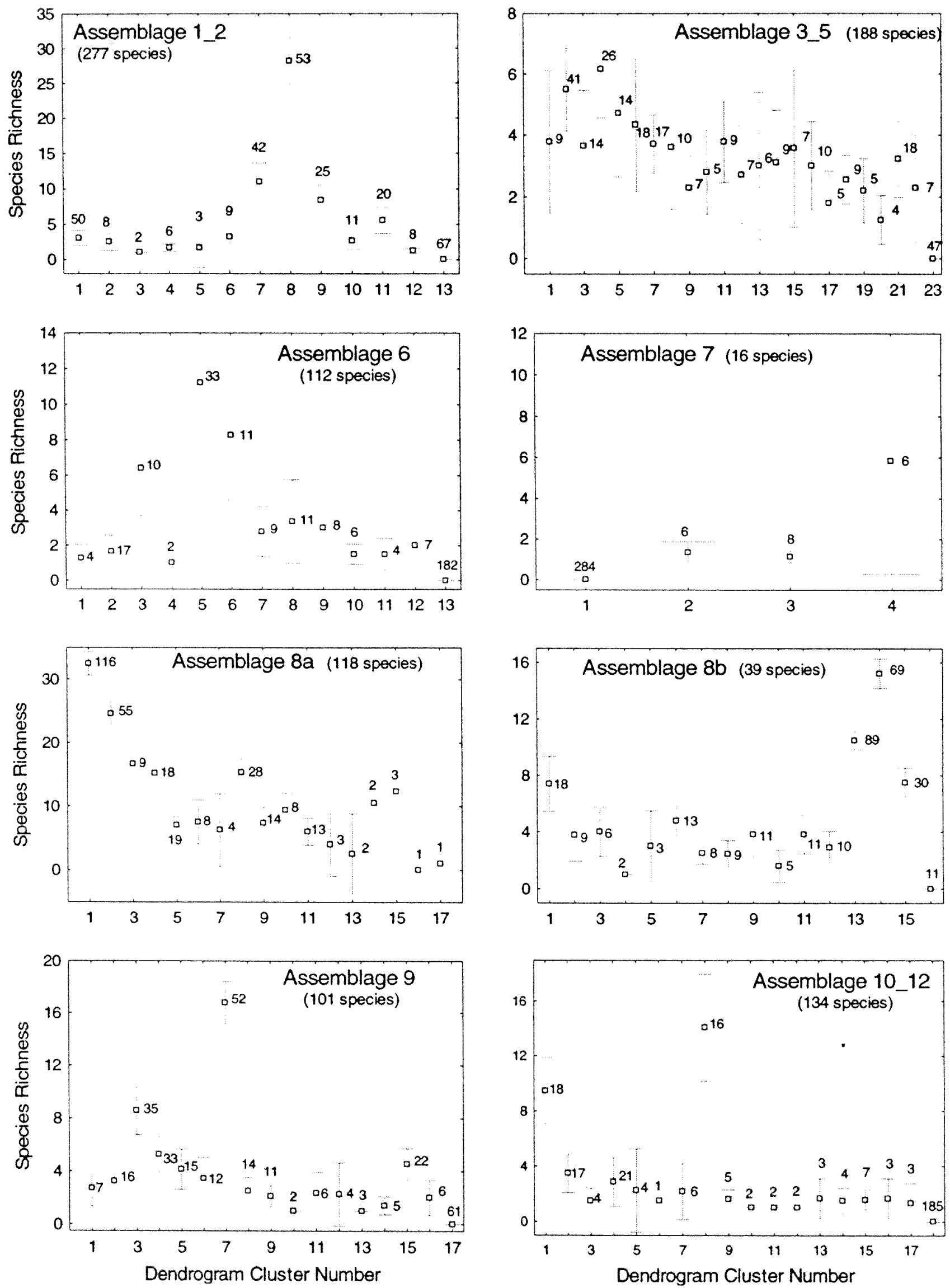

Figure 9 Relationship between richness (as a quadrat attribute) and composition (dendrogram structure) in each assemblage (see Figure 8 and Appendix 4). $N=$ number of species in the assemblage; $95 \%$ confidence intervals are shown with labels to indicate the number of quadrats in each cluster. 
Figure 9 (cont.)
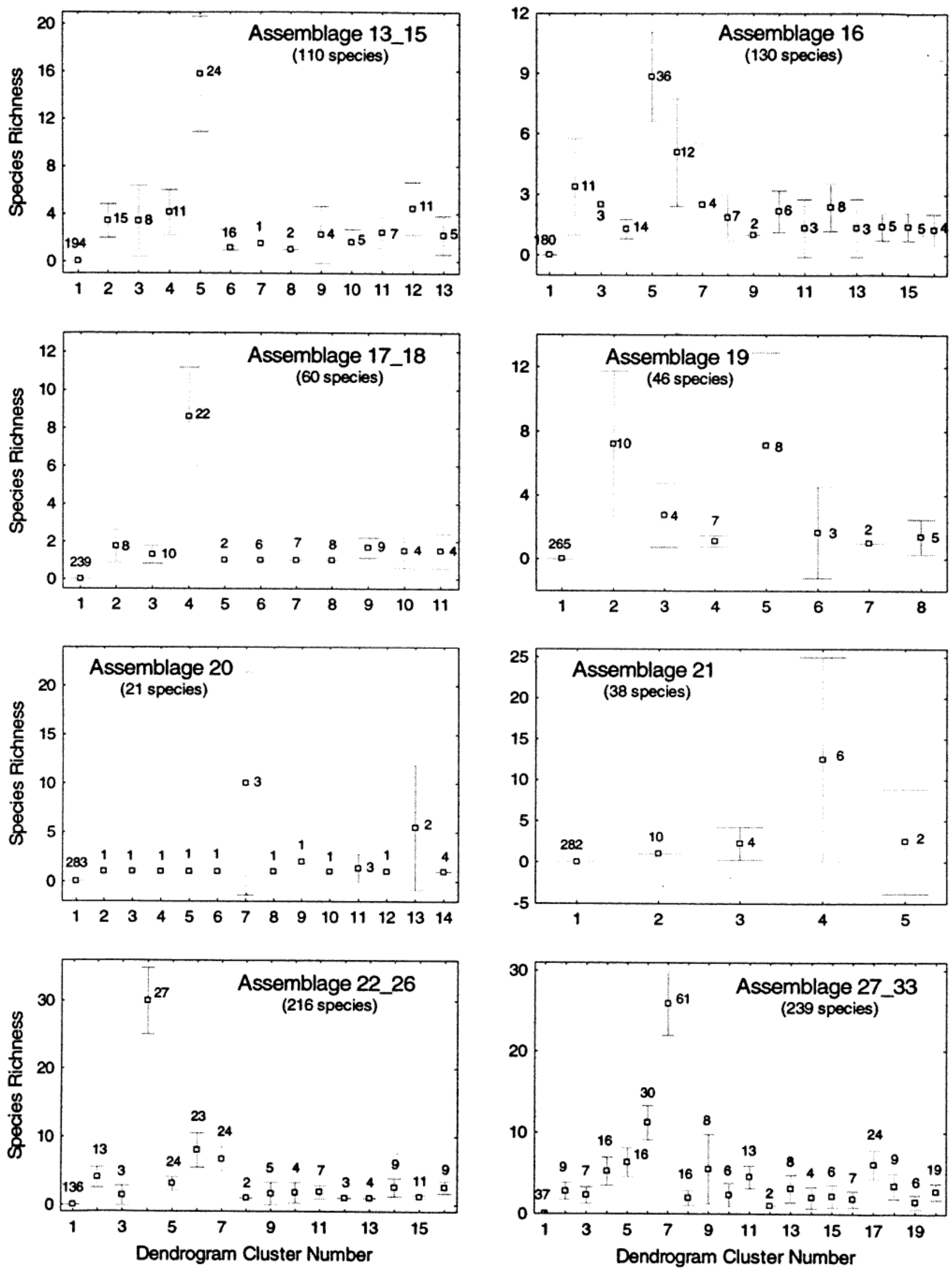
Figure 9 (cont.)

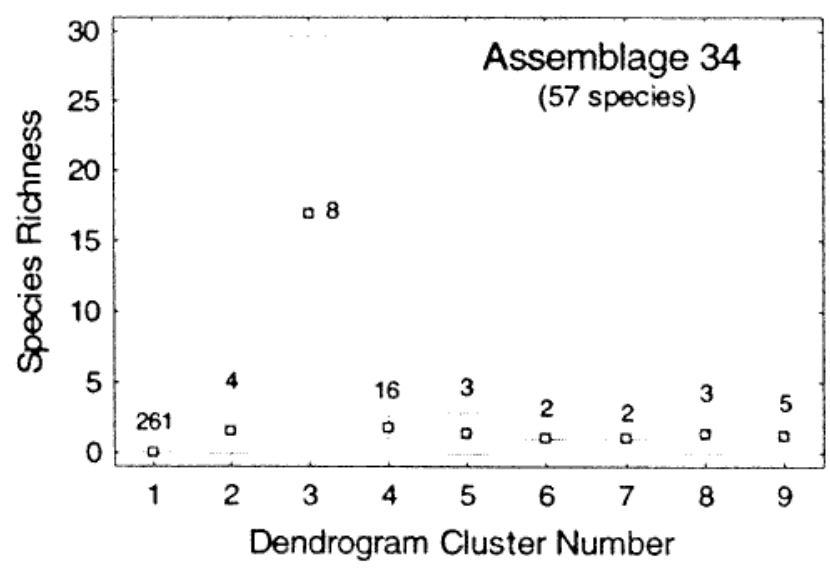

discriminates granite complexes from other landscape components (Table 6). There is a negative relationship between assemblage richness and salinity (electrical conductivity - Figure 10).

\section{Assemblages 6 and 7 (Species associated with Valley} Floor Drainage Systems)

Assemblage 6 comprises species typical of saline pans and/or salt-affected, seasonally inundated valley floor surfaces that previously supported woodlands or chenopod shrublands. It includes the dragon Ctenophorus salinarum and the plants
Casuarina obesa, Melaleuca halmaturorum, $M$. strobophylla, Halosarcia indica, H. halocnemoides, Frankenia cinerea, F. drummondii, Didymanthus roei and Agrostis avenacea. It also includes spiders such as Venatrix pullastra and $V$, arenaris (Lycosidae) which favour surfaces associated with swamp, river, estuary and mound spring habitats elsewhere in Western Australia. Other spiders in this assemblage are known only from our samphire quadrats, including Opisthoncus sp. 2, Lycidas sp. 19 and Bianor maculatus (Salticidae). Many weeds that occur on salt-affected surfaces are included, such as Cotula bipinnata, Spergularia rubra and Bromus hordeaceus. It also includes a sub-group of species found on the periphery of fresh-water soaks, seasonally inundated fresh-water claypans and fresh or slightly brackish seeps in and on the edge of salt lakes: Juncus pallidus, Lobelia alata and the weed Juncus acutus. Its species richness pattern conforms with its compositional structure (Figure 9) so, given its high nestedness value (Table 5), quadrat richness is a reasonable compositional surrogate. The environmental attributes significant in the relevant GLM richness model (Table 6) are consistent with the assemblage's characterisation, above. Assemblage richness appears to be salttolerant (Figure 10), but we have only one datapoint with electrical conductivity values greater than $1600 \mathrm{mSm}^{-1}$.

Table 7 Maximum assemblage richness value recorded at the quadrats in each survey area. Survey areas are mapped in Figure 1.

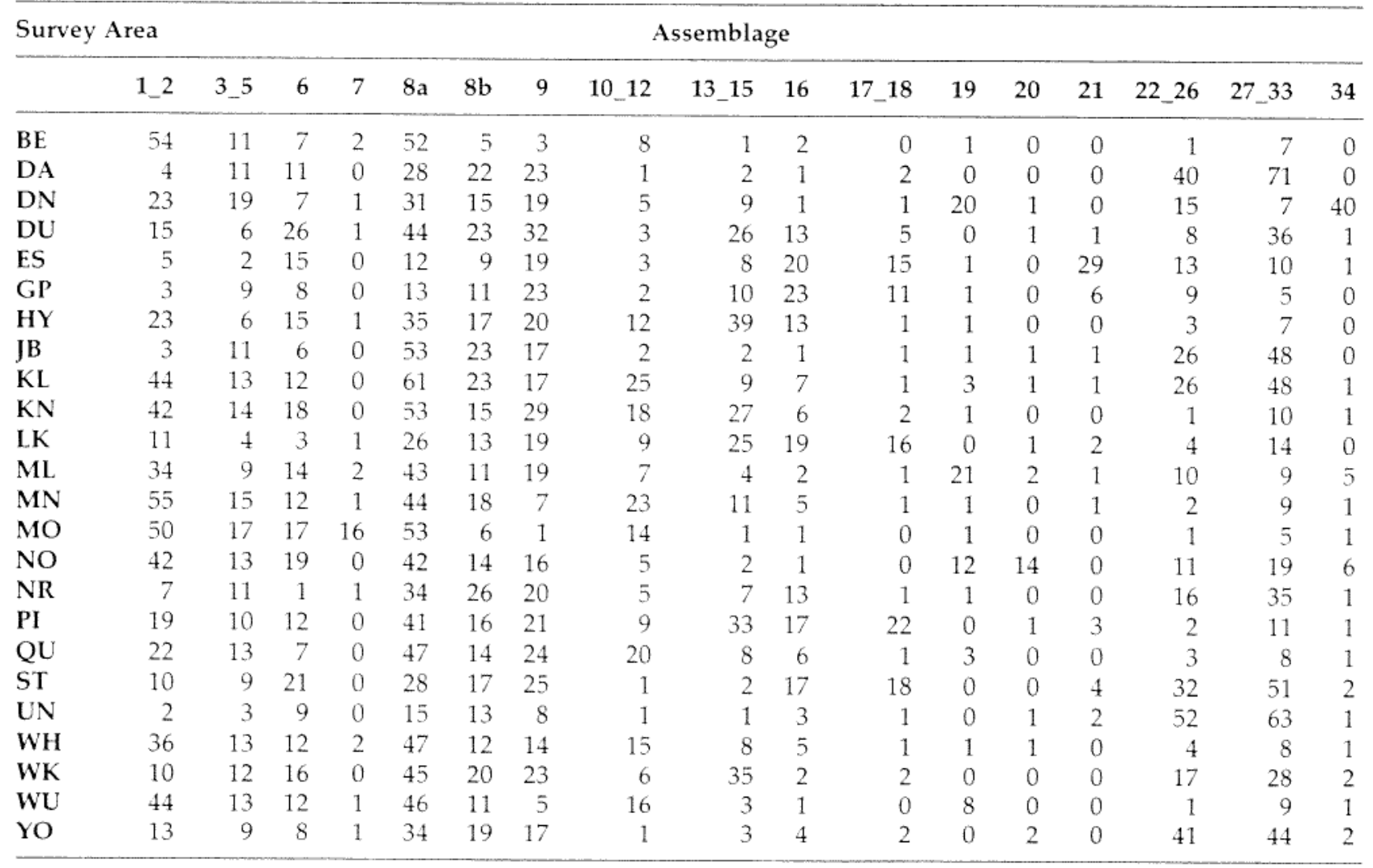



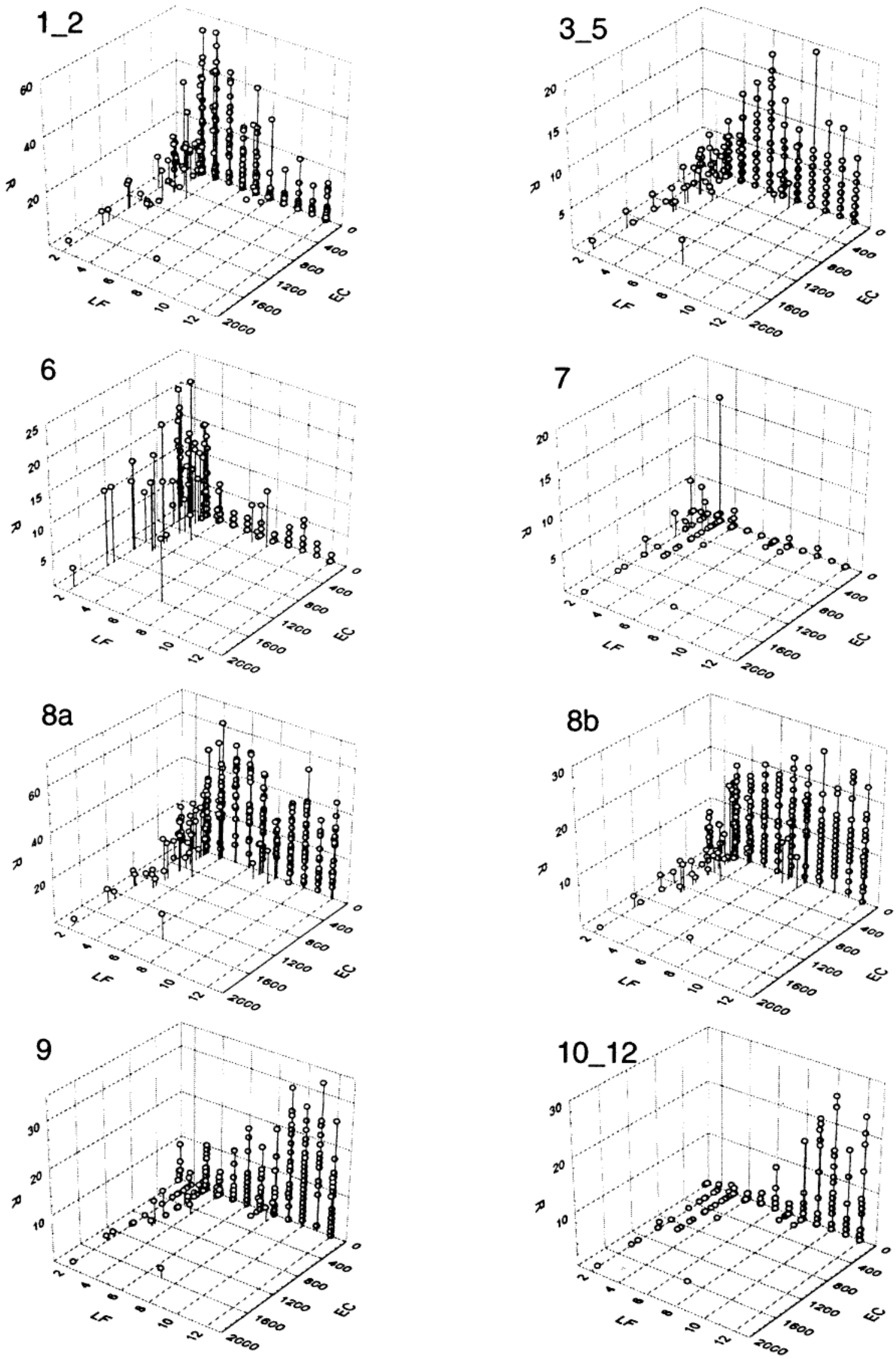

Figure 10 Assemblage species richness (R) at the 304 quadrats plotted against landform unit (LF) and soil electrical conductivity $\left(\mathrm{EC}, \mathrm{mSm}^{-1}\right)$. Assemblage 34 is not shown but its plot virtually the same as assemblage 21 . Landform units are numbered from the lowest levels in the landscape profile $(1=$ swamps and $2=$ saltflats $)$ to its top (12 = Qe, at its top $)$ as diagrammed in Figure 2. 
Figure 10 (cont.)
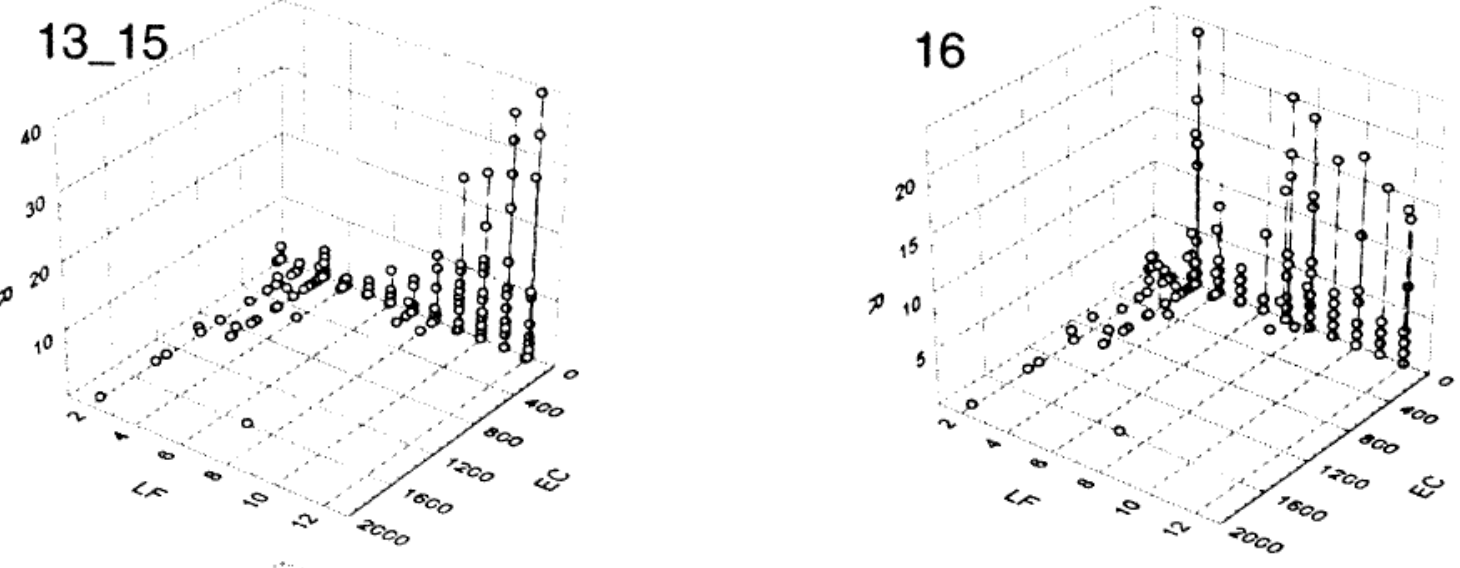

\section{7_18}
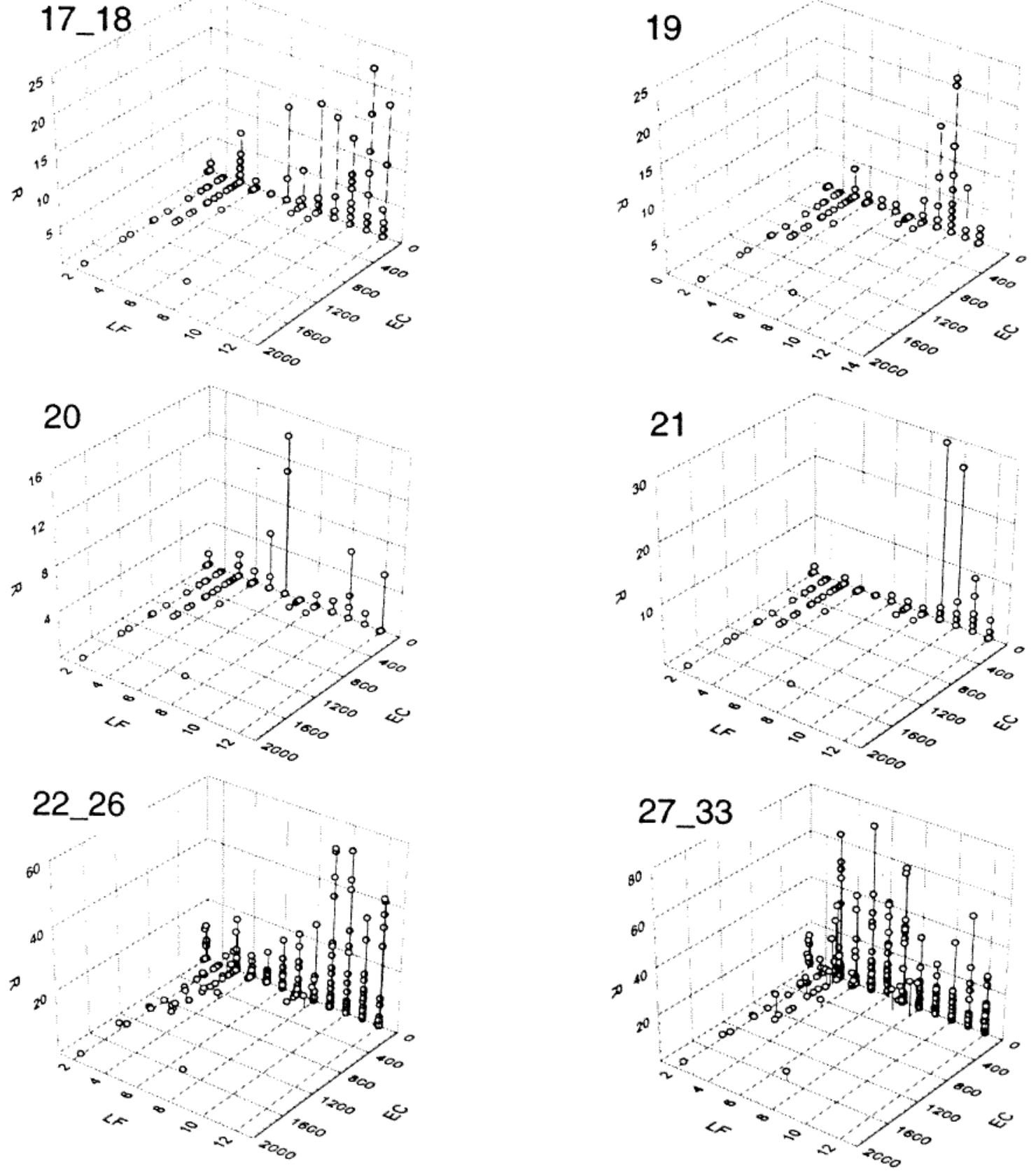
Assemblage 7 comprises arid and semi-arid zone species associated with semi-saline alluvial floors adjacent to salt lakes (often braided drainage floors) and partly mantled by sheets and dunes of aeolian sand. Species include Diplodactylus squarrosus, Stenopetalum salicola, Gunniopsis quadrifaria and Maireana tomentosa. Its species are members of an assemblage which is widespread in arid regions north and east of the study area. It is the smallest assemblage, comprising only 16 species. Only four of the 304 quadrats have more than two species and only four of the species occur on more than two quadrats. In compositional terms, four dendrogram clusters are defined and all quadrats with more than two species are confined to the fourth cluster (Figure 9). Although the matrix is not significantly nested (Table 5), its GLM model is robust, explains $79.0 \%$ of the scaled deviance in the null model, and is consistent with the characterisation, above (Table 6), although most of the species have wider tolerances. The assemblage is recorded at low levels in the landscape and its richness displays a negative relationship with high soil salinity (electrical conductivity - Figure 10).

\section{Assemblages $8 a$ and $8 b$ (Ubiquitous Distributions)}

Assemblage 8 a comprises widespread arid and semi-arid species that occur on most surface-types, except wetlands (saline or otherwise), but favour fine-textured soils and can extend well into the temperate arid zone. Most do not extend into the mesic forest and bioregions of the deep south-west. They include the mammals Sminthopsis dolichura, Mus musculus, the reptiles Oedura reticulata, Diplodactulus granariensis, D. pulcher, Ctenotus pantherinus, C. schomburgkii, Menetia greyi, the frogs Pseudophryne guentheri. Helioporus albopunctatus, Neobatrachus kunalpari, $N$. pelobatoides, the plants Eucalypus loxophloeba, Melaleuca uncinata, Acacia acuminata, Lawrencia rosea, Waitzia acuminata, Lomandra effusa, Trachymene ornata, Austrostipa elegantissma and spiders such as Australistica sp. 1 (Zodariidae), Lycidas chrysomelas, Maratus vespertilio and Grayenulla australensis (Salticidae), Lycosa leuckartii (Lycosidae), Latrodectus hasseltii (Theridiidae), Myrmopopae sp. (Oonopidae), Nicodamus mainae (Nicodamidae) and Wandella barbarella (Filistatidae). This assemblage is highly nested (Table 5) and its species-richness pattern conforms with the dominant compositional pattern as summarised by its dendrogram structure (centred on clusters 1, 2 and 3 in Figure 9). Thus, its richness patterns are a reasonable surrogate for composition even though some clusters (e.g. 4 and 8) are compositional variants. The physical attributes significant in the relevant GLM richness model (Table 6) are consistent with its characterisation, above. The compositional variants may explain why only $61 \%$ of the scaled deviance could be accounted for. While the assemblage is rich across the landscape profile, there are also a lot of low richness values at low EC, so its richness is constrained by (rather than negatively related to) soil electrical conductivity (Figure 10).

Assemblage $8 \mathrm{~b}$ comprises widespread temperate species that occur on all surface-types except wetlands, saline or otherwise. They are widespread in the mesic areas of south-west WA including the south-western wheatbelt, dropping out further east and barely penetrating the arid zone beyond the Coolgardie bioregion. Species include Sminthopsis gilberti, Cercatetus concinnus, Crenadactylus ocellatus, Cryptoblepharus plagiocephalus, Morethia obscura, Lerista distinguenda and Limnodynastes dorsalis. Plants are few, mainly grasses and herbs - e.g. Caladenia flava, Trachymene pilosa, Neurachne alopecuroidea. The assemblage is dominated by spiders and includes Lampona cylindrata (Lamponidae) which has ubiquitous habitat characteristics and mesic to semi-arid range characteristics in the south-east and south-west of Australia consistent with this assemblage, but there are virtually no extrinsic habitat data for any of the others. The assemblage is highly nested (Table 5) and its species-richness pattern conforms with the dominant compositional pattern as summarised by its dendrogram structure (Figure 9). Thus, richness patterns are a reasonable surrogate for composition even though some clusters (e.g. 1 and 13 in Figure 9) are compositional variants. The physical attributes significant in the relevant GLM richness model (Table 6) are consistent with its characterisation, above. The compositional variants may explain why only $62 \%$ of the scaled deviance could be accounted for. While the assemblage is rich-to-poor across the landscape profile, its richness is constrained by soil electrical conductivity (Figure 10).

\section{Assemblages 9, 10_12 and 13_15 (Inland Semi-arid Tertiary Pavement and Spillway Sand Species)}

Assemblage 9 species associate with Tertiary pavements and spillway sand sheets, sometimes gravelly, of the western Mallee, southern Avon Wheatbelt and/or eastern Jarrah Forest bioregions Allocasuarina humilis, A. microstachya, Dryandra armata, D. sessilis, Anigozanthus humilis, Daviesia incrassata, Xanthorrhoea drummondii, Petrophile brevifolia and Drosera zonaria. Animals include Myobatrachus gouldii, Neobatrachus albipes, Litoria cyclorhynchus, Helioporus psammophis, H. eyrei, Diplodactylus spinigerus, Egernia multiscutata, Ctenotus impar, Sminthopsis griseoventer and Tarsipes rostratus. Many of the animals also extend into equivalent habitats in surrounding regions such as the Swan Coastal Plain, Warren and/or Esperance Plains and southern Geraldton Sandplains bioregions. Its assemblage matrix is highly nested 
(Table 5) and its species-richness pattern conforms with its dominant compositional structure (Figure 9), so quadrat richness is a reasonable compositional surrogate even though clusters 3 and 15 are compositional variants. The physical attributes significant in the relevant GLM richness model (Table 6) are consistent with its characterisation, above. The assemblage is rich in the upper landscape on well drained soils unlikely to be affected by salinity (Figure 10).

Assemblage 10_12 comprises species with distributions centred on the deep Tertiary spillway yellow-sand sheets with subgroups of gravelly sands and thinly mantled laterite pavements of central and north-eastern wheatbelt (eastern Avon Wheatbelt bioregion). They also intrude into the north-western Mallee. Most are typically associated with Mallee-heaths and shrublands, and barely extend into the arid zone beyond the western Coolgardie bioregion. Examples include Eucalyptus burracopinensis, E. eudesmoides, Allocasuarina corniculata, A. campestris, A. acutivalvis, Ecdeiocolea monostachya, Drummondita hassellii, Verticordia eriocephala, Phebalium filifolium, Dryandra purdiana, $D$. vestita and D. erythrocephala. The frog Neobatrachus wilsmorei extends northwards into the arid Murchison and Carnarvon bioregions and the dragon Moloch horridus is widespread in Australia's arid zone. Its matrix is highly nested (Table 5) and its species-richness pattern conforms with the dominant compositional pattern as summarised by its dendrogram structure (Figure 9), so quadrat richness is a reasonable compositional surrogate even though cluster 1 is a compositional variant. The environmental attributes significant in the relevant GLM richness model (Table 6) are consistent with the assemblage's characterisation, above. The assemblage is rich in the upper landscape on well drained soils unlikely to be affected by salinity (Figure 10).

Assemblage 13_15 species are typical of Tertiary pavements and gravelly sand sheets in the central part of the Mallee, south-western Avon, and western Esperance Sandplains bioregions and, in some cases, the southwestern edge of the Coolgardie bioregion and eastern Jarrah Forest, avoiding deep sand soil profiles. They include Banksia baueri, B. violacea, B. gardneri, B. spherocarpa, Dryandra cynaroides, $D$. nivea, $D$. ferruginea, $D$. pallida, Eucalyptus albida, Callitris tuberculata, Isopogon teretifolius, I. buxifolius, Petrophile ericifolia, Hakea platysperma and Verticordia roei. The animals (Pseudomys albocinereus, Sminthopsis granulipes, Ctenophorus maculata and Rankinia adelaidensis) do not extend into the Jarrah Forest. Its speciesrichness patterns conform with its composition (Figure 9), and the assemblage matrix is highly nested (Table 5), so quadrat richness is a reasonable compositional surrogate. The environmental attributes significant in the relevant GLM richness model (Table 6) are consistent with the assemblage's characterisation, above. The assemblage is rich in the upper landscape unlikely to be affected by salinity (Figure 10).

\section{Assemblages 16,17_18,19 and 20 (Semi-arid Sub- coastal Distributions)}

Assemblage 16 species are virtually restricted to the duplex soils and clay surfaces expressed as plains in the Mallee bioregion and northern margin of the eastern Esperance Plains bioregion Eucalyptus platypus, E. eremophila, $E$. transcontinentalis, Callitris verrucosa and Acacia uncinata. Species that also occur on reworked calcareous versions of these soils, with kankar nodules, form a distinct group within the assemblage that also extends into the south-eastern part of the Coolgardie bioregion (e.g. Eucalyptus flocktoniae, E. uncinata, Melaleuca pauperiflora subsp. pauperiflora and Westringia rigida). It includes the eucalypt litter reptile Hemiergis initialis. Species restricted to duplex soils along the northern margin of the Esperance Plains bioregion form another group (Eucalyptus forrestiana, E. kessellii, Banksia pilosa, Grevillea pectinata and the dragon Amphibolurus norrisi). It also includes a distinct group of species that are characteristically found on sand-mantled pallid-zone clays (derived by Tertiary weathering of the granitic basement rocks) adjacent to the eroding edge of, or on, lateritic pavements Eucalyptus gardneri, E. drummondii, E. falcata and Dodonea bursarifolia. Some of these have a wider geographic range in the Wheatbelt and Coolgardie bioregions. The assemblage is dominated by plants; a number of spiders were included but there are no data on their habitat requirements outside our quadrats. The assemblage is highly nested (Table 5) but, while its species-richness pattern conforms with the dominant compositional pattern as summarised by its dendrogram structure, there is considerable variation in composition within cluster 5 , and clusters 2 and 6 are distinct compositional variants (Figure 9). This probably explains why the relevant GLM richness model accounts for only $56 \%$ of the scaled deviance in the null model (Table 6). Nevertheless, the physical attributes significant in this model are consistent with the assemblage's characterisation, above. The assemblage is rich at all levels in the landscape, the richness of versions on valley floors show a negative relationship with soil electrical conductivity (Figure 10). On their own, both -EC and -Saltyp explain a significant proportion of the scaled deviance in the GLM null model.

Assemblage 17_18 species associate with grey and white sandsheets and dunefields of the Esperance Plains bioregion, south-western corner and/or eastern Mallee bioregion and, for some species, the 
south-eastern Coolgardie. These are often peripheral to Quaternary lake systems, both saline and fresh. The assemblage includes the plants Eucalyptus tetraptera, Callitris roei, Allocasuarina pinaster, Dryandra pteridifolia, Melaleuca rigidifolia, Banksia media, Hakea corymbosa, H. nitida, Regelia inops, Petrophile media and the skinks Lerista dorsalis and Ctenotus gemmula. A few spiders for which there are no habitat or distributional data extrinsic to our quadrats are also included. Its matrix is highly nested (Table 5) and its species-richness pattern conforms with the dominant compositional pattern as summarised by its dendrogram structure (Figure 9), so quadrat richness is a reasonable compositional surrogate even though there is considerable variation in composition within cluster 4 (see Appendix 4). The physical attributes significant in the relevant GLM richness model (Table 6) are consistent with the assemblage's characterisation, above. The assemblage occurs both high and low in the landscape, and since examples on valley floor mosaics are usually on well-drained sand dunes, its is unlikely to be affected by salinity (Figure 10).

Assemblage 19 comprises species associated with semi-arid sand sheets and dunefields in the Geraldton Sandplains bioregion, many of which extend into mesic or arid zone versions of this habitat, including the northern Avon Wheatbelt and Yalgoo bioregions - plants such as Acacia blakelyi, Geleznowia verrucosa, Eremaea ebracteata, Actinostrobus arenarius, reptiles such as Pletholax gracilis, Menetia surda, Lerista praepredita, L. elegans, L. planiventralis, Diplodactylus michaelseni, $D$. alboguttatus, and several spiders. It includes some species that also extend into semi-arid and mesic sand habitats of the Avon Wheatbelt and Swan Coastal Plain (e.g. Xylomelium angustifolium and Banksia prionotes). Grevillea eriostachya and most of the reptiles extend into the Carnarvon bioregion, and even Australia's central deserts (e.g. the gecko Nephrurus levis). Its matrix is highly nested (Table 5) but the two species-rich clusters in the dendrogram (clusters 2 and 6) are compositionally distinct (Figure 9). Despite this, the relevant GLM richness model accounts for $80 \%$ of the scaled deviance in the null model (Table 6), and the physical attributes significant in this model are consistent with the assemblage's characterisation, above. The assemblage occurs on well drained soils high in the landscape, and is unlikely to be affected by salinity (Figure 10).

Assemblage 20 species are centred on Jurassic, Triassic and Permian sandstone surfaces and their derived fine-textured outwash soils in the Geraldton Sandplains bioregion (Melaleuca megacephala, Grevillea pinaster, Acacia uncinella and Stylidium elongatum). Acacia saligna has a wider range; it's inclusion may be a sampling artefact. The assemblage comprises only 21 species. Only five of the 304 quadrats have more than two species and only eleven of the species occur on more than two quadrats. The two species-rich clusters in this dendrogram (7 and 13) are compositionally distinct, hence their separation in Figure 9 , and 10 of the 14 clusters comprise quadrats with only a single species. Although the matrix is not significantly nested (Table 5), its GLM richness model explained $72.9 \%$ of the scaled deviance in the null model (Table 6), and the physical attributes significant in this model are consistent with its characterisation, although most of the species have wider ranges. Within this specification, the compositional difference of cluster-13 is due to two sand-laterite specialists (Stenanthemum notale subsp. notale and Stylidium macrocarpum). The assemblage is recorded at moderate and high levels in the landscape, and is unlikely to be affected by salinity (Figure 10).

\section{Assemblage 21 (Southern Mesic Sub-coastal Sandsheet Species)}

Assemblage 21 species typically associate with mesic white and grey sandplains of the Esperance bioregion that extend westwards into the southern Jarrah Forest bioregion and, except for the Esperance survey area, are peripheral to the southern edge of our study area. At their northern margin, these species can occur at the same sites as assemblage 17_18. Basically, they form the mesic component of heaths and shrublands on sand surfaces - Adenanthos cuneata, Franklandia fucifolia, Hakea obliqua, Banksia nutans, B. pulchella, B. speciosa and the locally endemic spider Genus-3 sp.1 (Zodariidae). This assemblage includes Ctenotus catenifer, a lizard typical of white sand habitats that also extends into the Swan Coastal Plain and Warren bioregions. Its matrix is highly nested (Table 5) and its species-richness pattern conforms with composition (Figure 9), so richness is a reasonable compositional surrogate. The environmental attributes significant in the relevant GLM richness model (Table 6) are consistent with the assemblage's characterisation. The assemblage occurs on landform units with deep, well-drained soils unlikely to be affected by salinity (Figure 10).

\section{Assemblages 22_26 and 27_33 (Mesic Distributions Centred on the Jarrah Forest)}

Assemblage 22_26 comprises species that are associated with high rainfall forests and woodlands centred on the Jarrah Forest bioregion, that extend into the Warren, Swan Coastal Plain and Esperance Plains bioregions. There are at least four recognisable groups within the assemblage. The largest comprises species typical of the lateritic plateau in the Jarrah Forest bioregion that is superficially mantled by sandy loams, but includes patches of deep yellow sands. Characteristic plants 
include Eucalyptus marginafa, E. calophylla, Banksia grantis, Persoonia longifolia, Xanthorrhoca preissii, Dryandra lindleyana. Acacia puldellat the legless lizard Aprasia puldella, the lamponid spiders Lamponusa gleme'ale and Lamponella aimslie', the salticid spider Maratus munsaich, and a variety of locally endemic spiders known only from our quadrats. Some of the component plant and vertebrate species also occur in the Warren bioregion, on the Swan Coastal Plain and/or extend along the coast as far as Esperance (e.g. Nuytsia floribuma, Melalima thymoides and the vertebrates Acritoscincus trilineatum, Crinia georgianai, C. slanerti, Litoria adilatensis). A second group includes a group of species associated with pallid-zone clays (Eucalyptus accedens, Dryandra somartosa, Grevillea temuiflora and Patersonia rutis). A third group comprises species of deep grey sands on slopes and valley floors within the forest - Banksin attentuata, $B$. menziesii, Adenanthos cygnormm, Lyginia barbata, Alexgergia nitens, Stirlingia latifolia, Phlebocarya ciliata, Eucalyptus patens and the vertebrates Ctenotus fillens and Helioports inornatus. Some of these occur on sandy environments in surrounding bioregions (e.g. B. attemmatn also occurs on sand in the Avon, Mallee, Swan and Geraldton bioregions). The fourth recognisable group comprises species associated with Quaternary valley floors in the southern Jarrah Forest that can be seasonally inundated (e.g. Banksia littoralis, Agonis paricips, Bossiaca linophylla, Eucalyptus decipiens, Kunzera recurad, Melaleuca spathulata, Hakea sulcata and the frog Litoria moorei). Most occur on the Swan Coastal Plain, Warren and western end of the Esperance Sandplains bioregion as well. The assemblage matrix is highly nested (Table 5) and its species-richness pattern conforms with the dominant compositional pattern as summarised by its dendrogram structure (Figure 9). However, quadrat-cluster 6 is a distinct compositional variant of cluster 4 (Figure 9), and cluster 4 masks considerable compositional variation, including quadrats with species lists that are up to $50 \%$ different (see Appendix 4). Our assemblage characterisation reveals that the assemblage is actually a complex of distinct Jarrah Forest communities which overlap the western edge of our study area. The physical attributes significant in the relevant GLM richness model (Table 6) are consistent with this interpretation. The statistical model indicates potential sensitivity to salinity (-SAL), expressed more as increasing inundation affecting the species that define cluster 6 (Figure 9), which occur low in the landscape, as is beginning to happen just east of quadrat DA12 in the Haddleton Springs Nature Reserve. The cluster that dominates this assemblage is rich on well drained soils higher in the landscape so it is unlikely to face increased EC from rising saline groundwater on-site or as runoff (Figure 10).
Assemblage 27_33 comprises species that have distributions centred on broad valley floors and Quaternary valley slopes (with granite exposures) in the eastern Jarrah Forest, western Avon Wheatbelt and western Mallee bioregions, with fine textured clays or fertile granite loams and, in both cases, impeded drainage (e.g. the plants Eucalyptus andudoe, Allocasuarina hewediana, Stypandra giauca, Borya sphacocephala, Lomandra micrantha, Orthrosanthus laxus, Stylidium uniflormm, the mammal Antechinus flavipes, the lizards Underaoodisantus millii, Chrystaina marmorata, Egernia napoleonis, the frogs Crinin psendimsignifera, Helyoperus barryeraigus and spiders such as Lampona punctigera, Longepi woodman and Que'meic mackny (Lamponidae). In more mesic parts some can even extend onto upland dunes (Phyllanthus calycimus and Backen camphorosma'). A group within this assemblage includes species typical of winter-wet, fresh-water claypans and swamps and extend into the Warren bioregion and Swan Coastal Plain (Encalyptus rudis, Melalenca viminera, Mecholdina camus and Melalenca preissiana) and/or as far east as Esperance (Eucalyptus ocidentalis, Austrostipa juncifolia). The assemblage matrix is highly nested (Table 5), and its species richness pattern conforms with its composition (Figure 9), so richness is a reasonable compositional surrogate despite the compositional variation apparent low in its matrix (Appendix 4). The environmental attributes significant in the relevant GLM model (Table 6) are consistent with the assemblage's characterisation. Although the assemblage occurs on virtually all geomorphological units across the landscape's profile, the statistical model as well as Figure 10 indicate that it is rich only at quadrats with low salinity (-EC). Also, given that the assemblage is richest on poorly drained surfaces low in the landscape, it is vulnerable to rising saline groundwater.

\section{Assemblage 34 (Western Mesic Sub-constal Sandsheet Species)}

Assemblage 34 comprises species typical of deep yellow and white sands, including sands mantling laterite, in the southern Geraldton Sandplains and northern Swan Coastal Plain bioregions. The assemblage includes Banksia cantolleana, $B$. leptophylla, B. incrassata, Dryandra subulata, D. schuttlecorthiana, Melalewa trichophylla, Darcinin speciosa, Stylitimm crossocephalmm, Jacksonia floribunda, Letista christime and several spiders. Its matrix is highly nested (Table 5) and its speciesrichness pattern conforms with its composition (Figure 9), so richness is a reasonable compositional surrogate. The physical attributes significant in the relevant GLM richness model (Table 6) are consistent with the characterisation. The assemblage is species rich at quadrats on the Dandaragan 
Assemblage 1_2

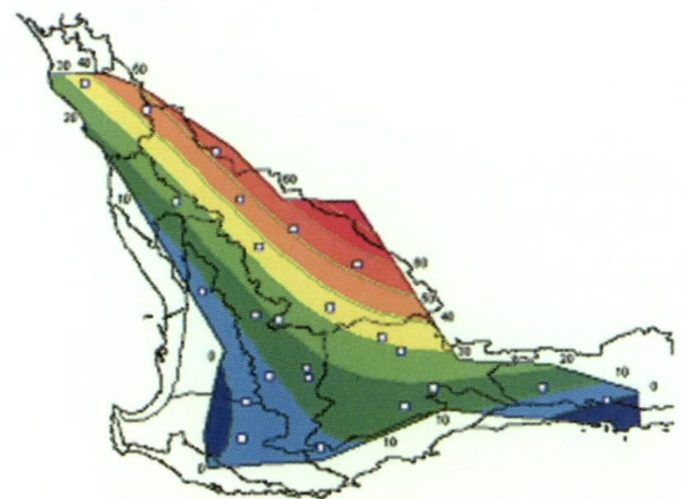

Assemblage 7

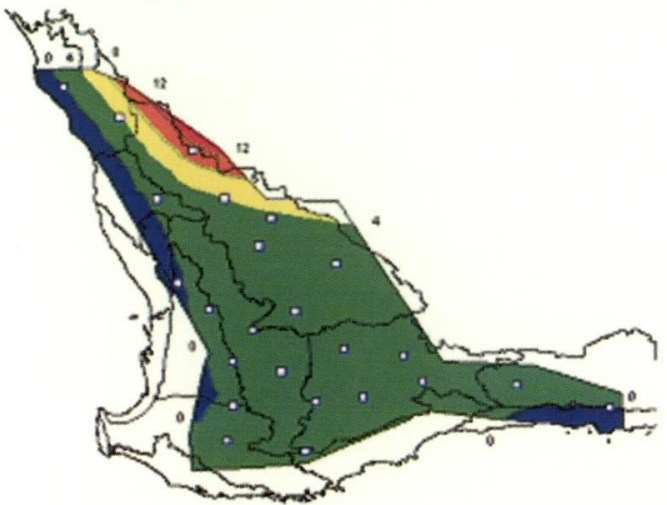

Assemblage $8 \mathrm{~b}$

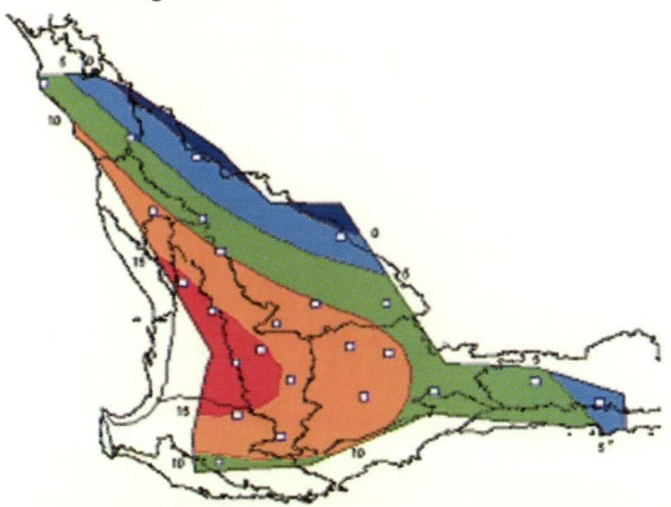

Assemblage 10_12

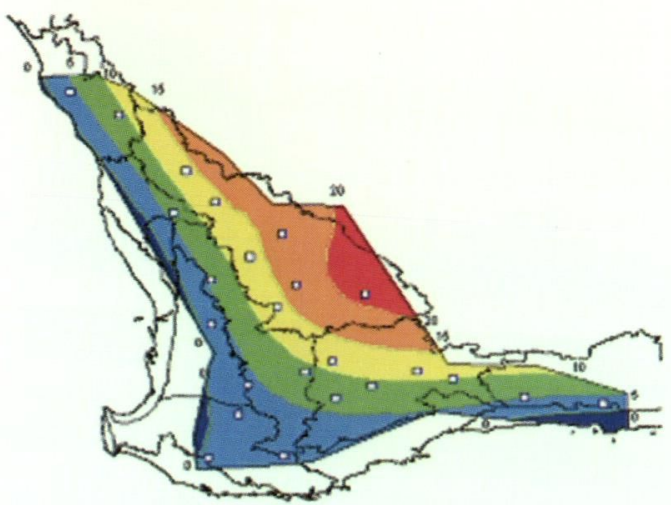

Assemblage 6

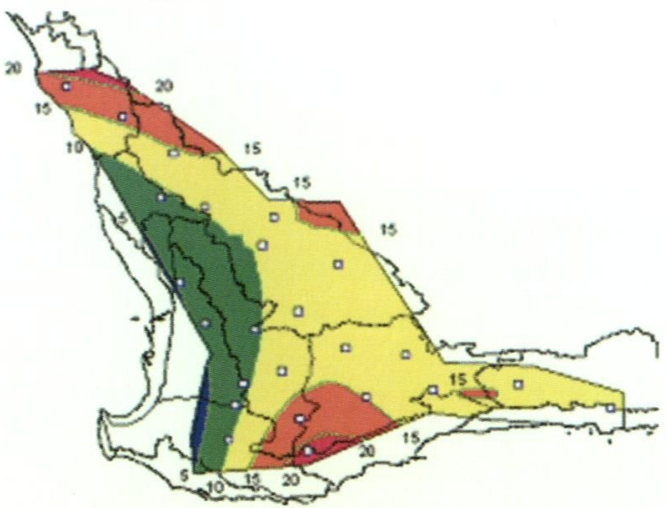

Assemblage $8 a$

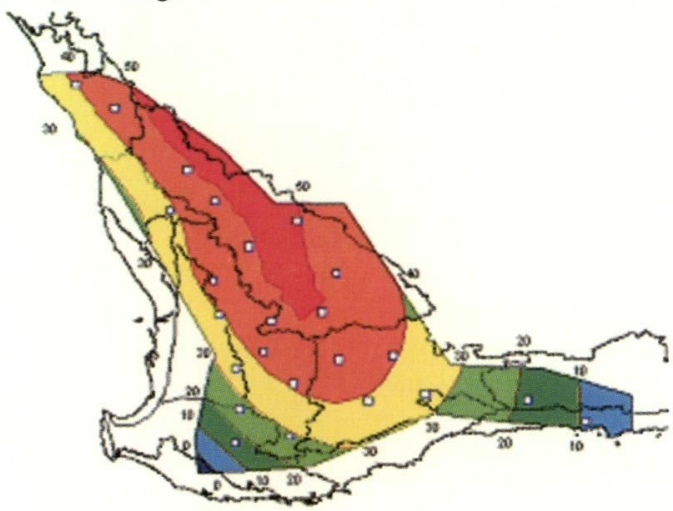

Assemblage 9

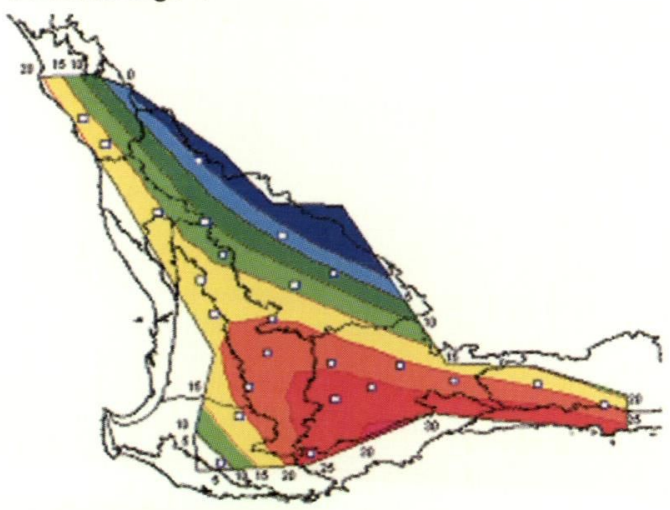

Assemblage 13_15

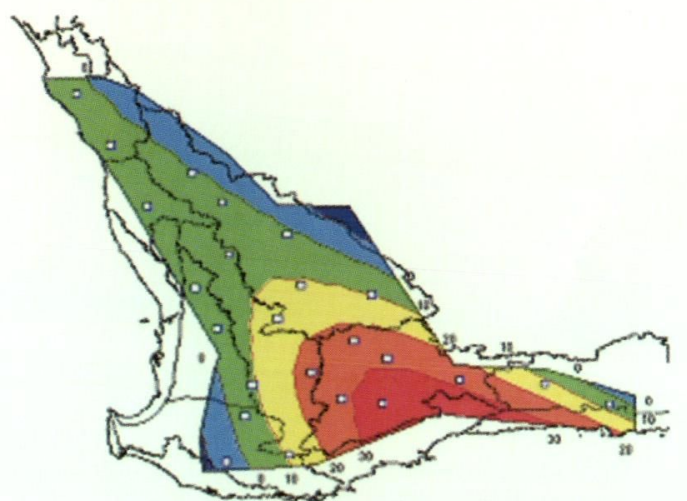

Figure 11 Species richness isolines for 16 of the 17 assemblages, superimposed on maps of the study area. Bioregional and sub-regional boundaries are shown (from Figure 1). Isolines (the boundaries between the colours) are labelled with richness values. 
Figure 11 (cont.)

Assemblage 16

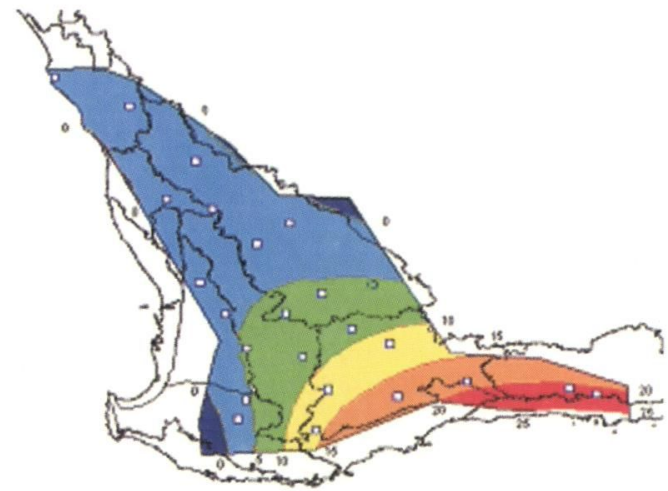

Assemblage 19

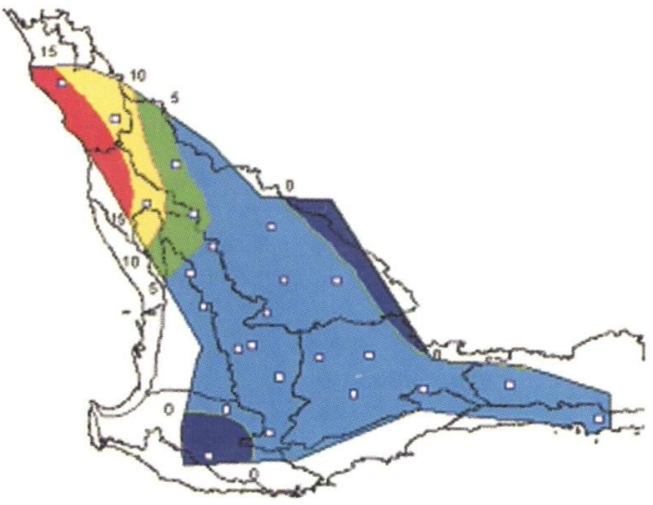

Assemblage 21

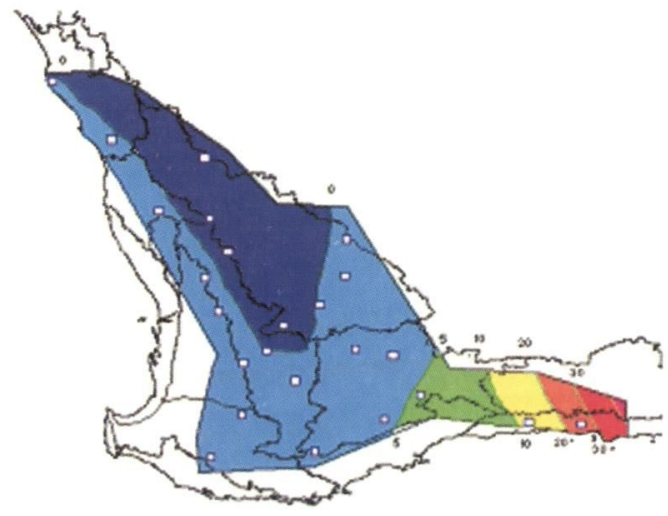

Assemblage 27_33

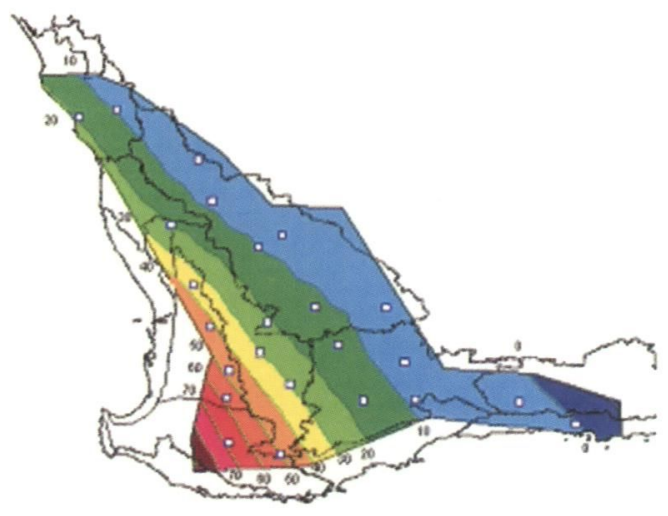

Assemblage 17_18

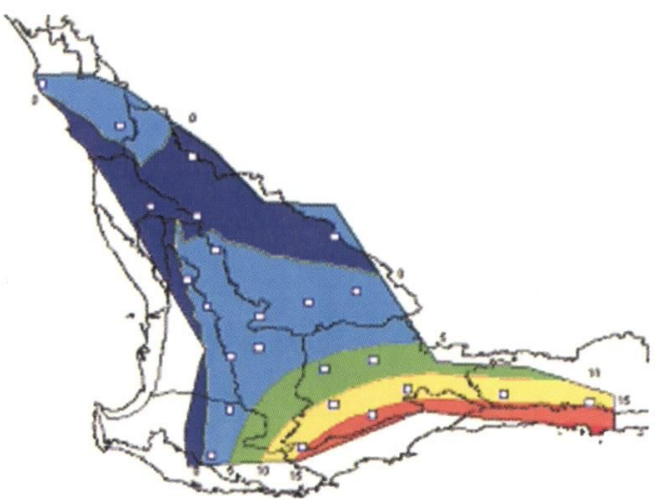

Assemblage 20

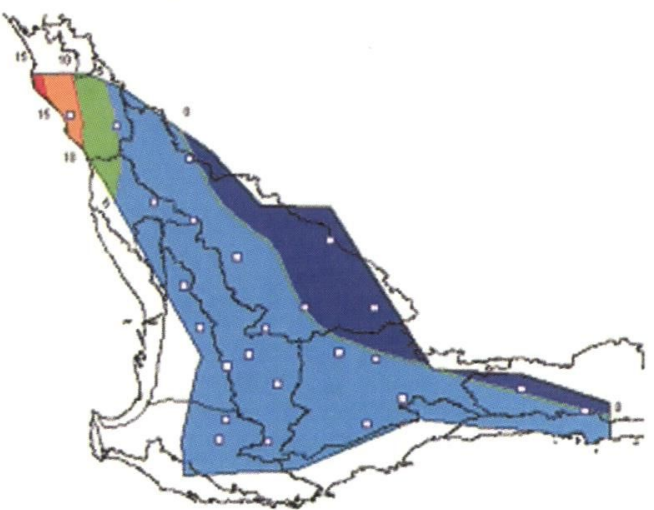

Assemblage 22_26

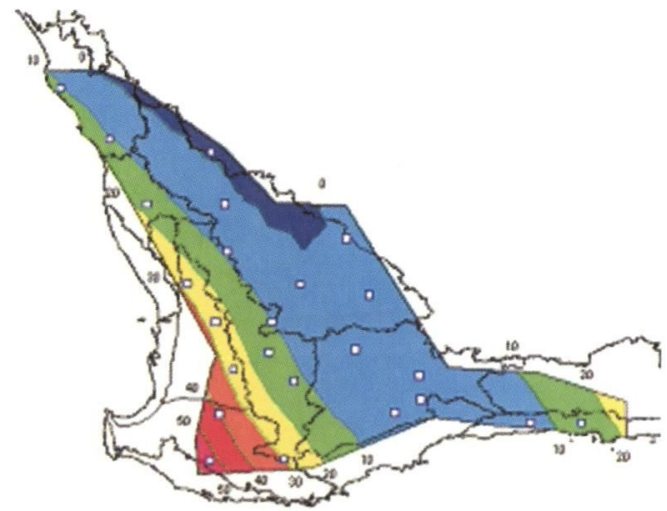

Assemblage 34

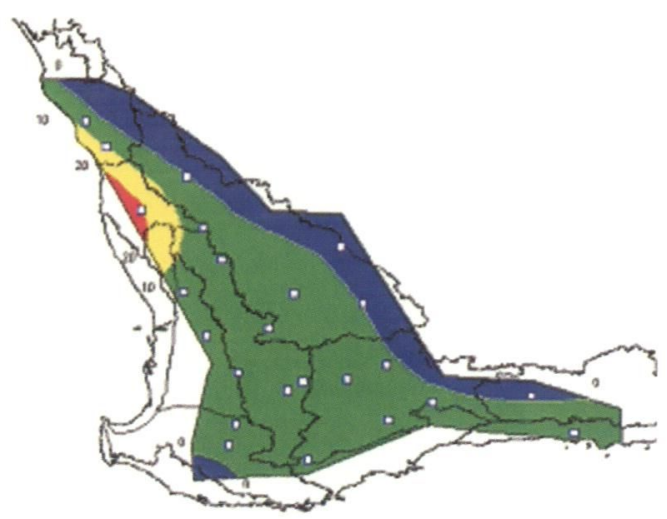


Plateau. It occurs on elevated landform units with deep, well-drained soils so it is unlikely to be affected by salinity.

\section{Geographical Patterns in Biodiversity}

\section{Assemblages}

To a greater or lesser extent, several of the 17 assemblages are represented at each quadrat. However, each assemblage has a different climatic and/or substrate envelope (see above) so most are centred in different parts of the study area. To define their different geographies, we determined the maximum species richness value recorded for each assemblage in each of the 24 survey areas (Table 7), and interpolated these values to produce 17 assemblage contour maps (Figure 11). This compositional variation was so strong in assemblage 3_5 that its richness contours provided only a first approximation of its compositional geography within the study area, so it is not included in Figure 11. Sixteen of the 17 assemblages were dominated by a single compositional gradient, although distinct sub-groups and species strings were present in all cases.

When IBRA regional and sub-regional boundaries were added to the assemblage isoline maps, the compositional contours were aligned with existing regional boundaries in only six of the 17 assemblages (1_2, 7, 8a, 10_12, 20, 22_26 and 34 in Figure 11) and three others if the extrapolative nature of the contouring algorithm is taken into account $\left(13 \_15,16,21\right)$. The centre of diversity of the other eight assemblages straddled regional and/or sub-regional boundaries. For instance, 27_33 and 8b both straddled the Jarrah Forest Avon Wheatbelt boundary, assemblage 9 straddled the boundary between the Mallee and Avon Wheatbelt, and 6 was well developed in disjunct areas of the Mallee, Avon Wheatbelt, Esperance Plains and Geraldton Sandplains bioregions. Subregional boundaries were inappropriate for 17_18 which straddled the eastern half of MAL1 and the western half of MAL2, while assemblage 19 straddled the boundary between two Geraldton Sandplains sub-regions.

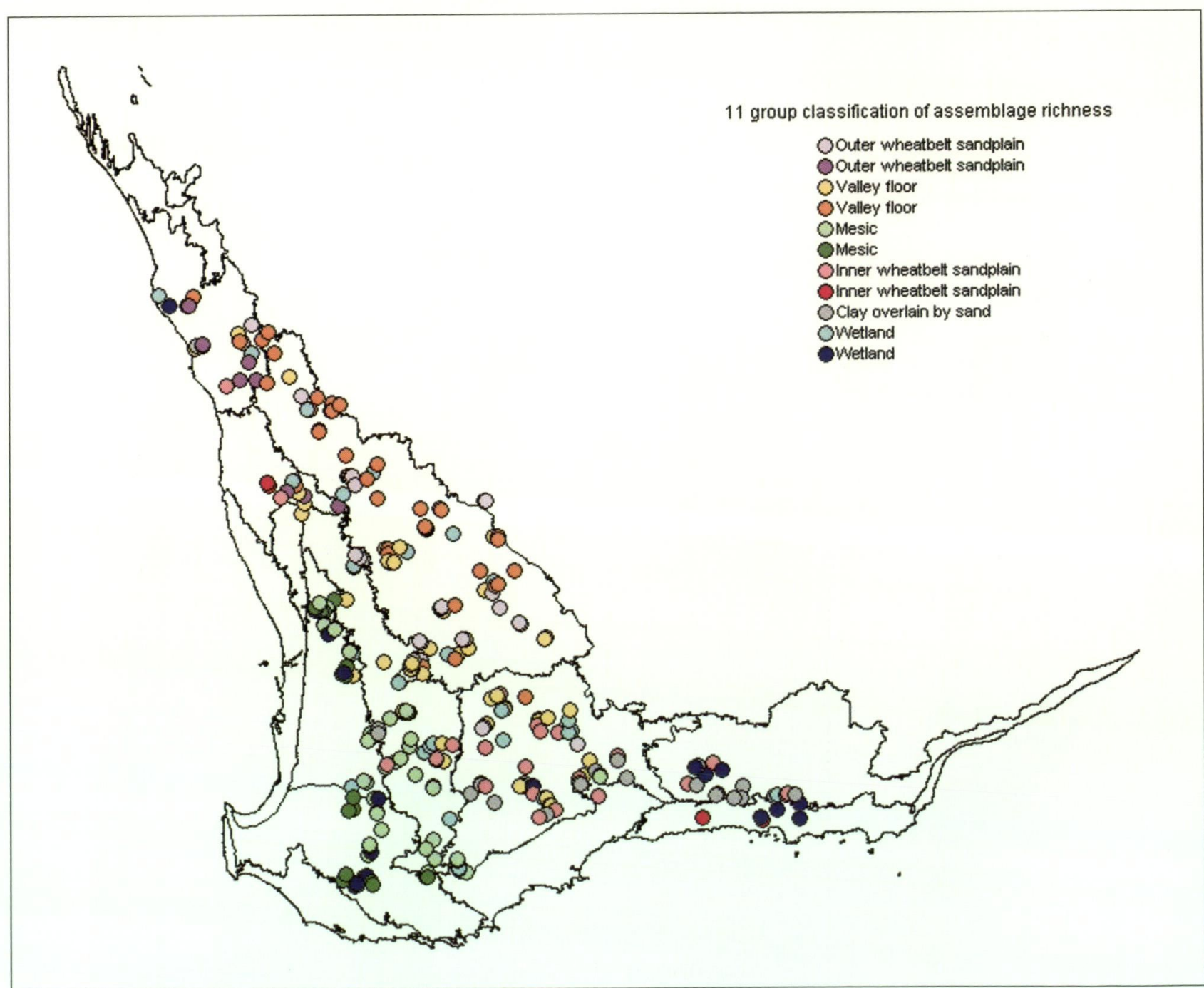

Figure 12 Eleven-group classification of the quadrats, based on the equally-weighted occurrence of the 17 assemblages at each quadrat. The six-group classification is indicated by the paired colour-shadings in the key. 
This result was confirmed when the 304 quadrats were classified in terms of their weighting for the 17 assemblages. The biogeography that emerged at the six group-level straddled the boundaries of the six bioregions currently recognised in the study area (Figure 12). On the basis that we actually sampled in 11 IBRA subregions, we also assessed the classification-result at the 11-group level (actually 11 multi-quadrat groups and a $12^{\text {th }}$ comprising just two wetland quadrats), with a similar result. At both levels, there was some concordance with the existing boundaries, but an equal level of conflict. Two axes are clear: a southwest to north-east axis aligned with rainfall and distance from the coast, and a north-south axis aligned with temperature.

\section{Broad Regionalisation}

Figure 13 was the dendrogram structure derived when the 24 survey areas were classified according to their total species composition. The resulting pattern could be displayed geographically (Figure
14), and revealed a strong geographical pattern related to rainfall and temperature gradients. When the structure was examined statistically against quadrat climatic attributes using the GSTA module of PATN, a combination of warmest quarter mean temperature and precipitation seasonality separated the four groups of survey areas (Figure 15).

\section{DISCUSSION}

Our study area occupies $74.5 \%$ of south-western Australia, one of the world's 25 bodiversity hotspots (Myers it al, 2000). We aimed to provide the first quantitative biodiversity benchmark against which future changes in the compositional complexity of the study area's indigenous ecosystems can be measured. So, as far as possible, co-occurrence patterns in species composition derived from our data set need to reflect those that ocurred across the region at the time of Eurpean settlement. For this reason, we positioned the

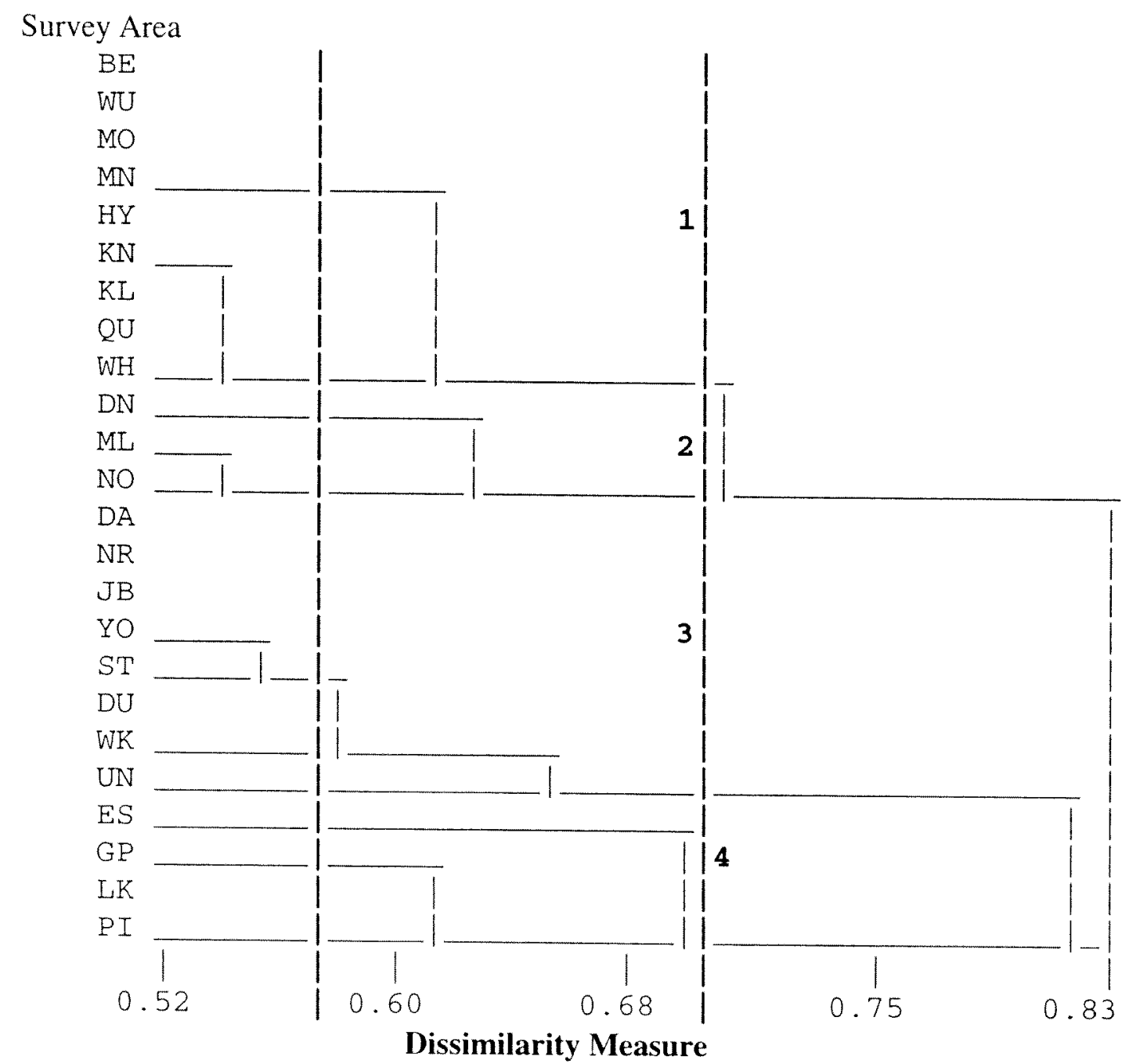

Figure 13 Dendrogram structure derived by classifying the 24 survey areas according to the combined species composition of their component quadrats. The 4 - and 10 -group levels are indicated. 


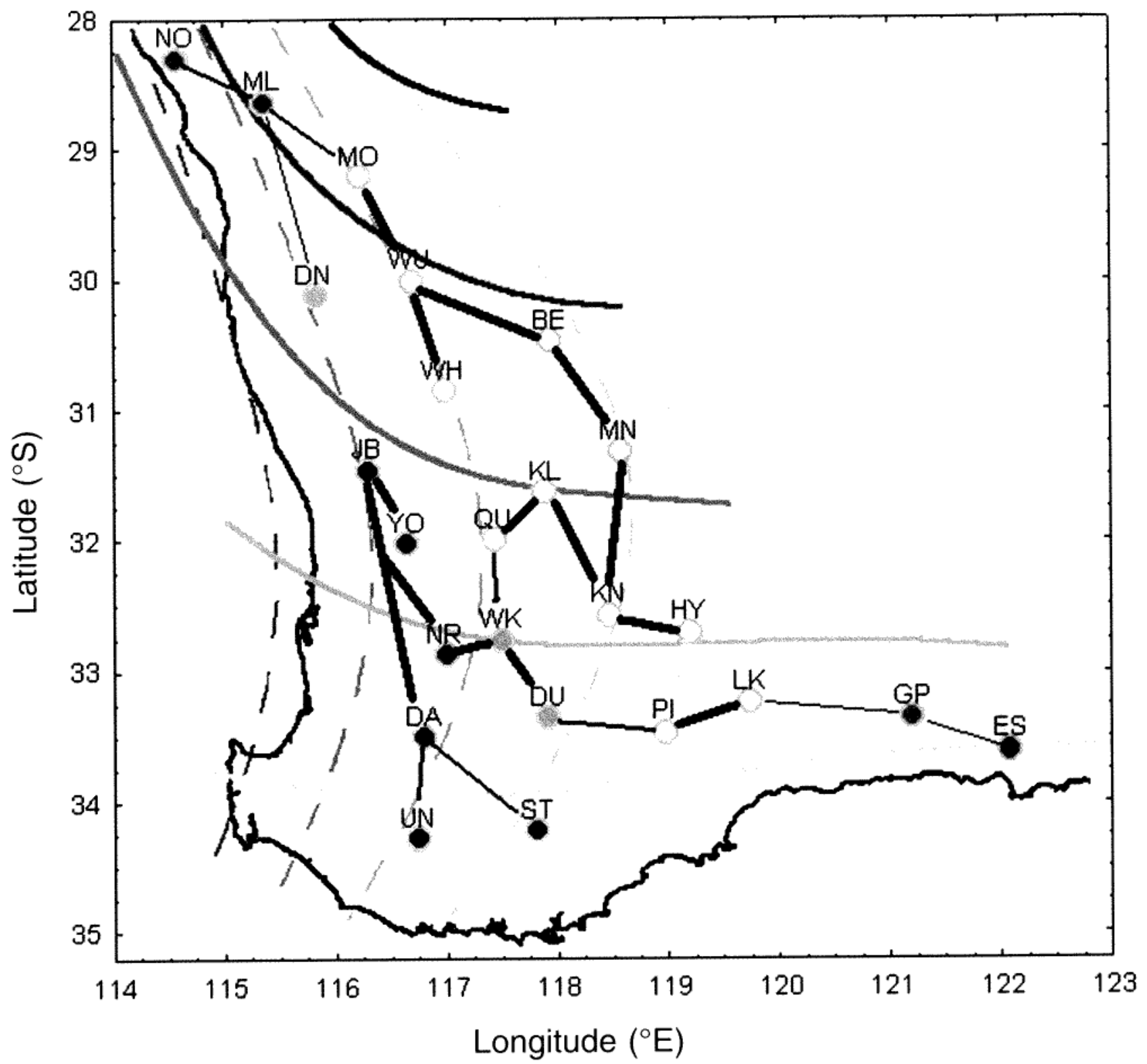

Figure 14 Results of the survey area classification (Figure 13) displayed geographically. Minimum spanning tree linkages are superimposed (thin lines are used for linkage distances $>0.51$, thick lines $<0.51$ ). Colours indicate relationships between survey areas down to the ten-group level: Yellow, red, blue and green indicate allocations at the 4-group level in Figure 13, while the shades of these colours indicate the 10-group level. Grey contour lines indicate warmest quarter temperature while dashed grey contour lines indicate precipitation seasonality; high values are dark grey and low values are light grey.

quadrats in the least disturbed examples of each habitat-type that we could find, and focussed our sampling on clades likely to be robust to threatening processes other than salinity. The clades chosen were small ground-dwelling animals (arachnids and vertebrates) with mean adult bodyweights between 0.005 and $25 \mathrm{gm}$, and plants.

However, weeds and feral predators such as foxes and cats have been ubiquitous for more than 80 years, and an open range grazing industry has operated across the region from the mid-1800's. While medium-sized mammals dominate the extinct $27 \%$ of the study area's mammalian fauna
(Burbidge and McKenzie 1989), there is mounting evidence that other taxa such as birds are being extirpated at local scales from small remnants in the fragmented landscape (e.g. Saunders, 1989). Furthermore, the pattern of clearing is biased towards the fine-textured soils of drainage valleys rather than sand surfaces associated with the Tertiary plateau. Thus, our data are biased in terms of the overall health and complexity of the study area's biodiversity.

Thirty-three percent of species were recorded from only a single quadrat. This compares with $29 \%$ recorded during an equivalent study in the 

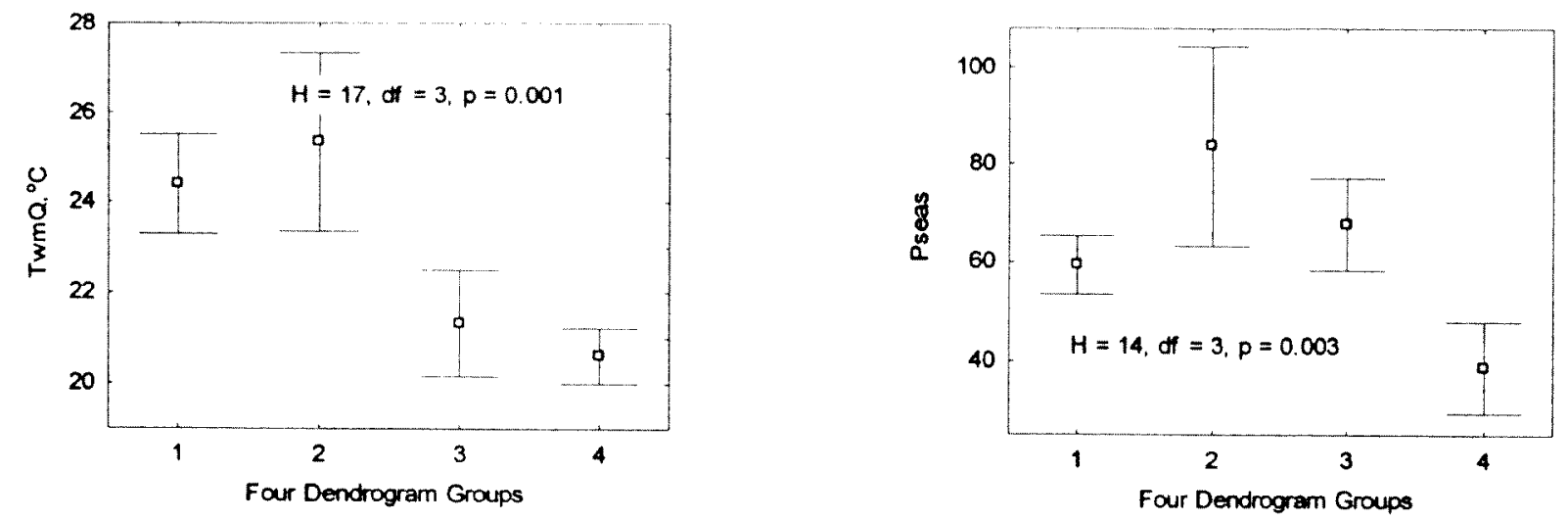

Figure 15 Climatic attributes that best separated the partition structure derived from the survey area classification at the 4-group level (Figure 13). Mean and 95\% confidence intervals are based on climatic values averaged across the 12 to 13 quadrats within each survey area $(\mathrm{H}=$ Kruskall-Wallis coefficient). Groups 1 and 2 were significantly different in terms of driest period precipitation $(\mathrm{H}=12$, d.f. $=3, \mathrm{p} .=0.005)$. TwmQ $=$ warmest quarter mean temperature. Pseas = precipitation seasonality.

Carnarvon Basin (McKenzie et al., 2000b) and 20\% on the southern Swan Coastal Plain (Gibson et al., 1994). Similar percentages have been reported by a variety of other studies (e.g. Wardell-Johnson and Williams 1996), and explanations have ranged from strongly localised species distributions, inefficient sampling methods, the temporal dynamics in species occurrence (ephemeral plants) and high levels of natural rarity. While all of these factors would contribute to singleton occurrences in our data set, the singletons were not randomly arrayed. In terms of their species richness at the 304 quadrats, they had a skewed Poisson distribution, and were most numerous in quadrats around the study area's periphery, where biogeographical edge-effects would be expected. Quadrats on the old Tertiary plateau and on silt-rich soils associated with granite exposures were also rich in singletons. The study area is within a biodiversity hotspot (Hopper, 1992: Myers et al., 2000), and communities on these surface-types are characterised by local species richness, turnover and endemism (Beard et al., 2000; Burgman, 1988; Cowling and Lamont, 1998; Hopper et al. 1996; Main, 1996, 2000). Besides sampling bias, the high percentages of plant and spider singletons (30\% and 29\% respectively) are likely to be a consequence of their strongly localised species distributions (e.g. Durrant, this volume; Guthrie and Waldock, this volume; Harvey, 2002; Main, 1996; Cowling and Lamont, 1998) and the elongate shape of the study area (Harvey et al., this volume). On average however, singletons comprised only $4.1 \%$ of the species richness of individual quadrats, and had little influence on dendrogram structure derived from classification analysis (Table 3 ).

An issue of immediate concern is the premise that a particular sub-set of the biota of the study area, such as its flora, can be used as a reliable surrogate for spatial patterns in all biodiversity. The question of whether spatial patterns in the biota coincide across different phylogenetic groups, termed congruence, has usually been addressed in terms of patterns in species richness (e.g. Howard et al., 1998) rather than composition. As with richness, available compositional studies have usually shown that different types of organisms show different geographical patterns of occurrence (e.g. Ferrier and Watson, 1996; Fleishman et al., 2002; Michaels and Mendel, 1998; McKenzie et al., 2000b; Solem and McKenzie, 1991, but also see Oliver and Beattie, 1996; Oliver et al., 1997; Yen, 1987). Our comparison of compositional patterns in four types of organism shows that each contributed significant amounts of information to our description of the biodiversity pattern. This result is consistent with one obtained using data from an arid region immediately north of our wheatbelt study area (McKenzie et al. 2000b). Low cross-taxon congruence is not surprising for several reasons:

- The substantial physiological differences between plants and animals, homeotherms and heterotherms, etc, imply very different responses to environmental gradients.

- Guild boundaries do not necessarily conform to taxonomic boundaries (Adams, 1985). For instance, small co-occurring predators such as spiders, scorpions, reptiles and frogs partition similar food resource axes, and show patterns of species replacement in geographical space independent of taxonomic origin (Spiller and Schoener, 1998).

- The diversity of prey species at sites is influenced by predation (e.g. Spiller and Schoener, 1998).

Pimm and Lawton (1998) point out, "... zve still do not have a theoretical understanding of why the geographical patterns of hotspots, rarity, and complementarity are so different among taxa. Although at large scales distinct biogeographic realms are apparent, 
within these, nature apparently plays dice with distributions." In identifying aspects of pattern and complexity in biodiversity, macroecological studies such as ours are a first step towards a rigorous understanding of the mechanisms that cause the patterns (Blackburn and Gaston, 1998; Brown, 1995). We conclude that a wheatbelt bio-regionalisation that is based on only one or two types of organism will produce distorted outcomes if it is used as a framework for conservation activities at landscapescales.

Figure 14 summarises the broad regionalisation derived from our survey area-x-species data set. Of the climatic variables used in analysis, the overall biodiversity patterns conform most closely to a summer mean temperature gradient with a northsouth axis, and a precipitation seasonality gradient with an east-west axis. However, the pattern in Figure 14 could also be explained in terms of broadscale landscape relationships. As pointed out in Methods, the ES and part of the GP survey areas are not actually on the Yilgarn Craton; nor are NO and DN in the north. Furthermore, Mulcahy and Hingston (1961) divided the Craton in the central part of the study area into eastern and western zones because the Tertiary Plateau is much more dissected in the west due to their different paleoclimatic histories (see Griffin and Stoneman, this volume). Also, the western zone has a rejuvenated drainage system that flows westwards while the eastern zone's ancient drainage system comprises chains of salt lakes and follows Tertiary paleodrainage lines that are orientated northwards and/or eastwards (e.g. Beard, 1999; 2000; McArthur, 1993). These broad landscape differences more or less correspond to the four dendrogram groups analysed; deductive studies such as this do not eliminate alternative hypotheses (Oksanen, 2001). Whatever factors are causal, the currently accepted bioregionalisation, which was based mainly on vegetation structure and dominant floristics (Beard, 1980) (see Figure 1), will need modification if it is to be used as a framework for planning nature conservation.

Several distinct stepwise structures dominated both the quadrat and the species classification dendrograms derived from our 'quadrat-xspecies' data set (Figures 5 and 7). In the context of our study, this would occur if the component species were responding to different environmental gradients and/or to the same gradients differently. On the reasoning that species which usually co-occur are more likely to be responding to the same environmental gradients than are species with different patterns of co-occurrence (see McKenzie et al., 1989, pp. 255-6), we sought to untangle the biogeographical processes by treating the 17 assemblages derived from the overall analysis as independent data sets, and analysing them separately (cf. McKenzie et al., 1989, 1991a, 2000b).

The geographical pattern in the species richness of each assemblage fitted a Poisson error model, with logarithmic links (Crawley, 1993; Nicholls, 1989). Within each assemblage, richness provided a useful surrogate for composition because:

- its species richness pattern conformed with the dominant compositional pattern summarised by its dendrogram and, except in assemblage 3.5 where strongly localised patterns in species occurrences were present, any species-rich clusters that were compositionally distinct comprised quadrats that were environmentally distinct from those of the dominant cluster.

- regionally-nested patterns in species composition (cf. Fleishman et al., 2002; Patterson and Brown, 1991; Wright et al., 1998) are visible in each assemblage (see Appendix 4).

- statistically all but two of the assemblages showed high levels of two-dimensional nestedness in their species composition (Table 5), although recent papers suggest that this statistic may sometimes overestimate the level of nestedness (e.g. Fischer and Lindenmayer, 2002).

This nestedness would be expected in re-ordered matrices, where species have been clustered according to their co-occurrences, and has previously been reported from equivalent studies elsewhere (McKenzie and Rolfe, 2000; McKenzie et $a l ., 2000 b)$. That they are not cleanly defined is due, in part at least, to localised patterns in allopatry and sampling errors (e.g. see Rolfe and McKenzie, 2000; but see also Patterson and Atmar, 2000 for additional discussion on the conservation implications of 'fuzzy' boundary lines in nested distributions after matrix-packing). Further, welldefined nested patterns in species composition would not be expected for assemblages where richness and composition are influenced by the interaction of several divergent environmental gradient vectors, and a variety of different trophic levels and guilds are represented (Brown, 1995; Taylor and Warren, 2001).

As expected, we found that geographical patterns in the occurrence of the various assemblages were related to different sets of environmental attributes. Even so, some attributes were significant for several assemblages (e.g. temperature, precipitation, and soil potassium and electrical conductivity). Potassium, for instance, is readily leached from soil profiles by rainfall or flood water and provides a sensitive measure of fertility (T. Stoneman, personal communication). As linear predictors, however, attributes such as soil potassium are of little practical value for unsampled sites because data on soil chemistry is virtually confined to the cleared agricultural lands in the study area. The strong correlation of soil potassium with soil texture 
suggests that sand and silt percentages might be useful surrogates (Kendall's tau $=-0.48, P<0.001$ and 0.52, p.<0.001, respectively).

The analyses exposed strong relationships between compositional patterns and environmental attributes for all assemblages. In all 17 cases, the relationships that emerged from the analysis were consistent with the assemblage characterisations. Thus, (1) the relationships represent the realised environmental niches of the assemblages (Patterson and Atmar, 2000; Peterson et al., 2002) which, incidentally, might be projected onto future landscape scenarios including salinity and climate change (Peterson et al., 2001), and (2) the relationships are unlikely to be artefacts of quadrat positioning or of the relatively small size of the study area in relation to the geographical range-size of most of the species (see Blackburn and Gaston, 1998).

In general, climatic as well as soil and/or geographical attributes were required to explain the observed pattern of occurrence of each assemblage across the study area (Table 6). Thus, patterns in the species composition of the study area's assemblages were being influenced by environmental processes operating at two geographical scales. At the biogeographical scale, patterns were related to the differences between the arid zone and mesic (Southwestern) biotas, and corresponding to the study area's arid-to-mesic and cool-to-warm climatic gradients, but mitigated by coastal effects in northern and south-eastern parts of the study area. At the local scale, patterns were related to topographic, vegetation structure and/or soil attributes. Previous studies have shown that scale is important in determining which environmental attributes emerge as significant correlates with compositional patterns (Bowers, 1997; Dale, 1983; Lichstein et al., 2002; Whitmore, 1984). Regional studies have usually linked compositional patterns to climatic and/or geological categories (Ashton, 1976; McKenzie et al., 1991a, 2000b), whereas the importance of topographic setting and lithology have emerged from more geographically restricted studies (Brooker and Margules, 1966; Main, 1996; Whitmore, 1984).

In our study area, the overt patterns of compositional variation that are usually referred to as patchiness or regional heterogeneity (Weiher and Keddy, 1995) could be explained numerically in terms of attributes of the physical environment. Thus, our results are consistent with the landscape paradigm proposed by Pastor et al. (1997), that spatial heterogeneity (patchiness) is a template to which organisms respond as well as an "emergent feature of their collective responses". At the geographical scale, it should be possible to reassemble an approximation of patterns in the composition of wheatbelt communities "from the bottom - up" because our sampling design provided the regional context required to understand their structure, as well as their responses to local (edaphic) factors (Cornell and Karlson, 1996; Stone et al., 1996). However, these predictions are not likely to be clear-cut for some of the reasons set out by Dirnbock et al. (2002) to explain the weak correlation they found between the distribution of vegetation structural types and topographically driven hydrological and erosional processes in the central part of our wheatbelt study area. These included hydrological and geomorphological heterogeneity of the basement strata not being reflected in contemporary surface topography because it is variably intersected/overlain by Tertiary profile units and dolerite dykes (e.g. McArthur, 1993), the subtlety of soil formation and erosional processes in the context of the study area's subdued relief, the physiological adaptation of some eucalypts to clay or lime sub-soils (Farrington et al., 1994), historical disturbances such as fire (e.g. Beard, 1990), and the strongly disjunctive or localised distributions of many species (e.g. Cowling and Lamont, 1998; Harvey, 2002; Main, 1996). Another reason is that the patches of remnant vegetation available for us to sample were a biased sub-set of the region's soil-types (Griffin and Stoneman, this volume).

While axes of habitat heterogeneity can be separate or totally coupled and confounded by species responses to the heterogeneity (Bowers, 1997; Huston, 2002), the question of scaling adds further to the complexity of landscape ecology (Bowers, 1997; Huston, 2002; MacNally and Quinn, 1997). To expose these patterns for reserve system design and other aspects of environmental management, we need to measure attributes of the environment that reflect processes at scales that fit the organisms' responses. To explain the biodiversity patterns defined herein, we had to invoke a wide range of attributes at a great range of scales. Consistent with contemporary theory, our results indicate that the study area's reserve system will need to at least sample the geographical extent of the various climatic and soil gradients identified by the analyses, if evolutionary processes are to be protected therein. Efforts to protect remaining biodiversity from threatening processes such as rising saline ground-water, both on and offreserves, will need to be focussed in the same way. Complex systems exhibit properties and behaviours that arise from the interaction of their constituent parts (e.g. Gaston and Blackburn, 1999); a significant contraction in the lowland components of the wheatbelt biota caused by a ecological process such as salinisation is likely to have pervasive consequences on all wheatbelt ecosystems. 
Peterson et al. (2002) discuss the limitations, restrictions and benefits of one- and two-step procedures to infer spatially continuous information from primary distributional data (i.e. from known points of occurrence and absence). A one-step interpolation procedure could be used to derive a richness contour map for each of the 17 assemblages because:

1. the 24 survey areas were evenly arrayed across the study area and an equivalent cross-section of the landscape profile was sampled by the 12 to 13 quadrats in each survey area (see Hollander et al. 1994 in Peterson et al. 2002, p. 618).

2. richness provided a good surrogate for composition in the assemblages.

3. most of the scaled deviance in assemblage richness gradients could be explained in terms of climatic and substrate attributes.

Given that substrates were expressed as local soilmosaics within regional climatic patterns, the localised influence of the soil attributes on assemblage richness could be suppressed by using the maximum richness value recorded in each survey area. Collectively, the 17 contour maps provide a perspective on the internal biogeography of the study area (cf. McKenzie et al. 1989, 1991, $2000 \mathrm{~b}$ ). These realised 'geographical' niches are only accurate to the extent that our sampling yielded true geographical distributions reflecting the complexity of ecological, historical and phylogenetic interactions (Peterson et al. 1999).

Examination of the assemblage isoline maps shows that the centres of diversity of nearly all assemblages appear to be near the periphery of the study area (Figure 11) - to be as rich or richer in adjacent (unsampled) regions. While it is tempting to conclude that our study area is a biogeographical transition zone, the peripheral bias is more likely to be an artefact of an interaction between the tapered ' $L$ ' shape of the study area (Figure 1) and the exponential nature of the surface contouring algorithm. These surfaces were fitted to the maximum-richness value in each survey area, a total of 24 points per assemblage. At best, our ' $L$ ' shaped study area is only four point-values (pixels) wide, and it averages 2.2 pixels wide. At least three elevation values are required to profile a peak, even in two dimensions. Contouring algorithms are designed for interpolation, not extrapolation. Even so, the geographical centres of diversity of the 17 assemblages were found to cross various biogeographical boundaries currently recognised within the study area, both regional and subregional (Figure 11). This result is consistent with results of our broad regionalisation analysis, discussed earlier (Figure 14). Thus, existing bioregional and sub-regional boundaries provide, at best, a biased approximation to biodiversity patterns within the study area.
Because they provide a view of geography from the perspective of a wide range of organisms, the centres of diversity provide a tactical framework for managing the effect of increasing salinisation on biodiversity. Today, between $3 \%$ and $15 \%$ of the wheatbelt's land surface is salinised (George and Coleman 2002), and assessing the effects of increasing salinity on biodiversity was an important aim of our study. There is no doubt that the taxa we chose to sample are sensitive to salinity - when we compared the species richness of quadrats according to surface-type, the saline playa surfaces were the poorest regardless of their condition (e.g. Figure 3). Even the abutting secondarily saline surfaces had about half of the species richness of soils with an electrical conductivity less than 100 $\mathrm{mSm}^{-1}$. This was true whether or not the lowsalinity soils were fine- or coarse-textured.

Rising saline groundwater is likely to reduce the uncleared area occupied by eight of the 17 terrestrial assemblages distinguished from our analysis. Its effect has been, and will continue to be, profound on woodland, mallee and shrubland communities confined to, or centred on, finetextured valley lower slopes and floors (Assemblages 1_2, 3_5, 6, 7, 16 and 27_33) (see Cramer and Hobbs, 2002; McKenzie et al., 2003). These six assemblages encompass wheatbelt populations of $50.1 \%$ (962) of the 1922 species included in our analyses. The compositional loss associated with secondary salinisation affects all biodiversity components surveyed: plants, vertebrates, spiders and scorpions (McKenzie et al., 2003; Gibson et al., this volume). In relation to assemblage 3_5, most granite outcrops are exposed at middle levels in the landscape profile, but their derived reddish loam and duplex soil units are desirable agricultural lands and extend as slopes to low-levels in the landscape. Uncleared remnants of these units are already salt affected in many parts of the study area. Given the strongly localised compositional variation visible in this assemblage (Appendix 4), and the extent to which its soil surfaces have already been cleared, it should be a focus for conservation activity. Although the other two assemblages ( $8 \mathrm{a}$ and $8 \mathrm{~b}$ ) occur across the entire landscape profile, a compositional variant of $8 \mathrm{a}$ (cluster-4, Figure 9) is confined to surfaces low in the landscape that are likely to become saline. Uncleared remnants of all eight assemblages need to be assessed against hydrological models to identify the priority areas of land for protecting biodiversity from salinity.

\section{ACKNOWLEDGEMENTS}

A.H. Burbidge, M. Conway, M. Cowan, K.J.M. Dickinson, L. Dorr, B.J. Durrant, N.A. Guthrie, P. van Heurck, M.A. Langley, M.N. Lyons, S.D. 
Lyons, A.F. Mark, W.P. Muir, L.A. Smith, T. Stoneman, A. Webb, A. Weston and K.H. Wyrwoll assisted in the sampling program. L. Craven, M.S. Harvey, B.J. Lepschi, B.Y. Main, B.R. Maslin, D. Roberts, B.L. Rye, L.A. Smith, M.E. Trudgen, E. Volschenk, J. Waldock and P.G. Wilson assisted in the identification of specimens. P. Gioia ran the computer package ANUCLIM to generate the climatic data set. We thank W. Atmar for supplying the computer program to measure nestedness, the Chemistry Centre (Western Australia) for carrying out soil chemical analyses, CALM Science Division soil laboratory for the soil mechanical analysis, Mark Harvey of the Western Australian Museum for supervising the arachnid identifications, CALM Information Management Branch for calculating the percentage of the study area remaining as bushland, and J.C.Z. Woinarski, R.J. Hobbs and S.A. Halse for their comments on the manuscript. We also thank Ted Griffin for valuable comments on soil landscape regions in relation to climatic gradients.

Funding for this study was provided as part of the State Salinity Strategy.

\section{REFERENCES}

Adams, J. (1985). The definition and interpretation of guild structure in animal communities. Journal of Animal Ecology 54: 43-59.

Anon. (1999). Flora of Australin. Volume 1. Introduction. ( 2 nd edition). Australian Biological Resources Study / CSIRO, Canberra

Ashton, P.S. (1976). Mixed dipterocarp forest and its variation with habitat in Malayan lowlands: a reevaluation at Pasoh. Malay Forester 39: 56-72.

Atmar, W. and Patterson, B.D. (1993). The measure of order and disorder in the distribution of species in fragmented habitat. Oecologia 96: 373-382.

Austin, M.P. (1984). Problems of vegetation analysis for nature conservation. In K. Myers and C.R. Margules (eds), Survey Methods for Nature Conservation: 1, 101130. CSIRO Division of Water and Land Resources, Canberra.

Austin, M.P. (1991). Vegetation theory in relation to costefficient survey. In C.R. Margules and M.P. Austin (eds), Nature Conservation: Cost Effective Biological Surveys and Data Analysis, 17-22. CSIRO Division of Wildlife and Ecology, Canberra.

Austin, M.P. and Heyligers, P.C. (1989). Vegetation survey design for conservation: gradsec sampling of forests in north-eastern New South Wales. Biological Conservation 50: 13-32.

Baxter, J.L. and Lipple, S.L. (1985). Perenjori, Western Australia, 1:250000 Geological Series. Geological Survey of Western Australia, Perth.

Beard, J.S. (1980). A new phytogeographic map of Western Australia. Western Australian Herbarium Research Notes 3: 37-.58.

Beard, J.S. (1981). Vegetation Survey of Western Australia:
Swan 1:1000 000 Series. University of Western Australia Press, Nedlands.

Beard, J.S. (1990). Plant Life of Western Australia. Kangaroo Press, Kenhurst, NSW.

Beard, J.S. (1999). Evolution of the river systems of the south-west drainage division, Western Australia. lournal of the Royal Society of Western Australia 82: 147 164.

Beard, J.S. (2000). Drainage evolution in the Moore Monger system, Western Australia. Journal of the Royal Society of Western Australia 83: 29-38.

Beard, J.S., Chapman, A.R. and Gioia, P. (2000). Species richness and endemism in the Western Australian flora. Journal of Biogeography 27: 1257-1268.

Belbin, L. (1980). TWOSTEP: a program incorporating asymmetric comparisons that uses two steps to produce a dissimilarity matrix. CSIRO Division of Land Use Research Technical Memorandum 80/9. CSIRO, Canberra.

Belbin, L. (1991). Semi-strong Hybrid Scaling: a new ordination algorithm. Journal of Vegetation Science 2: 491-496.

Belbin, L. (1995). PATN Technical Reference. CSIRO Division of Wildlife and Ecology, Canberra.

Blackburn, T.M. and Gaston, K.J. (1998). Some methodological issues in macroecology. The American Naturalist 151: 68-83.

Bowers, M.A. (1997). Mammalian landscape ecology. Joumal of Mammalogy 78: 997-998.

Brown, J.H. (1995). Macroecology. University of Chicago Press, Chicago.

Braithwaite, R.W. (1984). Problems of scale, complexity and patchiness in sampling vertebrate fauna. In $\mathrm{K}$. Myers, C.R. Margules and I. Musto (eds), Survey Methods for Nature Conservation: 1, 131-156. CSIRO Division of Water and Land Resources, Canberra.

Brooker, M.G. and Margules, C.R. (1966). The relative conservation value of remnant patches of native vegetation in the wheatbelt of Western Australia: I. Plant diversity. Pacific Conservation Biology 2: 268 277.

Burbidge, A.A. and McKenzie, N.L. (1989). Patterns in the modern decline of Western Australia's vertebrate fauna: causes and conservation considerations. Biological Conservation 50: 143-198.

Burbidge, A.H., Rolfe, J.K., McKenzie, N.L. and Roberts, J.D. (2004). Biogeographic patterns in small grounddwelling vertebrates of the Western Australian wheatbelt. Records of the Western Australian Museum Supplement 67: 109-137.

Bureau of Meteorology (2001). What is the weather usually like? Climate averages for Western Australian sites. http:/Www.bom.gov.au/climate/averages/ tables/ca_wa_names.shtml

Burgman, M.A. (1988). Spatial analysis of vegetation patterns in southern Western Australia: implications for reserve design. Australian Journal of Ecology 13: 415-429.

Chin, R.J. (1986). Kellerberrin, Western Australia, $1: 250000$ Geological Series. Geological Survey of Western Australia, Perth.

Clarke, K.R. (1993). Non-parametric multivariate 
analyses of changes in community structure. Australian Journal of Ecology 6: 163-174.

Commander, D.P., Fifield, L.K., Davie, R.F., Bird, J.R. and Turner, J.V. (1994). Chlorine-36 and Carbon-14 measurements on hypersaline ground water in Tertiary palaeochannels near Kalgoorlie, Western Australia. Geological Survey of Western Australia, Professional Papers 37, Perth.

Commander, D.P., Schoknecht, N., Verboom, W. and Caccetta, P. (2002). The geology, physiology and soils of wheatbelt valleys. In V. Read \& Associates (eds): Dealing with Salinity in Wheatbelt Valleys. Processes, Prospects and Practical Options', 1-27. Waters and Rivers Commission, Perth. (Available on CD)

Cornell, H.V. and Karlson, R.H. (1996). Species richness of reef-building corals determined by local and regional processes. Journal of Animal Ecology 65: 233241.

Cowling, R.M. and Lamont, B.B. (1998). On the nature of Gondwanan species flocks: diversity of Proteaceae in mediterranean South-western Australia and South Africa. Australian Journal of Botany 46: 335-355.

Cramer, V.A. and Hobbs, R.J. (2002). Ecological consequences of altered hydrological regimes in fragmented ecosystems in southern Australia: impacts and possible management responses. Austral Ecology 27: 546-564.

Crawley, M.J. (1993). GLIM for Ecologists. Blackwell Scientific Publications, Oxford.

Czekanowski, J. (1932). Coefficient of racial likeness, und durchschnittliche differenz. Anthropologischer Anzeiger 9: 227-249.

Dale, P.E.R. (1983). Scale problem in classification: an application of a stochastic method to evaluate the relative homogeneity of sample units. Australian Journal of Ecology 8: 189-198.

Department of Environment (2003). Salinity Investment Framework - Phase I Report. Salinity and Land Use Impacts Report SLUI 32. Department of Environment, Perth.

Dirnbock, T., Hobbs, R.J., Lambeck, R.J. and Caccetta, P.A. (2002). Vegetation distribution in relation to topographically driven processes in southwestern Australia. Applied Vegetation Science 5: 147-158.

Durrant, B.J. (2004). Biogeographical patterns of zodariid spiders (Araneae: Zodariidae) in the wheatbelt region, Western Australia. Records of the Western Australian Museum Supplement No. 67: 000-000.

Ehmann, H. (1992). Encyclopedia of Australian Animals: Reptiles. Collins Angus and Robertson, Australia.

Environment Australia (2000). Revision of the Interim Biogeographic Regionalisation for Australia (IBRA) and Development of Version 5.1. Environment Australia, Canberra.

Farrington, P., Bartle, G.A., Watson, G.D. and Salaman, R.B. (1994). Long-term transpiration in two eucalypt species in a native woodland estimated by the heatpulse technique. Australian Journal of Ecology 19: 17-25.

Ferrier, S. and Watson, G. (1996). An evaluation of the effectiveness of environmental surrogates and modelling techniques in predicting the distribution of biological diversity. Consultancy Report for
Department of Environment, Sport and Territories, Canberra.

Fischer, J. and Lindenmayer, D.B. (2002). Treating the nestedness temperature calculator as a "black box" can lead to false conclusions. Oikos 99: 193-199.

Fleishman, E., Betrus, C.J., Blair, R.B., MacNally, R. and Murphy, D.D. (2002). Nestedness analysis and conservation planning: the importance of place, environment, and life history across taxonomic groups. Oecologia 133: 78-89.

Gaston, K.J. and Blackburn, T.M. (1999). A critique for macroecology. Oikos 84: 353-368.

Geological Survey of Western Australia (1999). Western Australian Atlas of Mineral Deposits and Petroleum Fields 1999. Western Australian Geological Survey, Perth.

George, R.J., McFarlane, D.J. and Speed, R.J. (1995). The consequences of a changing hydrologic environment for native vegetation in Western Australia. In D.A. Saunders, J.L. Craig and E.M. Mattiske (eds), The Role of Networks, 9-22. Surrey Beatty \& Sons Pty Ltd, Chipping Norton, NSW.

George, R. and Coleman, M. (2002). Hidden menace or opportunity - groundwater hydrology, playas and commercial options for salinity in wheatbelt valleys. In V. Read \& Associates (eds): Dealing with Salinity in Wheatbelt Valleys. Processes, Prospects and Practical Options, 1-21. Waters and Rivers Commission, Perth. (Available on CD)

Gibson, N., Keighery, B.J., Keighery, G.J., Burbidge, A.H. and Lyons, M.N. (1994). A floristic survey of the southern Swan Coastal Plain. Unpublished Report for the Australian Heritage Commission.

Gibson, N., Keighery, G.J., Lyons, M.N. and Webb, A. (2004) Terrestrial flora and vegetation of the Western Australian wheatbelt. Records of the Western Australian Museum Supplement 67: 139-189.

Griffin, E.A. and Stoneman, T.C. (2004). Soils sampled during a biological survey of the Western Australian wheatbelt. Records of the Western Australian Museum Supplement 67: 91-107.

Guthrie, N.A. and Waldock, J.M. (2004). Patterns in the composition of the jumping spider (Arachnida: Araneae: Salticidae) assemblage from the wheatbelt region, Western Australia. Records of the Western Australian Museum Supplement 67: 203-216.

Halse, S.A., Ruprecht, J.K. and Pinder, A.M. (2003). Salinisation and prospects for biodiversity in rivers and wetlands of south-west Western Australia. Australian Journal of Botany 51: 673-688.

Harvey, M.S., Sampey, A., West, P.L.J. and Waldock, J.M. (2000). Araneomorph spiders from the southern Carnarvon Basin, Western Australia: a consideration of regional biogeographic relationships. Records of the Western Australian Museum Supplement 61: 295-322.

Harvey, M.S. (2002). Short-range endemism among the Australian fauna: some examples from non-marine environments. Invertebrate Systematics 16: 555-570.

Harvey, M.S., Waldock, J.M., Guthrie, N.A., Durrant, B.J. and McKenzie, N.L. (2004). Patterns in the composition of ground-dwelling araneomorph spider communities in the Western Australian wheatbelt. Records of the Western Australian Museum Supplement 67: 257-291. 
Hatton, T.J. and Ruprecht, J. (2002). Watching the rivers flow: hydrology of the wheatbelt. In V. Read \& Associates (eds): Dealing with Salinity in Wheatbelt Valleys. Processes, Prospects and Practical Options, 1-15. Waters and Rivers Commission, Perth. (Available on CD)

Hobbs, T.J., Morton, S.R., Masters, P. and Jones, K.R. (1984). Influence of pit-trap design on sampling of reptiles in arid spinifex grasslands. Wildlife Research 21: $483-490$.

Hopper, S.D. (1992). Patterns of plant diversity at the population and species level in south-west Australian mediterranean ecosystems. In R.J. Hobbs (ed), Biodiversity in Mediterranean Ecosystems in Australia, 27-46. Surrey Beatty \& Sons, Chipping Norton, NSW.

Hopper, S.D., Harvey, M.S., Chappill, J.A., Main, A.R. and Main, B.Y. (1996). The Western Australian biota as Gondwanan heritage - a review. In S.D. Hopper, J.A. Chappill, M.S. Harvey and A.S. George (eds), Gondwanan Heritage: Past, Present and Future of the Western Australian Biota, 1-46. Surrey Beatty \& Sons, Chipping Norton, NSW.

Hopper, S.D., Brown, A.P. and Marchant, N.G. (1997). Plants of Western Australian granite outcrops. Journal of the Royal Society of Western Australia 80: 141-158.

How, R.A., Dell, J. and Muir, B.G. (1988). Vertebrate fauna. In The Biological Survey of the Eastern Goldfields of Western Australia. Part 4: Lake Johnston-Hyden Study Area, 44-83. Records of the Western Australian Museum Supplement 30: 1-233.

Howard, P.C., Viskanic, P., Davenport, T.R.B., Kigenyl, F.W., Baltzer, M., Dickenson, C.J., Lwanga, J.S., Matthews, R.A. and Balmford, A. (1998). Complementarity and the use of indicator groups for reserve selection in Uganda. Nature 394: 472-475.

Hubert, L. and Arabie, P. (1985). Comparing partitions. Journal of Classification 2: 193-218.

Huston, M.A. (2002). Introductory essay: critical issues for improving predictions. In J.M. Scott, P.J. Heglund, M.L. Morrison, J.B. Haufler, M.G. Raphael, W.A. Wall and F.B. Samson (eds), Predicting Species Occurrences. Issues of Accuracy and Scale, 7-21. Island Press, Washington.

Jessop, J. (1981). Flora of Central Australia. Australian Systematic Botany Society, Reed, Sydney.

Keighery, G.J. (2004). State Salinity Strategy biological survey of the Western Australian wheatbelt: background. Records of the Western Australian Museum Supplement 67: 1-6.

Keighery, G.J., Gibson, N., Lyons, M.N. and Burbidge, A.H. (2000). The flora and vegetation of the southern Carnarvon Basin, Western Australia. Records of the Western Australian Museum Supplement 61: 77-154.

Keighery, G.J., Halse, S. and McKenzie, N.L. (2001) Why wheatbelt valleys are valuable and vulnerable: the ecology of wheatbelt valleys and threats to their survival. In V. Read \& Associates (eds): Dealing with Salinity in Wheatbelt Valleys. Processes, Prospects and Practical Options, 1-8. Waters and Rivers Commission, Perth. (Available on CD)

Kitchener, D.J. (1982). Predictors of vertebrate species richness in nature reserves in the Western Australian wheatbelt. Australian Wildlife Research 19: 1-7.
Koch, L.E. (1981). The scorpions of Australia: Aspects of their ecology and zoogeography. In A. Keast (ed.): Ecological Biogeography of Australia, 873-884. Dr W. Junk bv Publishers, The Hague.

Lichstein, J.W., Simmons, T.R., Schriner, S.A. and Franzreb, K.E. (2002). Spatial autocorrelation and autoregressive models in ecology. Ecological Monographs 72: 445-463.

MacNally, R. and Quinn, G.P. (1997). Symposium introduction: the importance of scale in ecology. Australian Journal of Ecology 23: 1-7.

Main, B.Y. (1996). Microcosmic biogeography: trapdoor spiders in a time warp at Durokoppin. In S.D. Hopper, J.A. Chappill, M.S. Harvey and A.S. George (eds): Gondwanan Heritage: Past, Present and Future of the Western Australian Biota, 163-171. Surrey Beatty \& Sons, Chipping Norton, NSW.

Main, B.Y. (2000). Habitat template for invertebrates on granite outcrops. Journal of the Royal Society of Western Australia 83: 139-147.

Main, B.Y., Sampey, A. and West, P.J. (2000). Mygalomorph spiders of the southern Carnarvon Basin, Western Australia. Records of the Western Australian Museum Supplement 61: 281-294.

Margules, C.R. and Austin, M.P. (1994). Biological models for monitoring species decline. Philosophical Transactions of the Royal Society of London B 344: 69-75.

McFarlane, D.J. and George, R.J. (in press). The extent and potential area of salt-affected land in Western Australia estimated using remote sensing and digital terraine models. $1^{\text {st }}$ National Salinity Engineering Conference, 9-12 November 2004. Perth, Western Australia.

McArthur, W.M. (1993). History of landscape development. In R.J. Hobbs and D.A. Saunders (eds), Reintegrating Fragmented Landscapes - Towards Sustainable Production and Nature Conservation, 10-22. Springer Verlag, New York.

McKenzie, N.L. and Rolfe, J.R. (1986). Structure of bat guilds in the Kimberley mangroves, Australia. Journal of Animal Ecology 55: 401-420.

McKenzie, N.L. and Rolfe, J.K. (1995). Vertebrate fauna. In The Biological Survey of the Eastern Goldfields of Western Australia. Part 11. The Boorabbin-Southern Cross Study Area, 31-65. Records of the Western Australian Museum Supplement No. 49: 1-167.

McKenzie, N.L., Belbin, L., Margules, C.R. and Keighery, G.J. (1989). Selecting representative reserve systems in remote areas: a case study in the Nullarbor region, Australia. Biological Conservation 50: 239-261

McKenzie, N.L., Belbin, L., Keighery, G.J. and Kenneally, K.F. (1991a). Kimberley rainforest communities: patterns of species composition and Holocene biogeography. In N.L. McKenzie, R.B. Johnstone and P.G. Kendrick (eds), Kimberley Rainforests of Australia, 423-451. Surrey Beatty and Sons Pty Ltd, Chipping Norton, NSW

McKenzie, N.L., Robinson, A.C. and Belbin, D.L. (1991b). Biogeographic survey of the Nullarbor district, Australia. In C.R. Margules, and M.P Austin (eds), Nature Conservation: Cost Effective Biological Surveys and Data Analysis, 109-126. CSIRO Division of Wildlife and Ecology, Canberra. 
McKenzie, N.L., Halse, S.A. and Gibson, N. (2000a). Some gaps in the reserve system of the southern Carnarvon Basin, Western Australia. Records of the Western Australian Museum Supplement 61: 547-568.

McKenzie, N.L., Keighery, G.J., Gibson, N. and Rolfe, J.K. $(2000 \mathrm{~b})$. Patterns in the biodiversity of terrestrial environments in the southern Carnarvon Basin, Western Australia. Records of the Western Australion Museum Supplement 61: 511-546.

McKenzie, N.L., Rolfe, J.K., Aplin, K.P., Cowan, M.A. and Smith, L.A. $(2000 \mathrm{c})$. Herpetofauna of the southern Carnarvon Basin, Western Australia. Records of the Western Australian Museum Supplement 61: $335-360$.

McKenzie, N.L., Burbidge, A.H. and Rolfe, J.K. (2003). Effect of salinity on small, ground-dwelling animals in the Western Australian wheatbelt. Australian Journal of Botany 51: 725-740.

McMahon, J.P., Hutchinson, M.F., Nix, H.A. and Ord, K.D. (1995). ANUCLIM Users Guide, Version 1. Centre for Resource and Environmental Studies, Australian National University, Canberra, Australia.

Michaels, K. and Mendel, L. (1998). Carabid beetle and vegetation associations in the Tasmanian Eastern Tiers: implications for conservation. Pacific Conservation Biology 4: 240-249.

Myers, N., Mittermeier, R.A., Mittermeier, C.G., da Foncesa, G.A.B. and Kents, J. (2000). Biodiversity hotspots for conservation priorities. Nature 403: 853858.

Morgan, G. (2001). Landscape Health in Australia. A Rapid Assessment of the Relative Condition of Australia's Bioregions and Subregions. Environment Australia and National Land and Water Resources Audit, Canberra.

Morgan, K.H. and Peers, R. (1973). Esperance-Mondrain Island, Western Australia, 1:250000 Geological Series. Geological Survey of Western Australia, Perth.

Muir, B.G. (1977). Biological survey of the Western Australian wheatbelt. Part 2. Vegetation and habitat of Bendering Reserve. Records of the Western Australian Museum Supplement 3: 1-142.

Mulcahy, M.J. and Hingston, F.J. (1961). The Development and Distribution of the Soils of the York - Quairading Area, Western Australia, in Relation to Landscape Evolution. CSIRO Soil Publication 17. CSIRO, Canberra, Australia.

Myers, J.S. and Hocking, R.M. (1998). Geological Map of Western Australia 1 : 2,500,000 (13 $3^{\text {th }}$ edition). Western Australian Geological Survey, Perth.

NAG (1986). The Generalised Linear Interactive Modelling System. Release 4.0 Manual. Numerical Algorithms Group, Oxford.

Newsome, A.E. and Catling, P.C. (1979). Habitat preferences of mammals inhabiting heathlands of warm temperate coastal, montane and alpine regions of southeastern Australia. In R.L. Specht (ed.), Ecosystems of the World. Volume 9A. Heathlands and Related Shrublands of the World, 301-316. Elsevier, Amsterdam.

Nicholls, A.O. (1989). How to make biological surveys go further with generalised linear models. Biological Conservation 50: 51-75.
Oksanen, L. (2001). Logic of experiments in ecology: is pseudoreplication a pseudoissue? Oikos 94: 27-38.

Oliver, I. and Beattie, A.J. (1996). Designing a costeffective invertebrate survey: a test of methods for rapid assessment of biodiversity. Ecological Applications 6: 594-607.

Oliver, I., Beattie, A.J. and York, A. (1997). Spatial fidelity of plant, vertebrate and invertebrate assemblages in multiple-use forest in eastern Australia. Conservation Biology 12: 822-835.

Paczkowska, G. and Chapman, A.R. (2000). The Western Australian Flora. A Descriptive Catalogue. The Wildflower Society of Western Australia Inc., Western Australian Herbarium, and Botanic Gardens and Parks Authority, Perth.

Paine, R.T. (1980). Food webs: linkage, interaction strength and community infrastructure. Journal of Animal Ecology 49: 667-685.

Pastor, J., Moen, R. and Cohen, Y. (1997). Spatial heterogeneities, carrying capacity, and feedbacks in animal-landscape interactions. Journal of Mammalogy 78: 1040-1052.

Patterson, B.D. and Brown, J.H. (1991). Regionally nested patterns of species composition in granivorous rodent assemblages. Journal of Biogeography 18: 395-402.

Patterson, B.D. and Atmar, W. (2000). Analysing species composition in fragments. In G. Rheinwald (ed.), Isolated Vertebrate Communities in the Tropics. Proceedings of the $4^{\text {th }}$ International Symposium, Bonn. Bonner Zoologische Monographien 46, 9-24.

Peterson, A.T., Soberon, J. and Sanchez-Cordero, V. (1999). Stability of ecological niches in evolutionary time. Science 285: 1265-1267.

Peterson, A.T., Sanchez-Cordero, V., Soberon, J., Partley, J., Buddemeier, R.W. and Navarro-Siguenza, A.G. (2001). Effects of global climate change on geographic distributions of Mexican Cracidae. Ecological Modelling 144: $21-30$

Peterson, A.T., Stockwell, R.B. and Kluza, D.A. (2002). Distributional prediction based on ecological niche modelling of primary occurrence data. In J.M. Scott, P.J. Heglund, M.L. Morrison, J.B. Haufler, M.G. Raphael, W.A. Wall and F.B. Samson (eds), Predicting Species Occurrences. Issues of Accuracy and Scale, 617623. Island Press, Washington.

Pimm, S.L. and Lawton, J.H. (1998). Planning for biodiversity. Science 279: 1068-1069.

Rand, W.M. (1971). Objective criteria for the evaluation of clustering methods. Journal of the American Statistical Association 66: 846-850.

Remigio, E.A., Hebert, P.D.N. and Savage, A. (2001). Phylogenetic relationships and remarkable radiation in Paratemia (Crustacea: Anostraca), the endemic brine shrimp of Australia: evidence from mitochondrial DNA sequences. Biological Journal of the Linnean Society 74: 59-71.

Rolfe, J.K. and McKenzie, N.L. (2000). Comparison of methods used to capture herpetofauna: An example from the Carnarvon Basin. Records of the Western Australian Museum Supplement 61: 361-370.

Rosenzweig, M.L. (1992). Species diversity gradients: we know more and less than we thought. Journal of Mammalogy 73: 715-730. 
Rosenzweig, M.L. and Abramski, Z. (1986). Detecting density-dependent habitat selection. The American Naturalist 126: 405-417.

Roxburgh, S.H. and Chesson, P. (1998). A new method for detecting species associations with spatially autocorrelated data. Ecology 79: 2180-2192.

Ruprecht, J.R. and Schofield, N.J. (1991). Effects of partial deforestation on hydrology and salinity in high salt storage landscapes. I. Extensive block clearing. Journal of Hydrology 129: 19-38.

Saunders, D.A. (1989). Changes to the avifauna of a region, district and remnant as a result of fragmentation of native vegetation: the wheatbelt of Western Australia. A case study. Biological Conservation 50: 99-135.

Schofield, N.J., Ruprecht, J.K. and Loh, I.C. (1988). The impact of agricultural development on the salinity of surface water resources of south-west Western Australia. Report No. WS27. Water Authority of Western Australia, Perth.

Schoknecht, N. (2002). Soil groups of Western Australia, edition 3. Resource Management Technical Report 246. Department of Agriculture, Western Australia.

Sneath, P.H.A. and Sokal, R.R. (1973). Numerical Taxonomy. The Principles and Practice of Numerical Classification. W.H. Freeman, San Francisco.

Smith, G.T. and McKenzie, N.L. (2000). Biogeography of scorpion communities in the southern Carnarvon Basin, Western Australia. Records of the Western Australian Museum Supplement 61: 269-280.

Solem, A. and McKenzie, N.L. (1991). The composition of land snail communities in Kimberley rainforest communities. In N.L. McKenzie, R.B. Johnstone and P.G. Kendrick (eds), Kimberley Rainforests of Australia, 247-263. Surrey Beatty and Sons Pty Ltd, Chipping Norton, NSW

Somerfield, P.J. and Clarke, K.R. (1995). Taxonomic levels in marine studies, revisited. Marine Ecology Progress Series 127: 113-119.

Spiller, D.A. and Schoener, T.W. (1998). Lizards reduce spider species richness by excluding rare species. Ecology 79: 503-516

Statsoft (2001). STATISTICA System Reference. Tulsa, USA.

Strahan, R. (Ed.) (1995). The Mammals of Australia. Reed Books Australia, Sydney.

Stone, L., Dayaqn, T. and Simberloff, D. (1996). Community assembly patterns unmasked: the importance of species' differing geographical ranges. The American Naturalist 148: 997-1015.

Storr, G.M., Smith, L.A. and Johnstone, R.E. (1990), Lizards of Western Australia. III Geckos \& Pygopods. Western Australian Museum, Perth.

Storr, G.M., Smith, L.A. and Johnstone, R.E. (1999). Lizards of Western Australia. I Skinks. Western Australian Museum, Perth.

Taylor, J.A. and Friend, G.R. (1984). Sampling strategies for fauna surveys. In K. Myers, C.R. Margules and I. Musto (eds), Survey Methods for Nature Conservation: 1,
179-192. CSIRO Division of Water and Land Resources, Canberra.

Taylor, C.M. and Warren, M.L. (2001). Dynamics in species composition of stream fish assemblages: environmental variability and nested subsets. Ecology 82: $2320-2330$

Thackway, R. and Creswell, I.D. (Eds) (1995). An interim biogeographic regionalisation for Australia: a framework for setting priorities in the National Reserves System Cooperative Program. Version 4.0. Australian Nature Conservation Agency, Canberra.

Tyler, M.J., Smith, L.A. and Johnstone, R.E. (2000). Frogs of Western Australia. Western Australian Museum, Perth.

van Gool, D. and Moore, G. (1999). Land evaluation standards for land resource mapping, $2^{\text {nd }}$ edition. Resource Management Technical Report 181. Agriculture Western Australia, Perth.

Wardell-Johnson, G. and Williams, M. (1996). A floristic survey of the Tingle Mosaic, south-western Australia: applications in land use planning and management. Journal of the Royal Society of Western Australia 79, 241276.

Warner, R.R. and Chesson, P.L. (1985). Co-existence mediated by recruitment fluctuations: a field guide to the storage effect. The American Naturalist 125: 769787

Weiher, E. and Keddy, P.A. (1995). Assembly rules, null models, and trait dispersion: new questions from old patterns. Oikos 74: 159-164.

Whitmore,T.C. (1984). Tropical Rainforests of the Far East. Clarendon Press, Oxford.

Whisenant S.G. (1999). Repairing Damaged Wildlands. A Process-orientated, Landscape-scale Approach. Cambridge University Press, Cambridge.

Wiens, J.A. (1985). Vertebrate responses to environmental patchiness in arid and semi-arid ecosystems. In S.T.A. Pickett and P.S. White (eds), The ecology of Natural Disturbance and Patch Dynamics, 169-193. Academic Press, New York

Wilson, S.K. and Knowles, D.G. (1988). Australia's Reptiles. A Photographic Reference to the Terrestrial Reptiles of Australia. Collins, Australia.

Wright, D.H., Patterson, B.D., Mikkelson, G.M., Cutler, A. and Atmar, W. (1998). A comparative analysis of nested sub-set patterns of species composition. Oecologica 123: 1-20.

Wyrwoll, K.H., Stoneman, T., Elliot, G. and Sandercock, P. (2000). Geoecological setting of the Carnarvon Basin, Western Australia: geology, geomorphology and soils of selected sites. Records of the Western Australian Museum Supplement 61: 29-76.

Yen, A.L. (1987). A preliminary assessment of the correlation between plant, vertebrate and coleoptera communities in the Victorian mallee. In J.D. Majer (ed.). The Role of Invertebrates in Conservation and Biological Survey, 73-88. Western Australian Department of Conservation and Land Management, Perth. 